\title{
Der Erwerb des Artikels als Genus-Anzeiger im deutschen Erstspracherwerb
}

\author{
Franziska Bewer \\ f.bewer@gmx.de
}

\section{$1 \quad$ Einleitung*}

Wenn wir miteinander sprechen, benutzen wir einen Wortschatz, der zu knapp 60\% aus Nomina besteht. Im Deutschen ist jedem Nomen ein grammatisches Genus zugeordnet, das beim Einsatz bestimmter anderer Wortarten wie Artikel oder Adjektiv zu beachten ist. Gut 10\% unserer Rede verwenden wir darauf, auf diese Nomina bzw. die von ihnen bezeichneten Objekte mit dem einen oder anderen Artikel zu verweisen, sei es durch einen bestimmten, unbestimmten, Possessiv- oder Negationsartikel. Zusammen mit den Adjektiven und den Personalpronomina der dritten Person Singular bestehen etwa 15\% unserer Rede aus Formen, bei denen wir das Genus eines Nomens zu berücksichtigen haben (vgl. Ruoff 1981:20, 513). Das ist nicht gerade wenig, wenn man bedenkt, dass , at present there is probably no one who can say what gender as a grammatical category really is" (Bittner 1999:1). Wenn auch der Sinn und Zweck der Klassifizierung der Nomina in die drei Genera nicht vollkommen eindeutig ist, so steht doch außer Frage, dass dieses aufwendige System eine gewisse Relevanz in der deutschen Sprache haben muss - denn sonst wäre diese Kategorisierung mit der Zeit vermutlich reduziert oder ganz aufgegeben worden. Da aber Kinder im Spracherwerb den Gebrauch der vielen durch das Genus unterschiedenen Formen der Artikel, Pronomen und Adjektive recht problemlos erwerben, ist vielmehr anzunehmen, dass es sich bei dieser Kategorisierung nicht bloß um sprachhistorischen Ballast handeln kann.

Die vorliegende Arbeit befasst sich mit dem muttersprachlich Erwerb (L1) des Genus im Deutschen. Im Zentrum der Untersuchung steht die Frage, wie ein Kind aus dem ihm angebotenen Sprachinformationen das komplexe System der Genusmarkierung erwirbt. Sie wird anhand von Daten aus einer Langzeitstudie eines monolingual aufwachsenden deutschen Kindes erörtert. Der Rahmen dieser Arbeit erforderte bei ihrem Aufbau gewisse Einschränkungen. So habe ich mich in der Auswertung der Erwerbsdaten auf den bestimmten Artikel als Genusanzeiger konzentriert. Als Artikel zeichnet er sich gegenüber den ebenfalls genusabhängigen Adjektiven dadurch aus, dass er eine meist obligatorische Konstituente einer Nominalphrase (NP) mit einem Substantiv darstellt. Der bestimmte Artikel wiederum ist einerseits der frequenteste unter den Artikelwörtern und weist andererseits das differenzierteste Formeninventar auf, wobei er als einziger Artikel im Nominativ alle drei Genera differenziert. Auch habe ich mich entschlossen, auf eine Gegenüberstellung und Diskussion verschiedener Spracherwerbstheorien zu verzichten und stattdessen ausführlicher auf die Aspekte, die im Erwerbsprozess selbst und somit für die Datenanalyse relevant sind, einzugehen. Dabei sollen unterschiedliche Ansätze berücksichtigt sowie die aktuelle Forschungslage dargestellt werden.

Dies ist die durchgesehene Version meiner Magisterarbeit, eingereicht im April 2003 bei der TU Berlin. Während der Abfassung habe ich sehr viel Unterstützung erfahren. Ganz besonders danke ich Dr. Dagmar Bittner und Dr. Helene Imendörffer $(\dagger)$, die sich die Zeit nahmen, die einzelnen Teile kritisch zu lesen. Ihre Kommentare und Fragen waren mir eine große Hilfe und Motivation. 
Die ersten beiden Kapitel dieser Arbeit widmen sich dem Genus als grammatische Kategorie (Kap. 1) sowie dem Artikel als genusabhängigem Referenzanzeiger (Kap. 2). Aus der Darstellung werden die Komplexität der Lernaufgabe im Erwerb des Genus sowie die Einzelheiten seiner Markierung am bestimmten Artikel deutlich. Die Untersuchung erfolgt im Rahmen eines funktionalistischen Ansatzes zum Spracherwerb, der in Kapitel 3 vorgestellt wird. Er geht von der Frage nach der Funktion eines sprachlichen Phänomens in der Grammatik aus, die sich, wie sich zeigen wird, auch für den Spracherwerb stellt. Im 4. Kapitel erfolgt schließlich die Auswertung der Spracherwerbsdaten der Langzeitstudie. Hier geht es darum, die einzelnen Schritte und Strategien des Mädchens Simone im Genuserwerb bzw. im Erwerb der Genusmarkierung durch den bestimmten Artikel zu ermitteln und zu interpretieren. Die Ergebnisse werden mit bisher vorliegenden Untersuchungen zu diesem Erwerbsaspekt verglichen und diskutiert. Die Arbeit schließt mit einer Bewertung der Ergebnisse sowie einigen Überlegungen zum weiteren Vorgehen in dieser Fragestellung (Kap. 5).

\section{$2 \quad$ Das Genus}

Das Deutsche ist eine Genussprache, d.h. jedem Nomen wird obligatorisch eines der drei Genera zugewiesen: Maskulinum (Mask.), Femininum (Fem.) oder Neutrum (Neutr.) (z.B. der Raum, die Tür, das Haus). Das jeweilige Genus ist dabei nicht oder nur selten an der äußeren Form des Nomens selbst zu erkennen. Es stellt vielmehr ein inhärentes Merkmal des Nomens dar, nimmt aber Einfluss auf die jeweils vom Nomen abhängigen Wortarten: „Genders are classes of nouns reflected in the behaviour of associated words." (Hocket 1958:231, zit. in Corbett 1991:1) Die Auswirkungen des Genus zeigen sich sowohl innerhalb der NP an Artikeln und Adjektiven (ein großer Raum, eine offene Tür, ein schönes Haus) als auch in den stellvertretenden Positionen an den Pronomina (der Raum, welcher...; die Tür, welche...; das Haus, welches...). Dabei erscheint das Genus immer in Kombination mit den Kategorien Kasus und Numerus zu einem einzigen Flexionsmorph ${ }^{1}$ verknüpft. Die Kategorie Genus unterscheidet sich insofern von ihren ,Schwester"-Kategorien Kasus und Numerus, als dass hier die Zuweisung nicht vom semantischen oder syntaktischen Kontext bestimmt wird. Die Numeruskategorien Singular und Plural werden vom Sprecher selbst festgelegt, je nach dem, ob er sich auf einen oder mehr als einen Referenten bezieht. Die Werte der Kasuskategorie werden dagegen von der syntaktischen Struktur, meist durch das finite Verb der Verbalphrase (VP) oder durch eine Präposition, bestimmt. Diese beiden Kategorien werden zudem mehr oder weniger stark am Kopf-Nomen der NP selbst markiert. Für das Genus gibt es dagegen keine Instanzen, die die jeweilige Zugehörigkeit je nach Kontext zuweisen. Es ist für jedes Nomen direkt im Lexikon verbindlich festgelegt und wird nicht explizit an diesem selbst angezeigt. In der Mehrzahlkategorie Plural spielt das nominale Genus im Deutschen dagegen

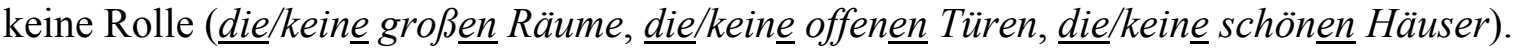

Auch wenn das Genus sich selbst nicht z.B. in Form eines speziellen Morphems am Nomen präsentiert, so gibt es doch einige mehr oder weniger auffällige Regelmäßigkeiten in Bezug auf die Form und/oder Bedeutung der Nomina und das jeweilige Genus, die über die offensichtliche Unterscheidung zwischen weiblichen und männlichen Personenbezeichnungen ( $\underline{\text { der }}$ Mann, der Bruder, die Frau, die Schwester) hinausgehen. Diese Regelmäßigkeiten, oder bes-

1 Dieser Begriff betont, dass es sich dabei um die grammatisch unanalysierte Lautkette handelt, in Abgrenzung zum Morphem, dass einer bestimmten grammatischen Kategorie zugeordnet wird und gerade in flektierenden Sprachen wie dem Deutschen Segmentierungsprobleme mit sich bringt (vgl. Durrel 1977). Auf die Verschmelzung der drei Kategorien Genus, Kasus und Numerus zu einem Morph gehe ich im Abschnitt 3.2 ein. 
ser: Tendenzen, sowie die Unregelmäßigkeiten und Widersprüche möchte ich zu Beginn der vorliegenden Arbeit darstellen. Auch in meiner weiter unten folgenden Datenauswertung werden diese Genustendenzen einen Schwerpunkt bilden, da ihnen i.A. eine wichtige Rolle im Spracherwerb zugeschrieben wird. Ebenso ist die Funktion der Genusdifferenzierung, auf die ich anschließend eingehen werde, keineswegs derart eindeutig, dass sie die Verteilung ausreichend begründen könnte.

\subsection{Die Verteilung der Genera}

Die Hinweise auf das Genus, die das Nomen selbst bietet, können sowohl in seiner Lautgestalt als auch in seiner jeweiligen Bedeutung liegen. Neben diesen phonologischen und semantischen Eigenschaften werden manchmal auch morphologische, wie beispielsweise die Pluralflexion des Nomens, zur Bestimmung der Genuszugehörigkeit genannt. Diese werden hier nicht berücksichtigt, da sie sich m.E. vielmehr aus dem Genus ableiten, statt es selbst zu bestimmten (vgl. Köpcke 1982, Wegener 1985:78ff., Bittner 1999).

\subsubsection{Phonologische Genushinweise}

Auf phonologischer Ebene sind vor allem die Wortauslaute von Bedeutung. Besonders eindeutig geben hier Suffixe aus dem Bereich der Wortbildung (Derivation) Auskunft über das Genus des Nomens, wie z.B. -chen, -lein > Neutr., -(er)ei, -heit, -keit, -schaft, -ung, -ion > Fem., -ling, -ismus > Mask.; auch die Affix-Kombination Ge-(..-e), die neutrisches Genus zuweist, gehört in diese Reihe. Es gibt unter ihnen jedoch auch solche, die weniger zuverlässig in Bezug auf die Genuszuweisung sind, z.B. -tum > Neutr. (das Herzogtum), aber: der Reichtum, der Irrtum.

Auch außerhalb der Derivationsmorphologie finden sich unter den sog. Pseudosuffixen gewisse Regelmäßigkeiten in Bezug auf das Genus eines Nomens. Die Schwankungen bei der Genusverteilung sind in diesem Bereich allerdings teilweise sehr hoch, so dass hier eher von Tendenzen zu sprechen ist. Nomina mit einem Auslaut auf -e (Schwa) sind zwar zu 90,5\% Feminina (die Ente), und Ausnahmen haben z.T. eine hohe Gebrauchsfrequenz (wie z.B. der Junge, das Ende). Die Zuweisungssicherheit der Endsilben -el, -en und -er zu Maskulina (der Würfel, der Daumen, der Eimer) beträgt jedoch nur 60,5 bzw. 72,1 bzw. 64,2\% (alle Zahlen nach Wegener 1995:91).

Für den Bereich der einsilbigen Nomina konnte Köpcke (1982) gewisse Zuweisungstendenzen anhand von Lautkombinationen feststellen, die sich nicht nur auf den Endrand eines Nomens beziehen. ${ }^{2}$ An dieser Stelle will ich nur beispielartig auf einige dieser zahlreichen „Regeln“ eingehen. In der Datenauswertung werde ich an gegebener Stelle weitere, für die Diskussion relevante Regeln besprechen. $\mathrm{Zu}$ den wichtigsten, d.h. umfassendsten dieser Regeln gehört z.B. die Beobachtung, dass monosyllabische Substantive ${ }^{3}$, die auf $k n$ - oder $d / t+r$ anlauten, typischerweise Maskulina sind (der Knopf, der Draht), sowie dass Auslautkombinationen von nicht-sibilantischem Frikativ $+t$ meist mit femininem Genus übereinstimmen (die Fracht) (Köpcke 1982:88f., 97f.). Zuweisungstendenzen können aber auch als „Strukturregeln“ genereller formuliert sein, z.B. dass mit zunehmender Konsonantenzahl im An- und Auslaut die Tendenz zum maskulinen Genus zunimmt (vgl. ebd., Köpcke/Zubin 1984:29f.).

2 Die phonologische Struktur und die jeweilige Genuszugehörigkeit von mehrsilbigen, nicht abgeleiteten Nomina ist laut Wegener (1995:77, Anm. 17) dagegen noch nicht untersucht worden, und auch meines Wissens liegt hierzu noch kein konkretes Ergebnis vor.

3 Die Begriffe „Nomen“ und „Substantiv“ verwende ich in dieser Arbeit als gleichberechtigte Synonyme. 
Bei diesen Tendenzen für den monosyllabischen Nominalwortschatz dürfen jedoch, gerade in Bezug auf den Spracherwerb, einige Aspekte nicht übersehen werden: Einerseits liegt dieser Untersuchung das gesamte Einsilbervokabular des Rechtschreibdudens ${ }^{4}$ zugrunde, ohne Rücksicht auf Aktualität und Verbreitung der Lexeme, so dass zahlreiche Begriffe in die Statistik eingegangen sind, die dem Großteil der kompetenten Sprecher des Deutschen unbekannt sein dürften, wie z.B. das Spill, die Nock, die Kuff, der Kneip. Andererseits betreffen die deduktiv ermittelten Tendenzen z.T. sehr eingeschränkte Wortmengen mit recht unterschiedlich starken Gültigkeitsschwankungen. So trifft das feminine Genus auf nur 63,6\% der Fälle mit nicht-sibilantischem Frikativ $+t$-Auslaut zu, und zwar konkret auf 35 von 55 entsprechende Substantive (Köpcke/Zubin 1984:29). Bei den Substantiven auf $k n$ - gibt es zwar nur eine Ausnahme (das Knie), jedoch sind von dieser Regel insgesamt nur 15 Lexeme betroffen (ebd.). ${ }^{5}$ Als drittes ist zu beachten, dass durch diese Regeln häufig nicht ein gültiges Genus generiert, sondern lediglich eins ausgeschlossen wird, so dass weiterhin zwei Genera (meist das Maskulinum und das Neutrum) als Kandidaten für eine Zuweisung in Frage kommen.

Die psychologische Existenz von phonologischen Genusregularitäten ist wiederholt in Experimenten, in denen kompetente Sprecher den deutschen Lautregeln entsprechenden Kunstwörtern ein Genus zuweisen sollten, überprüft worden (vgl. Köpcke/ Zubin 1983, 1984, Mills 1986, Wegener 1995). Als Gesamtergebnis kann mit Wegener festgehalten werden, dass für Einsilber bei Sprechern des Deutschen keine Assoziationen mit exakten An- und Auslautmustern nachzuweisen sind, vielmehr würde aufgrund der Tatsache, dass etwa zwei Drittel dieser Wortgruppe Maskulina sind ${ }^{6}$, die Zuweisung des Maskulinum allein durch ihre Einsilbigkeit hervorgerufen - wenn nicht Analogiebildungen zu realen Wörtern die Genuswahl beeinflussen (Wegener 1995:83f.). Für Nomina mit Pseudosuffixen konnte dagegen nur für $-e$ und -er eine signifikante Bevorzugung desjenigen Genus festgestellt werden, das auch im realen Wortschatz das überwiegende ist (ebd.:85).

\subsubsection{Semantische Genushinweise}

Genuszuordnungen, die mit der Bedeutung des Nomens in Zusammenhang stehen, betreffen z.B. Lebewesen. Bei Personenbezeichnungen stimmt das grammatische Genus sehr häufig mit dem natürlichen Geschlecht (Sexus) überein (der Mann, die Frau, der Bruder, die Schwester, der Opa, die Oma), aber auch hier gibt es Abweichungen (das Mädchen, das Mannequin). In Zusammenhang mit dem Sexus sehen Köpcke/Zubin eine Motivierung für abweichendes Genus bei Personenbezeichnungen in abwertenden Konnotationen nach dem „Prinzip des perzipierten Geschlechts“ (Köpcke/Zubin 1996:481). So würden z.B. das Neutrum Unreife bei Kindern anzeigen (das Kind, das Baby), und abwertende Bezeichnungen für Männer seien oft Feminina, vor allem zur Betonung von „unmännlichen“ Eigenschaften (die Tunte, die Memme, die Schwuchtel) (ebd.:483). Ihre Feststellung, Abwertungen von männlichen Personen würden „niemals durch das Neutrum“ (ebd.) geschehen, kann jedoch mit das Weichei widerlegt werden. Für Frauen würde den Autoren zufolge dagegen ein Wechsel zum Neutrum eine pejorative Bedeutung im Sinne von ,bemitleidend, verachtend“ anzeigen (das Weib, das Frauenzimmer), ein Wechsel des Genus würde jedoch nicht bei sexuell abwertenden Begrif-

\footnotetext{
4 Gemeint ist die Ausgabe von 1952 oder 1954, eine eindeutige Angabe wird nicht gegeben.

5 Köpcke weist dabei selbst ausdrücklich darauf hin, dass es sich bei diesen „Regeln“ um ein „theoretisches Konstrukt“ handelt und sie „lediglich eine im Prinzip plausible Möglichkeit“ zur Erklärung der Genuszuweisung im Deutschen darstellen, die für Annahmen über Abläufe im Spracherwerb dienen können (Köpcke 1982:133ff.).

6 In Köpckes Korpus stellen sie einen Anteil von 64,1\% (vgl. Köpcke 1982:132).
} 
fen stattfinden, wobei sich jedoch z.B. mit das Flittchen wiederum ein Gegenbeispiel finden lässt. ${ }^{7}$

Eine sexusdifferenzierte Genuszuweisung lässt sich darüber hinaus auch bei Bezeichnungen für (hauptsächlich domestizierte) Tiere feststellen, mit denen auf das jeweils spezifische Geschlecht bzw. auf Jungtiere durch das Neutrum als geschlechtsunspezifisch, referiert wird (z.B. der Bulle - die Kuh - das Kälbchen, der Eber - die Sau-das Ferkel, der Hahn-die Henne - das Küken, etc.) (Köpcke/Zubin 1984:33f.).

Des Weiteren sind Bezeichnung für Klassen- und Oberbegriffe häufig Neutra (z.B. das Tier, das Rind, das Geflügel; das Getränk, das Obst, das Werkzeug, das Material) (vgl. Köpcke/Zubin 1984). Daneben finden sich einige Regelmäßigkeiten bei Gegenstandsbezeichnungen. So wird beispielsweise Markennamen das jeweilige Genus des bezeichneten Gegenstandes zugewiesen (das Waschmittel - das Spee, das Persil; die Zigarette - die Marlboro, die Lord) (ebd.:28). Durch das Genus wird auch zwischen Auto- und Motorradbezeichnungen unterschieden (der/die BMW, der/die Honda) und Schiffsnamen sind grundsätzlich feminin (die Bismarck, die Titanic). Solche semantisch-lexikalischen Felder mit überwiegend einheitlichem Genus bilden z.B. auch Farben (neutr.), Spiele (neutr.), Sprachen (neutr.), alkoholische Getränke (mask.) und Früchte (fem.) (vgl. Köpcke/Zubin 1996:479f.). Semantische Kriterien wirken sich darüber hinaus bei der Genuszuweisung zu morphologisch einfachen, d.h. nicht abgeleiteten Lehnwörtern aus. Hier wird das Genus des ,semantisch naheliegendsten deutschen Äquivalents“ (Gregor 1983:59, zit. in Wegener 1995:86) gewählt (das Match (Spiel), die Tour (Reise), der Service (Dienst)).

Zubin/Köpcke (1984) konnten zudem eine Übereinstimmung von Genus und Bedeutung innerhalb des Vokabulars für Betroffenheit und Erregung („Affektlexikon“) feststellen. Anhand der Nomina auf -mut, die selten Komposita mit dem Maskulinum der Mut sind (vgl. ebd.:46, Anm. 8), veranschaulichen die Autoren, dass im Affektlexikon feminines Genus prototypischerweise mit Introversion (charakterisiert durch „,fügsam/gefügig, aufnehmend, zugänglich/verletzlich, selbstlos“ (Zubin/Köpcke 1984:51)) und maskulines Genus mit Extroversion (verstanden als „offensiv, abweisend, verschlossen, eigennützig“ (ebd.)) assoziiert wird. Die Zuordnung der Genera durch Testpersonen ergibt eine Skala, auf der sich die Begriffe mit variablem Genus zwischen einem eindeutig femininen Pol (die Armut, die Anmut) und einem eindeutig maskulinen Pol (der Lebensmut, der Übermut) gleichmäßig verteilen (z.B. die (der) Sanftmut, der/die Gleichmut, der (die) Hochmut) (ebd.:50). Diese Genusverteilung haben die Autoren im gesamten deutschen Affektlexikon wiedergefunden und darüber hinaus anhand von Sprachwandeldaten etymologisch nachvollzogen und begründet.

Auf die Bildung lexikalischer Nominalgruppen durch die Genera werde ich im Abschnitt 2.2.1 als eine der Funktionen der Genusunterscheidung noch einmal zurückkommen.

\subsubsection{Zusammenfassung}

Die oberflächlich eher undurchsichtig erscheinende Verteilung der drei Genera im nominalen Lexikon erweist sich bei näherer Betrachtung als weniger unsystematisch, arbiträr; es zeigen sich vielmehr einige Regelmäßigkeiten bezüglich des Genus und der phonologischen Form und Struktur des Nomens mit unterschiedlicher Reichweite. Bei echten Suffigierungen wird das Genus meist durch eine 1:1-Korrelation mit dem jeweiligen Suffix zugewiesen, bei den Pseudosuffixen können die Zuweisungsregeln dagegen nur mehr oder weniger starke Tendenzen sein. Bezüglich der semantischen Inhalte der Nomina lassen sich zwar zahlreiche

Auf maskuline Frauenbezeichnungen mit abschätziger Bedeutung gehen die Autoren nicht ein. Ich möchte an dieser Stelle aber auf die Beispiele der Backfisch und der (Haus-)Drache hinweisen. 
Klassen mit einem jeweils dominierenden Genus finden, eine solche Strukturierung ist jedoch nicht für das gesamte Nominallexikon gültig.

Die unterschiedlichen Zuordnungshinweise führen häufig zu Überschneidungen ihrer Wirkungsbereiche, wobei es z.T. zu Konflikten ihrer Vorhersagen kommt. Z.B. hat das Substantiv Junge einen typischen Feminina-Auslaut, erhält allerdings aufgrund seiner Bedeutung maskulines Genus, und Rind wäre wegen seiner Einsilbigkeit eher maskulin, ist jedoch als Klassenbegriff ein Neutrum. Die Genuszuordnungen wirken dabei jedoch nicht willkürlich gegeneinander sondern hierarchisch. Die Genuszuweisung durch echte Wortbildungssuffixe dominiert dabei die anderen Prinzipien; semantische Zuordnungen sind wiederum stärker als die übrigen phonologischen Zuweisungstendenzen (Pseudosuffixe und Simplizia). Schematisch ergibt sich somit folgende Wirkungshierarchie: 1. echtes Suffix - 2. Semantik - 3. Pseudosuffix/Simplex (Wegener 1995:87f., vgl. auch Köpcke 1982:109ff.).

Es kann festgehalten werden, dass das nominale Lexikon zwar durch zahlreiche unterschiedliche Kriterien, jedoch in nur drei Genuskategorien gegliedert ist. Für diese Kategorisierung existiert kein explizites Signal, das die Funktion hätte, das Genus anzuzeigen; lediglich die echten Wortbildungssuffixe können als eine Art „Genusmorphem“ betrachtet werden (Wegener 1995:74).

\subsection{Die Funktionen des Genus}

Die Kategorisierung der Nomina in die drei Genera sagt an sich jedoch nichts über die Funktion aus, die eine solche Gliederung ausüben könnte. Da mit der Zugehörigkeit eines Nomens zu einer der Genuskategorien kein direkter semantischer Wert verbunden ist, die einzelnen Kategorien also keine eigene spezifischen Bedeutungen zuweisen, ist unklar, weshalb sich eine Sprache wie das Gegenwartsdeutsche überhaupt ein solch umständliches System leistet. Trotzdem hält sich das Genussystem im Deutschen auffallend stabil und zeigt keine Abbautendenzen oder Ansätze einer Reduzierung der drei auf zwei Genera (vgl. Wegener 1995:60). Dies bedeutet,

daß sie [die Kategorie Genus; F.B.] offenbar ausreichende semantische, syntaktische und/oder kommunikative Funktionen erfüllt - oder aber, daß der Erwerb formaler Systeme unabhängig von Funktionen irgendwelcher Art möglich ist. (Ebd.)

Die Tatsache, dass das Genus - im Deutschen wie in anderen Sprachen - nicht vollkommen überflüssig ist, wird heute aber kaum mehr bezweifelt. Maratsos' Äußerung ,The presence of such a system in a human cognitive system constitutes by itself excellent testimony to the occasional nonsensibleness of the species.“ (Maratsos 1979:235, zit. in Köpcke/Zubin 1984:26) ist mehrfach aufgegriffen und bestritten worden. Die einzelnen Aufgaben, die dem Genus im Deutschen zugeschrieben werden, sollen im Folgenden dargestellt werden.

\subsubsection{Organisation des Lexikons}

Die lexikalische Strukturierung des Wortschatzes in semantische Felder wird allgemein als eine der Hauptfunktionen von nominalen Klassifizierungssystemen betrachtet (vgl. Corbett 1991). Für das Deutsche gilt sie zwar ebenfalls eine unbestrittene, jedoch nicht als die hauptsächliche Funktion der Genuseinteilung (vgl. Köpcke 1982, Köpcke/Zubin 1984, Claudi 1986, Mills 1986, Wegener 1995, van Berkum 1996):

Theoretisch könnte jedes Substantiv spezifischen semantischen Klassen angehören, denn eine Systematisierungsneigung seitens des Sprecher/Hörers, Ordnung in das sprachliche Inventar zu bringen, ist genau wie für die phonologisch-morphologische auch für die semantische Ebene anzunehmen. (Köpcke 1982:11) 
Wie bereits in Abschnitt 2.1.2 dargestellt wurde, fungiert das Genus als ein Organisationskriterium im nominalen Lexikon. Unterstützung findet diese These aus der Sprechfehlerforschung. Hier wird aufgrund der Analyse von Sprechfehlerkorpora ein Zusammenhang von Versprechern und Genus angenommen. Es zeigte sich, dass bei Versprechern, in denen ein intendiertes Nomen durch ein bedeutungsverwandtes ,aus Versehen“ vertauscht wurde, dieses in der Mehrzahl der Fälle das gleiche Genus wie das intendierte aufwies, und zwar auch dann, wenn der syntaktische Kontext der Äußerung keine Genusmarkierungen enthielt (Marx 2000). Es liegt daher „die Annahme nahe, daß sich beim lexikalischen Zugriff auf ein Nomen eine anfängliche Kohorte semantisch ähnlicher und vorwiegend genusgleicher Lemmas bildet.“ (ebd.:220) Das bedeutet, dass die Nomen eines semantischen Feldes über ihr gemeinsames Genus im mentalen Lexikon des Sprechers miteinander in Verbindung stehen.

Bei Versuchen, ein möglichst umfassendes Netz von lexikalisch-semantischen Feldern zu spannen (vgl. die Übersicht von Spitz in Köpcke 1982:13), müssen jedoch immer eine Reihe von Ausnahmen in Kauf genommen werden. Beispielsweise schließt ein lexikalisches, maskulin markiertes Feld für „Winde“ die Böe nicht ein, im Feld ,alkoholische Getränke“, dessen Elemente ebenfalls meist maskulin sind, sind das Bier und die Bowle wiederum nicht enthalten. Daraus, sowie aus

[...] der Tatsache [...], daß es im Deutschen nur drei gegenüber einer dort [in den afrikanischen und asiatischen Sprachen; F.B.] bisweilen großen Zahl von Genera bzw. Klassifikatoren gibt, wird sofort auch klar, daß dies ihre wesentliche Funktion nicht sein kann. (Wegener 1995:61)

\subsubsection{Pronominalisierung}

Als „major function“ von Genussystemen bezeichnet Corbett (1991:321) die Disambiguierung durch die Genera bei pronominaler Referenz. Die Möglichkeit der eindeutigen Referenz durch Pronomina leistet einen erheblichen Beitrag zur Textkohärenz (vgl. Werner 1975, Karmiloff-Smith 1979, Köpcke/Zubin 1984, Mills 1986, Wegener 1995, van Berkum 1996):

gender markers may be crucial in helping the listener to keep track of referents across a complex passage of discourse (Bates/MacWhinney 1989:18f., zit. in van Berkum 1996:20)

Wie sich die Disambiguierung mittels der genusdifferenzierten Pronomina im Deutschen gegenüber dem Englischen auswirkt, verdeutlicht Mills an folgendem Beispiel (vgl. Mills 1986:38; Hervorhebungen von mir):

(1a) Maria fotografierte Tobias vor dem Haus, als er/sie/es 10 Jahre alt war.

Noch deutlicher zeigt sich dies, wenn Tobias durch einen unbelebten, ebenfalls maskulinen Referenten ersetzt wird und somit der Verweis nicht aufgrund einer semantischen Differenzierung motiviert ist, sondern durch die Genusunterscheidung auch bei unbelebten Nomina eindeutig ist:

(1b) Maria fotografierte den Wagen vor dem Haus, als er/sie/es 10 Jahre alt war.

Dagegen ist im Englischen, das im pronominalen Bereich semantisch nach männlichweiblich-unbelebt differenziert, nur die entsprechende Konstruktion zu (1a) eindeutig. Ein Satz wie in (1b), in dem zwei unbelebte Objekte für den Bezug in Frage kommen können, muss dagegen durch eine andere Konstruktion realisiert werden, um Eindeutigkeit sicherzustellen: 
(2a) Mary photographed Tobias in front of the house, when he/she/it was 10 years old.

(2b) Mary photographed the car in front of the house, when she/it was 10 years old.

Wegener sieht vor allem in dieser Eigenschaft des Genus, die wesentlich zur Erleichterung des Verstehens und der Kommunikation beiträgt, die Basis für die Stabilität des Genussystems im Deutschen. Gerade nicht-abgeleitete Nomina aus dem Nahbereich des Menschen, die sehr frequent verwendet werden und intuitiv zu einem semantischen Feld gruppiert werden, zeichnen sich durch unterschiedliche Genuseigenschaften aus (Körperteile: der Fuß, die Hand, das Bein; Gesicht: der Mund, die Nase, das Ohr; Besteck: der Löffel, die Gabel, das Messer; Werkzeug: der Nagel, die Schraube, das Brett) (Wegener 1995:66f.).

Die Möglichkeit der eindeutigen Bezugnahme durch Pronomen steht aber in Widerspruch zu Punkt 2.2.1, der Organisation des Wortschatzes durch semantischer Felder. Den Vorteil, den die genusdifferenzierte Pronominalisierung bei semantisch naheliegenden Nomina gerade bietet, läuft einer möglichen lexikalischen Strukturierung zuwider und schwächt das Argument der Genusverteilung aufgrund semantischer Motivation (ebd.). Eine hinreichenden Begründung für die Existenz des Genus kann somit auch in diesem Funktionsbereich nicht liegen, da einerseits Kongruenz auch durch Kasus und Numerus hergestellt wird, andererseits Sprachen auch ohne dieses detaillierte Gliederungssystem auskommen und evtl. einfachere Mittel zur Herstellung eindeutiger Referenz einsetzen. Die Gliederung der deutschen Nomina erscheint dagegen als unnötige und unökonomische Verkomplizierung.

Speziell der Disambiguierung in der pronominalen Referenz mit Hilfe der Genera schreibt Claudi nur eine untergeordnete Rolle zu:

Genuskonkordanz kennzeichnet Bezüge zwischen Nomen und anderen Konstituenten; die Notwendigkeit dieser Kennzeichnung im Sinne einer Vermeidung ansonsten bestehender Ambiguität ist jedoch nur in begrenztem Maße gegeben. (Claudi 1985:44; Hervorhebung von mir)

Die Autorin hat „Mühe, ein Beispiel zu finden“ (ebd.:43), in dem die Zugehörigkeit zu unterschiedlichen Genera den Bezug der Pronomen zu den NPs innerhalb eines Satzes klarstellt. Sie geht zwar auf die Ambiguität ein, die bei anaphorischer Referenz über eine Satzgrenze hinaus entstehen und durch das Genus aufgehoben werden kann, da dies aber wiederum nur möglich ist, wenn beide Konstituenten auch tatsächlich unterschiedlichen Genera angehören, schreibt sie dieser Funktion keine große Bedeutung zu.

\subsubsection{Antizipation des Referenten}

„Antizipatorische Konstruktionen“ (Köpcke/Zubin 1984:43) sind eine weitere Aufgabe der Genusdifferenzierung der Nomina (vgl. auch Mills 1986, Wegener 1995, van Berkum 1996). Durch die Übereinstimmung im Genus der NP-Anfangsmarkierung und dem zugehörigen Nomen am Endrand der NP kann der Hörer bereits nach der ersten genusmarkierten Form, meist einem Artikel, und in Kombination mit weiteren syntaktischen, semantischen und/oder kontextuellen Informationen eine erste Vorauswahl bezüglich des intendierten Bezugswortes treffen. Mills zitiert ein anschauliches Beispiel von Zubin/Köpcke (1983, zit. in Mills 1986:36): Beim Betrachten einer Landschaft kann der Hörer der Äußerung Guck mal. Das große, im Garten stehende Haus zusammen mit den visuellen Informationen bereits nach der Nennung des Artikels das Objekte selektieren, auf die seine Aufmerksamkeit möglicherweise gelenkt werden soll. Die nachfolgenden semantischen Informationen (große und im Garten stehende) schränken die Möglichkeiten des zu erwartenden Referenten immer weiter ein und lenken seinen Blick in die gewünschte Richtung, bis das antizipierte Nomen geäußert wird. 
Diese antizipatorische Funktion des Genus spielt auch bei Komposita eine Rolle. Die Genusmarkierung am Artikel liefert dem Hörer einen Hinweis auf das letzte Glied des Kompositums. Die Beispiele zur Referentenantizipation bei Komposita entnehme ich Köpcke/Zubin (1984:44):

\section{(3) die Umwelt \\ der Umweltschutz \\ das Umweltschutzgesetz \\ der Umweltschutzgesetzvorschlag}

In den vergangenen Jahren wurden vermehrt Untersuchungen zum Effekt einer pränominalen Genusmarkierung auf den zeitlichen Abrufprozess des Nomens (Primingeffekt) durchgeführt. Marx nennt eine Untersuchung zum Lemmaabruf im Deutschen von Schmidt (1986, in Marx 2000), in der unter bestimmten Umständen ${ }^{8}$ eine Beschleunigung bei der Wortbenennung durch einen genuskongruenten Artikel nachgewiesen werden konnte. Ein genusinkongruenter Artikel dagegen hemmt diesen Prozess.

\subsubsection{Syntagmatische Kohärenz}

Die Aufteilung der Nomina auf unterschiedliche Genera erleichtert die Konstruktion komplexer NPs und erhöht die syntagmatische Kohärenz einer Äußerung, eine Funktion, die sehr eng mit der unter 2.2.3 genannten verknüpft ist (Karmiloff-Smith 1979, Köpcke/Zubin 1984, Mills 1986, Wegener 1995, van Berkum 1996). Die Genusmarkierungen am Nomen und den zugehörigen Konstituenten bilden eine Klammer, die auch längere und komplexe NPs, z.B. über eine eingeschobene NP hinweg, die zusammengehörigen Elemente verbindet (Beispiel aus Köpcke/Zubin 1984:44):

(4) Das den Kölnern durch die unfaire Schiedsrichterentscheidung aberkannte Tor

In Sprachen, in denen das Genus zusätzlich zum Numerus des Subjektes auch am Verb markiert wird, wie z.B. im Polnischen, z.T. auch im Russischen, leistet die Genuskongruenz zwischen NP und dem finiten Verb der VP einen weiteren Beitrag zu Herstellung der syntagmatischen Kohärenz (vgl. Karmiloff-Smith 1979:149).

\subsubsection{Zusätzliche Funktionen}

Des Weiteren nennt Mills (1986) die Differenzierung von Singular- und Pluralzuordnungen, die das Genus bei Nomina mit endungslosem Plural übernimmt. Solche Nomina, wie z.B. der Löffel und das Kätzchen, sind immer Maskulina oder Neutra und können daher im Nominativ und Akkusativ Plural die dem Femininum identische Artikelform erhalten, ohne dass es zu Ambiguitäten käme: die Löffel, die Kätzchen.

Auch wird von einigen Autoren auf die bedeutungsdistinguierende Eigenschaft des Genus hingewiesen. In manchen Fällen sei die jeweilige Bedeutung nur unter Berücksichtigung des Genus eindeutig, wie beispielsweise der/die Kiefer oder der/das Laster (Werner 1975:38f., Wegener 1995:63). Homophone Nominalpaare sind allerdings im Deutschen verhältnismäßig selten und eine Verwechslung ist zudem meist durch den Kontext bereits ausgeschlossen; es dürfte sich hierbei daher wohl eher um einen „Nebeneffekt" handeln.

8 Voraussetzung für diesen Effekt war, dass der vorangehende Artikel laut mitgelesen wurde. Wurden die Artikel zwar visuell präsentiert, jedoch nicht laut mitgelesen, waren dagegen nur hemmende Effekte durch genusinkongruente Artikel nachweisbar. 
Darüber hinaus können Genussysteme noch eine Reihe weiterer Funktionen oder Eigenschaften aufweisen, die jedoch nicht für das Deutsche gelten. So kann das Genus z.B. die jeweilige Sprechereinstellung anzeigen, um den Status von Personen zu markieren, Respekt bzw. Respekt-Mangel oder Zuneigung zum Ausdruck zu bringen (Corbett 1991:332).

\subsubsection{Zusammenfassung}

Die verschiedenen Aufgaben des Genussystems übernehmen mehr oder weniger wichtige Rollen im Funktionsgefüge des Gegenwartsdeutschen. Jedoch kann keine dieser Eigenschaften eine Rechtfertigung für die Existenz dieser Nomenklassifikation im Deutschen sein. Vielmehr übernimmt das - aus bislang noch nicht gesicherten Gründen (vgl. Abschn. 2.3) existierende Genussystem Funktionen, die sonst von anderen sprachlichen Elementen ausgeübt würden (Mills 1986:36). Sprachen, die nur teilweise über eine Genusdifferenzierung verfügen, wie z.B. das Englische, oder solche wie beispielsweise das Türkische, das ganz auf ein nominales Klassifikationssystem verzichtet, sind funktional schließlich nicht beeinträchtigt. Die Genera fungieren im Deutschen lediglich als distinktive Merkmale, weisen jedoch keine eigenen, einheitlich semantischen Werte oder syntaktisch-pragmatischen Funktionen auf (Köpcke/Zubin 1984:47). Van Berkum resümiert daher:

maybe it [das Genussystem; F.B.] is just there because of a series of linguistic accidents, controlled by general principles of language change. We cannot exclude the possibility that, once they have sprung into existence, gender systems are simply tolerated because they do no harm. (1996:22)

Die Unklarheit über die Funktion der Genera hängt eng zusammen mit der Frage nach der Entstehung dieses Klassifizierungssystems. Man geht davon aus, dass Genussysteme anfangs wie auch immer motivierte Kategorisierungen gewesen sein müssen. $\mathrm{Zu}$ den verschiedenen Theorien, die zu diesem Aspekt formuliert wurden und mitunter recht kurios anmuten, sei an dieser Stelle auf Claudi (1985) verwiesen. Im Folgenden möchte ich vielmehr einen neuen Ansatz darstellen, der den Genera tatsächlich eine ursprünglich grammatisch-funktionale Motivierung bescheinigt.

\subsection{Das Genus als Nominalaspekt}

Zum Ursprung und der Entwicklung des deutschen Genussystems konnten Leiss und Weber in den vergangenen Jahren neue Erkenntnisse vorstellen. Sie sind in ihren Untersuchungen auf Anhaltspunkte gestoßen, die eine ursprüngliche Funktion von Genussystemen vermuten lassen, deren Spuren sich auch heute noch im Deutschen wiederfinden lassen.

Vorweg sei darauf hingewiesen, dass die Genusdifferenzierung bei Lebewesen, speziell bei Personen, bezüglich des natürlichen Geschlechts nichts mit der Entstehung des Genussystems zu tun hat, wie es lange Zeit von einigen Autoren angenommen wurde (vgl. z.B. die Übersicht in Weber 2001:15-27). Weber klammert diesen Aspekt daher sehr früh aus ihren Untersuchungen aus. Die sexualistische Theorie, nach der das ursprüngliche Genussystem vermeintlich auf der Zuordnung von „typisch“ weiblichen und männlichen Merkmalen basierte, kann als unbegründet zurückgewiesen werden, da nach den Erkenntnissen Brugmanns die Übertragung des maskulinen und femininen Genus auf männliche bzw. weibliche belebte Referenten erst später als die ursprüngliche, rein grammatikalische Kategorisierung erfolgte (ebd.:32).

Den Ausgangspunkt der Überlegungen von Leiss und Weber stellt eine Entdeckung von Brugmann aus dem Jahre 1897 dar. Nach einem umfassenden Vergleich von Feminina mit dem Suffix - $a$ oder -ie (-i) in verschiedenen indoeuropäischen Sprachen nimmt er als die ursprüngliche Funktion dieser Suffixe die Bildung von Abstrakta und Kollektiva an (Leiss 1994:291, Weber 2001:33). Hinzu kommt die Beobachtung, dass in Sprachen unterschied- 
lichster Herkunft die Formen des femininen Paradigmas häufig mit denen der Pluralmarkierung identisch sind (Leiss 1994:286f.).

Leiss greift zudem eine Arbeit von Lehmann von 1958 wieder auf, in der er eine variable Kategorie Genus des Indoeuropäischen rekonstruiert hat. Diese Kategorie wies eben jene Eigenschaften auf, deren Mangel im Gegenwartsdeutschen das Genus von seinen grammatischen „Schwester"-Kategorien Kasus und Numerus unterscheidet und weshalb Leiss diesen Status einer grammatischen Kategorie für das deutsche Genus in Frage stellt: die freie Morphemvariabilität am Nomen, so dass ein Wechsel des Genusmorphems einen semantischen Wechsel bewirkt (Leiss 1997:35ff.). Diese Endungen waren das maskuline $-s$, welches Singularität anzeigte, $-\bar{a}$ bzw. $-h$, das feminin war und Kollektiva markierte und $-m$, das als Neutrum die Kategorie „Resultat“ zuwies. So konnte beispielsweise das maskuline und somit singulare Nomen himá-s („Kälte, Frost") sein Genus mithilfe des femininen Morphems zu him-ā $(<$ himah) wechseln. Als Kollektivum im Sinne von „Gesamtheit der Fröste“ bedeutete es „Winter“. Ein Wechsel in die Neutrum-Kategorie (hima-m) bewirkte eine resultative Bedeutung und meinte als „Resultat von Kälte“ „Schnee“ (ebd.).

Diese Ergebnisse werden durch die von Greenberg formulierte Universalie ergänzt, die besagt, dass eine Sprache, die die Kategorie Genus aufweist, immer auch die Kategorie Numerus enthält; der Umkehrschluss kann dagegen nicht angenommen werden. Eine Klassifizierung der Nomina in Genera basiert also immer auf dem Vorhandensein der Kategorie Numerus - es muss daher ein funktionaler Zusammenhang zwischen diesen beiden Kategorien bestehen (Leiss 1994:287f., Weber 2001:52).

Aus diesen Argumenten zieht Leiss den Rückschluss, dass sich diese ursprünglichen Bedeutungen der Genera (Maskulinum=Singulativum/count noun, Femininum =Kollektivum, Neutrum= Massennomen), wenn auch reliktartig, im Deutschen sowie seinen vorangegangenen Sprachstufen wiederfinden lassen müssen. Die Autorin zeigt entsprechende Beispiele von Genuswechsel im Althochdeutschen”, „eine Art Goldmine für Genusforscher, die endlich fündig werden wollen“ (Leiss 1997:33) auf, die

nicht das Resultat willkürlichen Lautwandels sind, sondern [...] vielmehr ein noch hochmotiviertes Reliktsystem darstellen. (Ebd.:46)

Die Kategorie Femininum bildete dabei die Schnittstelle zwischen Genus und Plural. Mit seiner kollektiven Bedeutung bezeichnete das feminine Genus Nomina, die eine Vielzahl von einzelnen Objekten als eine Gesamtheit darstellen, indem es eine Singularmarkierung zuweist, wie z.B. in nhd. die Mannschaft (Leiss 19994:292f., Weber 2001).

In diesem Zusammenhang stellt Weber (2001:78ff.) nach einem ausführlichen, sprachübergreifenden Vergleich unterschiedlicher Genus- und Klassifikatorsysteme fest, dass alle nominalen Klassifizierungssysteme mehr oder weniger offensichtlich auf der Unterscheidung des Merkmals [+/-partikularisierend] basieren. Dieses Merkmal gibt an, ob ein Nomen eher auf ein individuiertes Einzelobjekt, [+partikularisierend], oder ein Massennomen oder Abstraktum, [-partikularisierend], verweist.

Bezüglich der Suffixe im Deutschen stellt Weber eine funktionale Nähe von Derivation und Flexion innerhalb der Wortbildung fest: Man könne „die Derivation als Morphologie in der Wortbildung“ (Welke 1995:80; zit. in Weber 2001:94) betrachten, da sich die Wortbildungssuffixe wie flexivische Genusmarker verhielten. Somit „wird die Grenze zwischen Flexion und Wortbildung fließend“ (ebd.:95). Die Autorin sieht in der fehlenden Genusmarkierung

9 Die Autorin merkt an, dass Vennemann die althochdeutsche Periode um fast ein Jahrtausend vordatiert hat (Leiss 1997:37). 
am Substantiv eine „Lücke im grammatischen Paradigma“ (Fleischer/ Barz 1995:5; zit. in ebd.), die nach Fleischer/Barz mittels der Wortbildung geschlossen werden könne. Dadurch würde das Genus wieder den Status einer grammatischen Vollkategorie erhalten:

Die Wortbildung hält also potentiell die Möglichkeit bereit, diese Lücke zu schließen und damit das Genus im Gegenwartsdeutschen zu einer regelgerechten Nominalkategorie werden zu lassen. (Weber 2001:95)

Die Mehrheit der deutschen Wortbildungssuffixe, wie z.B. -heit, -keit, -ung, dienen der Abstraktabildung und weisen feminines Genus zu. Daneben gibt es einige Derivationssuffixe, die Neutra betreffen und z.B. Kollektiva durch die Affix-Kombination Ge-...(-e) bilden, oder Abstrakta auf -tum sind (Weber 2001:97ff.). Aus der Tatsache, dass nicht-abgeleitete Substantive zu etwa zwei Drittel maskulin sind (s. auch Abschn. 2.1.1), leitet die Autorin eine Markiertheitsopposition zwischen dem Maskulinum als dem morphologisch und funktional unmarkierten Genus gegenüber dem formal und funktional extrem markierten Femininum ab. Das Neutrum nimmt dabei eine Mittelstellung zwischen diesen beiden Polen ein. Diese Opposition korreliert mit der im übersprachlichen Vergleich festgestellten Merkmalsunterscheidung von [+/-partikularisierend]: Die femininen Suffixe als Anzeiger von Abstraktheit tragen das Merkmal [-partikularisierend], das Maskulinum markiert ein Nomen mit [+partikularisierend $]^{10}$ als Individuativum (Weber 2001). Die oben genannte Position des Femininums als Schnittstelle zwischen Singular und Plural findet sich also in den Derivationsmorphemen des Neuhochdeutschen wieder. Das Merkmal [-partikularisierend] impliziert die Eigenschaft, nur bedingt pluralfähig zu sein - was für Abstrakta und Kollektiva typisch ist. Individuativa können dagegen problemlos pluralisiert werden (ebd.).

Im heutigen Deutsch zeigen sich diese semantischen Merkmalsunterschiede in Ableitungen wie z.B. der Dreh, was als Maskulinum eine singulative Bedeutung und keine morphologische Markierung in Form einer Endung aufweist. Das Femininum die Drehung erhält mittels des Derivationssuffixes -ung eine abstrakte Konnotation und das Drehen zeigt als Neutrum mit der Deverbativendung -en Kontinuativität an (vgl. auch Leiss 1997). Man beachte, dass das genannte Maskulinum heute eine übertragene, abstrakte Bedeutung im Sinne von „Einfall, Kunstgriff“ (Duden) hat, daneben aber auch individuiert für „Filmaufnahme“ verwendet wird und zumindest in letzterer Bedeutung problemlos pluralisierbar ist.

Wegen seiner Funktion, die Substantive nach dem Merkmal [+/-partikularisierend] zu klassifizieren, kann das Genus laut Weber als nominaler Aspekt betrachtet werden (Weber 2001:115). Es übernimmt damit, ähnlich wie der Verbalaspekt (der z.B. im Russischen eine voll ausgebildete grammatische Kategorie ist und sich auf lexikalischer Ebene manifestiert), die Aufgabe, eine jeweils unterschiedliche Perspektive auf die Entitäten einzunehmen - mal als individuierte Einzelobjekte, mal als Gesamtheit von Einzelobjekten oder als Masse. Diese Aufgabe des Perspektivenwechsels durch die Genera ist dabei seit dem Althochdeutschen zunehmend auf die Suffixe übergegangen, denn diese weisen heute sowohl die Bedeutungsperspektive als auch das Genus zu (Leiss 1997, Weber 2001). Es hat also ein Grammatikalisierungsprozess stattgefunden, in dem sich ursprünglich selbständige Lexeme über Kompositabildungen $\mathrm{zu}$ heutigen Derivationsmorphemen entwickelt haben. Ein Beispiel ist das ahd. Femininum heit/hait= „Stand, Stellung, Wesen, Beschaffenheit, Art und Weise“ (Weber 2001:97), das mit variierendem Genus auch „vornehme Person“ bedeuten konnte. Heute kann es in seiner Eigenschaft als Wortbildungssuffix -heit nicht mehr selbständig auftreten, es deriviert hauptsächlich Abstrakta aus Adjektiven (z.B. klug > Klugheit) und enthält dabei die Bedeutungskomponente „Wesen, Art und Weise“ (ebd.:98) sowie das feminine Genus. Weber

10 Dass das Maskulinum als unmarkierte Kategorie die positive Merkmalsmarkierung trägt, ist laut Weber (2001:101) nichts Ungewöhnliches für Grammatikalisierungsprozesse. 
geht davon aus, dass dieser Grammatikalisierungsprozess im Neuhochdeutschen noch nicht abgeschlossen ist und sich die heutigen Wortbildungssuffixe wieder zu genusanzeigenden Flexiven reduzieren werden. Wegen ihrer genusmarkierenden Eigenschaft sieht die Autorin die heutigen Derivationssuffixe in diesem Grammatikalisierungsprozess bereits in der Übergangsphase zu Flexionsmorphemen:

Das Genussystem des Gegenwartsdeutschen erscheint also nur auf den ersten Blick als unmotiviert, es scheint sich zu einem offen flexivisch markierten System zu entwickeln. (Ebd.:116)

Die redundante Genusmarkierung am Artikel und anderen, vom Nomen abhängigen NPKomponenten sorgt dabei hauptsächlich für Kongruenz innerhalb der Nominalphrase - wie es ja auch für die zusätzlichen Kasus- und Numerusmarkierungen an diesen Wortarten der Fall ist.

Weber vermutet - explizit zumindest für die femininen Suffixe - für die zukünftige Entwicklung, dass nur jeweils eine Flexionsendung sich durchsetzen und somit zu einem neuen, eindeutigen Genus- und damit Aspektmarkierer mit Paradigmenwahl wird.

\section{$2.4 \quad$ Fazit}

Mit der Beschreibung des Ursprungs sowie der vergangenen und möglichen zukünftigen Entwicklung des deutschen Genussystems wird die Ursache für die heute (außerhalb der Derivation) komplizierte Genusverteilung sowie die scheinbare Funktionslosigkeit dieser Nominalkategorie deutlich. Das ehemals perspektivierende Genussystem mit freiem Paradigmenwechsel ist in eine erstarrte Kategorie des Gegenwartsdeutschen übergegangen und stellt nun ein inhärentes Merkmal des Nomens dar. Die funktionale Lücke, die der Schwund der Aspekteigenschaft der Genera hinterlassen hat, wurde durch verschiedenen Aufgaben gefüllt.

Vor diesem Hintergrund scheint das Netz aus Einzelfunktionen im Gegenwartsdeutschen lediglich zur Überbrückung der Entwicklung von der ursprünglichen bis zur eventuell zukünftigen, wieder voll ausgebildeten nominalen Aspektkategorie zu dienen, d.h. einen Zusammenfall aller oder nur einiger Genera zu verhindern.

Im Hinblick auf den Spracherwerb stellt sich die Frage, wie sich der Erwerbsverlauf eines im Übergang befindlichen Systems vollziehen kann, wenn eine Kategorie vorübergehend keine konkrete, offensichtliche Funktion inne hat. Suffigierte Nomina und Abstrakta stellen einen Teil des Lexikons dar, der erst relativ spät im Erwerbsprozess auftritt. Wie sich zeigen wird, ist zu diesem Zeitpunkt der wesentliche Prozess des Genuserwerbs bereits abgeschlossen und wurde hauptsächlich lexikalisch durch die formal und funktional unmarkierten Simplizia gemeistert. In der Phase des Genuserwerbs spielen im Bereich der Wortbildung lediglich Ableitungen auf -chen eine nennenswerte Rolle. Das Derivationssystem mt seiner relativ einheitlichen Genuszuweisung kann somit nicht die Basis für den Erwerb der Genuszuordnung sein.

\section{$3 \quad$ Die Artikel}

Die Artikelwörter - oder auch Determinantien (Vater 1986:7ff.) - lassen sich Durrell (1977) folgend jeweils in zwei Morphe gliedern. ${ }^{11}$ Das erste Morph übernimmt dabei die spezifische Funktion des jeweiligen Artikelwortes, die darin besteht, für das zugehörige Nomen die vom

11 Damit widerspricht er Vater, der diese Trennung zumindest für den bestimmten bzw. „der-Artikel“ für nicht möglich hält: „Beim Artikel der lassen sich nicht einmal Stamm und Endung unterscheiden“ (1979 [1963]:35). 
Sprecher intendierte Referenz auf das jeweilige Objekt in der Welt herzustellen. Solche „Referenz-Morphe“" sind u.a. $d$-, dies-, jen-, ein-, kein- oder mein-. Das zweite Morph enthält die Flexion, die, wie auch bei Pronomen und attributiven (dem Nomen vorangehenden) Adjektiven, das jeweilige Genus sowie den Kasus und Numerus des Kopf-Nomens des Phrase kodiert. Die Artikelwörter sind somit an der Herstellung der formalen Kategorienübereinstimmung der NP-Konstituenten, der Kongruenz, beteiligt (vgl. Abschn. 2.2.3 und 2.2.4). Die einzelnen Merkmale werden jedoch nicht separiert angezeigt, sondern sind zu einem gemeinsamen Flexiv verschmolzen.

Eine häufig anzutreffende Auffassung ist, die Funktion des bestimmten Artikels bestünde darin, das Genus des zugehörigen Nomens anzuzeigen. Beispiele für solche Darstellungen finden sich besonders in allgemeinen Nachschlagewerken wie Meyers Taschenlexikon (1996) oder im Anhang von fremdsprachigen Wörterbüchern: „The article indicates the gender of a noun.“ (PONS 1988:1351) Im Fremdwörterduden ist unter dem Stichwort „Artikel“ im sprachwissenschaftlichen Sinne lediglich „Geschlechtswort (der, die, das)“ vermerkt. Der Grammatikduden weist dagegen auf diese Bezeichnung als überholt hin, allerdings mit der Begründung, dass früher angenommen wurde, der Artikel bestimme selbst das Genus des Substantivs. Bei Bußmann (1990:99) erscheint der Begriff „Geschlechtswort“ neben „Determinans, Determinator“ als offenbar gleichberechtigte, alternative Bezeichnung für „Artikel“.

Das Genus (gemeinsam mit Kasus und Numerus) schlägt sich aber lediglich im Flexionsmorph des Artikels nieder, die spezifischen Funktionen der einzelnen Determinantien werden dagegen im ersten, dem „Referenz-Morph“ ausgedrückt. Die

\begin{abstract}
Funktion des Artikels ist es nicht, Genus oder Sexus zum Ausdruck zu bringen, seine eigentliche Aufgabe besteht darin, Definitheit im Gegensatz zu Indefinitheit [...] zum Ausdruck zu bringen [...] Beide sind mit gemeinsamer Last beladen, die sie zusätzlich zu transportieren haben. Da sind einmal die Kasusbedeutungen, dann die Numerusbedeutungen [...] und zum anderen das sogenannte Femininum, Maskulinum, Neutrum. Doch so wie niemand auf die Idee kommt, einen Esel mit seiner Packlast zu verwechseln, genausowenig darf der Artikel mit diesen zusätzlichen grammatischen Funktionen, die er transportiert, verwechselt werden. (Leiss 1994:284)
\end{abstract}

Die Klasse der Artikelwörter gehört zu den sog. Funktionswörtern oder Funktoren, denn sie drücken keinen semantisch-lexikalischen Wert aus (wie z.B. Haus=,,bewohnbares, geschlossenes Objekt aus Wänden und einem Dach“, rot=,farbliche Eigenschaft, die beispielsweise Blut und Rose gemeinsam haben"). Funktoren haben vielmehr einen funktional-grammatischen Wert, d.h. sie üben modifizierende Aufgaben in einer Äußerung aus und setzen die semantischen Konzepte zueinander in Beziehung. Artikel übernehmen dabei die Modifikation oder Spezifikation der oben bereits erwähnten Referenz der NP.

Im Folgenden sollen zuerst die Hauptfunktionen der Artikel, angezeigt durch das jeweilige Referenz-Morph, beschrieben werden. Anschließend gehe ich auf die Flexionsformen des bestimmten und des unbestimmten Artikels sowie die Schwierigkeit der gemeinsamen Kategorienanzeige, verbunden mit der Frage, welche Rolle das Genus dabei einnimmt, ein.

\title{
3.1 Das Referenz-Morph: Die Funktionen
}

Die Funktionen der Artikel der, die, das, etc. und ein, eine, etc. wird i.A. mit der Kennzeichnung von definiter bzw. indefiniter Referenz beschrieben; entsprechend werden für die Artikel auch die Bezeichnungen „definit“ und ,indefinit“"verwendet. Je nach Definition werden auch die Attribute „bestimmt“ und „unbestimmt“" gebraucht. Viele Autoren vermeiden eine Festlegung auf den einen oder anderen Terminus, indem sie auf die Bezeichnungen ,der- 
Form“ für den definiten/bestimmten und „ein-Form“ für den indefiniten/unbestimmten Artikel ausweichen (z.B. Vater 1979 [1963]).

\subsubsection{Der pragmatische Ansatz}

Bisle-Müller gründet seine Untersuchung der Artikelwörter auf die Betrachtung der Referenz als kommunikative Handlung, die er als „Koordination des gemeinsamen Wissens“ (BisleMüller 1991:ix) bezeichnet, und knüpft damit an die Griceschen Kommunikationsprinzipien an. Die Wahl eines Artikels hängt folglich nicht nur von der jeweiligen Sprecherintention ab, sondern auch das (vermutete) Wissen des Hörers spielt eine entscheidende Rolle.

Der „definite“ Artikel, d.h. die Formen der, die und das mit ihren Kasusvarianten, ist „,bei Problemlosigkeit der Referenz angebracht“" (Bisle-Müller 1991:156), im Gegensatz z.B. zum Demonstrativartikel dieser, bei dem die ,unproblematisch gegebene Bestimmtheit von Referenten [...] in Frage gestellt" (ebd.) wird. Diese Problemlosigkeit, also das gemeinsame Wissen von Sprecher (S) und Hörer (H), kann zum einen durch den sprachlichen oder situativen Kontext hergestellt werden. Dann wird entweder durch die vorausgegangene oder folgende Äußerung (anaphorische bzw. kataphorische Referenz) nur eine sinnvolle Interpretation der Referenz zugelassen (ebd.:51f):

(5) Wir hatten ein fürchterliches Hotelzimmer. Und das Loch hatte uns unser Reisebüro als komfortabel beschreiben. (Ebd.:51) $)^{12}$

Oder es ist die konkrete Sprechsituation, die den „situativen Rahmen“ (ebd.:55) darstellt, so dass durch deiktische Referenz (beispielsweise eine Zeigegeste) der Bezug hergestellt werden kann. So ist der Referent in dem Satz

\section{(6) Das Buch gehört mir!}

eindeutig, wenn S und H ein bestimmtes Buch im Blickfeld haben. Der situative Kontext kann durch generisches (allgemeingültiges) Dauerwissen erweitert sein, so dass mit bestimmter Referenz nicht unbedingt ein ganz bestimmter Referent verbunden sein muss. Wenn S z.B.

\section{(7) Kann ich bitte den Salzstreuer haben? (Ebd.:54)}

äußert, weiß H, auch wenn mehrere Salzstreuer auf dem Tisch stehen, dass es S wahrscheinlich nicht auf einen ganz bestimmten Salzstreuer ankommt. Hierbei wird „stehendes Rahmenwissen“ (ebd.:55) abgerufen, d.h. dass im Rahmen „Essen“ ein Element „Salzstreuer“ enthalten ist, auf das direkt referiert werden kann, ohne dass es darüber hinaus im sprachlichen Kontext enthalten sein muss. ${ }^{13}$

Zur Herstellung von bestimmter Referenz können auch Orientierungspunkte, die sich auf die Kommunikationssituation und -beteiligten beziehen, dienen (ebd.). Solche Orientierungspunkte können z.B. der Sprechort und die Herkunft der Kommunikationsteilnehmer sein. In einer Äußerung wie

(9) Der Hauptbahnhof wird nächstes Jahr renoviert. (Ebd.:57)

12 Diesen Kontext muss nicht unbedingt eine NP darstellen. Auch auf eine Verbalphrase (VP) kann nominal referiert werden: „Ich bin gestern nach München gefahren. Die Fahrt dauerte 2 Stunden.“ (Bisle-Müller 1991:51).

13 Solches Rahmenwissen kann auch episodischer oder spezifischer Art sein, d.h. bestimmte Interpretationsbezüge gelten nur für einen begrenzten Zeitraum und/oder Personenkreis (wodurch sich z.B. spezielles Fachwissen auszeichnet) (Bisle-Müller 1991:53). 
ist der Bahnhof eindeutig bestimmt, wenn $\mathrm{S}$ und $\mathrm{H}$ in der Stadt leben, in der zwischen ihnen diese Äußerung getan wird. Erst wenn sich die Orientierungspunkte voneinander unterscheiden, muss die Referenz durch eine eindeutigere sprachliche Konstruktion gesichert werden (z.B. mittels eines Possessivartikels).

Für die ein-Form hält Bisle-Müller die Bezeichnung „unbestimmt“ für unangemessen. Die Eigenschaft des ,indefiniten“ Artikels liegt seines Erachtens darin, auch bei Singular-NPs Zählbarkeit, und zwar den Wert 1 anzuzeigen. ${ }^{14}$ Auch Abstrakta kann das Merkmal [+zählbar] und demnach auch der indefinite Artikel zugewiesen werden, wenn sie eine zusätzliche Attribuierung durch ein Adjektiv (10a), eine Kompositabildung (10b) oder einen Relativsatz erhalten, bzw. die potenzielle Möglichkeit dazu besteht (10c) (vgl. ebd.:110ff.):

(10a) Sie zeigte eine Heidenangst.

(10b) Die Anstrengung löste bei ihm einen unvorstellbaren Hunger aus.

(10c) Das ist vielleicht ein Wetter. (alle Beispiele: ebd.:114)

Das Zählbarkeitsmerkmal kommt auch bei Konkreta nur durch Pluralbildung am Nomen selbst zum Ausdruck, im Singular übernimmt der indefinite Artikel die Markierung dieser Eigenschaft (ebd.:110).

Der Indefinitartikel signalisiert nicht speziell Unbestimmtheit, sondern seine Funktion liegt im Bereich der anderen Numeralia. Aber seine Verwendung impliziert natürlich, daß S-H-Bestimmtheit nicht thematisiert wird, da S aufgrund der Exklusivitätsbedingung gerade voraussetzt, daß zusätzliche Referenten auch möglich wären. (Ebd.:116)

Die Exklusivitätsbedingung beruht auf einem Ansatz von Hawkin, der damit die Referenz auf explizit „nicht alle“ beschreibt (ebd.:106). Daher enthält ein Satz wie

(11) ? Putz dir bitte eine Nase!

gewissermaßen überflüssige Informationen, da der angesprochene sowieso nur eine Nase besitzt, die er putzen könnte (ebd.:108).

Der Possessivartikel kann laut Bisle-Müller ,als gleichwertiger Ersatz für den Definit- oder Demonstrativartikel“ (ebd.:97) fungieren. Er grenzt die Zahl der möglichen Referenzrahmen mittels „grammatischer Brücken“ (ebd.:96) ein, die durch die doppelseitige Kongruenz sowohl mit dem Besitzer (Possessor) als auch mit dem Besessenen (Possessum) geschlagen werden (vgl. sein_Sohn, ihr_Sohn vs. seine Tochter, ihre Tochter). Dadurch kann eine eindeutige Referenz ermöglicht aber auch erschwert werden (vgl. ebd.:96f).

\subsubsection{Der kognitive Ansatz}

Aus der Spracherwerbsforschung kommt ein Ansatz zur Beschreibung der Artikelwörter, der auf der Beobachtung beruht, dass die Artikelwörter i.A. in der Reihenfolge unbestimmter Artikel $>$ Possessivartikel > bestimmter Artike ${ }^{15}$ erworben werden (vgl. Bittner 1998:259ff.). ${ }^{16}$ Innerhalb der Natürlichen Grammatik formulierte Leiss ein Prinzip, nachdem alle Kategorien

14 Den Ausgangspunkt für diese Betrachtung des Indefinitartikels bildet die Diskussion darum, ob die Form ein ein Numeral oder ein unbestimmter Artikel ist (vgl. Bisle-Müller 1991:100ff).

15 Ihre Betrachtungen schließen auch die Kategorie der Adjektive, darunter ander- als Spezialfall mit ein, die ich hier jedoch unberücksichtigt lasse; s. dazu Bittner (1998:267f.).

16 D.h. nicht, dass dies bei jedem Kind eindeutig zu erkennen sein muss. Erst der Vergleich mehrerer Erwerbsverläufe deutet auf diese generelle Abfolge hin (Bittner 1998:262f.). 
einer funktionalen Klasse auf einem allen gemeinsam zugrundeliegenden Konzept beruhen, welches „sich vom ,natürlichen' egozentrischen Standpunkt des Sprechers ableiten“ (Leiss 1992:3; zit. nach Bittner 1998:256) lässt. Die Kategorien bauen dabei durch eine schrittweise Komplexitätszunahme ihrer Merkmale aufeinander auf, d.h. die komplexere Kategorie impliziert gleichzeitig sämtliche Merkmale der weniger komplexen Stufen (Bittner 1998).

Ausgehend von der Annahme, dass im Spracherwerb zuerst die einfachen und anschließend die komplexeren sprachlichen Elemente erworben werden, ist der unbestimmte Artikel ein demnach der allen Artikelwörtern funktional zugrunde liegende. Er weist die Basiseigenschaft der Referenz auf, die nach Bittner das Definitheitsmerkmal [+definit] in dem Sinne ist, dass ein „Gegenstand bzw. Geschehen [...] als abgeschlossen, in ihrer Gesamtheit und ihrem äußeren Konturen vollständig erfaßbar gekennzeichnet" (ebd.:264) wird. Durch den unbestimmten Artikel wird ein nicht individualisierter Vertreter aus der Gesamtmenge dieser Elemente sprachlich-referenziell herausgehoben.

Der bestimmte Artikel der weist einer NP zusätzlich das grammatische Merkmal [+bekannt] $\mathrm{zu}$, er referiert auf ein individuelles, konkretes Objekt, dessen spezifische Bekanntheit aus dem sprachlichen, situativen oder assoziativen Kontext herrührt (ebd.:272ff.). Dabei ist das Merkmal [+definit] bei Bekanntheit des Referenten implizit enthalten: „Bekanntheit ist ein Spezialfall von Definitheit.“ (Ebd.:274)

Den Possessivartikel setzt die Autorin, anders als Bisle-Müller, mehr in funktionale Nähe zum unbestimmten als zum bestimmten Artikel. Seine Verwendung setzt zwar die Bekanntheit des Possessors voraus, die Indivualität des besessenen Objektes ist dagegen nicht wie beim bestimmten Artikel zwingend (ebd.:268ff.).

Bevor die unterschiedlichen Artikel und andere Nomen-Spezifizierer (wie z.B. Adjektive) vollständig erworben sind, muss in der kindlichen Sprache eine eingliedrige NP, die nur das Nomen selbst enthält, als unterspezifiziert gelten und die intendierten Referenzeigenschaften aus dem Kontext erschlossen werden. Ein Kind kann mit einem Satz wie Ball spielen sowohl einen ganz bestimmten als auch irgendeinen, unbestimmten Ball meinen, mit dem es spielen will, es kann aber auch nur die Tätigkeit an sich, meinen, wobei mit Ball auf das kognitive Konzept und nicht auf den Gegenstand selbst referiert wird (ebd.:265).

\subsection{Das Flexions-Morph: Die Formen}

Die Formen des Flexionsmorphs richten sich nach den drei Genera, vier Kasus und zwei Numeri des Kopf-Nomens der NP. Es handelt sich hierbei jedoch, wie bereits erwähnt, nicht um eine separate Kategorienmarkierung in dem Sinne, dass jede Position der drei anzuzeigenden Kategorien jeweils durch ein spezifisches sprachliches Zeichen repräsentiert wird. Alle drei Kategorien sind in nur einem Flexiv miteinander verschmolzen und die einzelnen Positionen ergeben sich immer nur unter Berücksichtigung aller drei Kategorien. Diese kombinierte Markierung mehrerer Merkmale mit Hilfe eines Flexivs ist auch dahingehend nicht eindeutig, dass jede Merkmalskombination durch jeweils eine spezifische Flexionsform wiedergegeben würde. Die 16 Felder des kreuzklassifizierten Paradigmas der drei Kategorien werden nur durch (je nach Wortart) maximal 6 verschiedene Formen ausgefüllt. D.h. es muss folglich zu Mehrfachvorkommen der einen oder anderen Form kommen. Tatsächlich ist es so, dass es keine einzige Artikelform gibt, die nicht mindestens doppelt im jeweiligen Paradigmensystem auftritt. (Auf die einzige potenzielle Ausnahme gehe ich weiter unten in diesem Abschnitt ein.)

Im weiteren Verlauf der Formendarstellung werde ich mich auf die Besprechung des bestimmten und unbestimmten Artikels beschränken. Es soll hier vor allem darum gehen, die 
Markierungsproblematik an sich und in Bezug auf das Genus im Besonderen zu veranschaulichen. Der bestimmte Artikel ist dabei nicht nur derjenige mit der höchsten Gebrauchshäufigkeit (Frequenz) in sprachlichen Äußerungen (vgl. Ruoff 1981:25, 513-516 und Bisle-Müller 1991:3, Anm. 2), er weist außerdem sowohl quantitativ als auch qualitativ die stärkste Differenzierung der Formen in den Paradigmen auf. Der unbestimmte Artikel steht bezüglich der Häufigkeit unter den Artikelwörtern an zweiter Stelle (vgl. ebd.). Da er keine lautliche Form für die Kategorie Plural aufweist, habe ich die unbestimmte Pluralkategorie aus der folgenden Übersicht ausgeschlossen und damit auf die Darstellung eines eventuellen Null-Morphems ${ }^{17}$ verzichtet:

\begin{tabular}{|c|c|c|c|c|c|c|c|}
\hline \multirow[b]{2}{*}{ Sg: } & \multicolumn{4}{|c|}{ best. Art. } & \multicolumn{3}{|c|}{ unbest. Art. } \\
\hline & mask. & neut. & fem. & PI. & mask. & neut. & fem. \\
\hline Nom. & der & das & die & die & ein & ein & eine \\
\hline Akk. & den & das & die & die & einen & ein & eine \\
\hline Dat. & dem & dem & der & den & einem & einem & einer \\
\hline Gen. & des & des & der & der & eines & eines & einer \\
\hline
\end{tabular}

Tabelle 1: Die Formen des bestimmten und des unbestimmten Artikels.

\subsubsection{Der bestimmte Artikel}

Im Paradigmensystem des bestimmten Artikels findet sich keine Form, die exklusiv für eine Zuordnungsmöglichkeit stehen würde. Die Form der, die im Nominativ (Nom) maskulines Genus und damit auch den Singular (Sg) anzeigt, erscheint darüber hinaus im Genitiv (Gen) und Dativ (Dat) des Femininums, sowie im Dativ Plural (Pl). Sowohl im Nominativ als auch Akkusativ (Akk) weisen die Kategorien Femininum und Plural die einheitliche Form die auf. Als am wenigsten kategorienübergreifend erweisen sich dagegen die Formen das, dem und des. Die das-Form kann als Neutrummarkierer angesehen werden, da es hier zwar ebenfalls für zwei Kasus (Nom und Akk) steht, jedoch in keiner weiteren Genuskategorie vertreten ist. Die Formen dem und des beschränken sich auf die Anzeige von Dativ bzw. Genitiv, beide aber sowohl bei Maskulina als auch bei Neutra.

Trotz dieser Vielzahl von gleichlautenden, sich überschneidenden Formen kommt es nur selten zu Fällen, in denen die Zuordnungen uneindeutig, ambig, bleiben und nur durch den über die Äußerung hinausgehenden Kontext geklärt werden können. Häufig leistet dies entweder die inhärente Genus- oder die offen markierte Numerusmarkierung am Nomen ${ }^{18}$, so dass auch bei einer markierten Stellung der Satzkonstituenten wie in (12) die Zuweisung der syntaktischen Rollen durch die Kasus eindeutig ist:

\section{(12) Der Katze biss der Hund in den Schwanz.}

Es kann hier nicht Katze das beißende Subjekt bzw. Agens der Handlung sein, da das Nomen Katze inhärent feminines Genus besitzt und dies in der Subjekt- bzw. Nominativ-Position die Form die aufweist. Die NP der Katze allein zeigt zwar sowohl Dativ als auch Genitiv an, das Prädikat beißen weist jedoch keine Position zu, die Genitiv verlangen würde. Stattdessen regiert es die syntaktische Position Benefaktiv zur Bezeichnung des „Nutznießers“ des Hand-

17 Eine Festlegung, ob es sich dabei tatsächlich um sog. Artikellosigkeit, einen Nullartikel oder einen ausgelassenen Artikel handelt, ist für diese Arbeit nicht unbedingt erforderlich. Ich werde ggf. von „Artikellosigkeit" sprechen und beziehe mich damit auf die Tatsache, dass diese Formen nicht positiv identifizierbar, d.h. nicht eindeutig vorhanden sind (zur Diskussion vgl. u.a. Bisle-Müller 1991:4ff.).

18 Die Kasusflexion am Nomen selbst ist im Deutschen bereits so weit reduziert, dass hier kaum mehr von einem ausgebildeten Flexionssystem gesprochen werden kann und nur in seltenen Fällen hierdurch die Ambiguität verhindert wird. 
lungsergebnisses und diese Rolle anzuzeigen ist typischerweise Funktion des Dativ. Das Genusmerkmal des Nomens ist in diesem Beispiel somit die Voraussetzung zum Erkennen der Kasus- bzw. Rollenzuweisung, denn am Artikel selbst ist es nicht abzulesen. Nur wenn das jeweilige Genus bekannt ist, können auch die Kasusmarkierungen erschlossen und markierte NP-Stellungen interpretiert werden. D.h. es muss mindestens ein Merkmal (Kasus/syntaktische Rolle, Numerus bzw. Genus) kontextuell oder durch lexikalisches Wissen bekannt sein muss, um die jeweilige Form im Paradigma lokalisieren und seine aktuelle Funktion erschließen zu können.

Auch der syntaktische Kontext außerhalb der NP enthält Informationen, die Aufschluss über die Kategorienzuordnung geben können. So ist die Kategorie Numerus für Subjekt-NPs zusätzlich am finiten Verb markiert und Genitiv- und Nominativ-NPs schließen sich positionell gegenseitig aus. Wird die NP durch eine zusätzliche Konstituente, z.B. ein Adjektiv, erweitert, werden einige Ambiguitäten hierdurch bereits formal aufgelöst (der neue Lehrer $=$ Nom.Mask. vs. der neuen Lehrer $=\mathrm{Gen} . \mathrm{Pl})$.

Ambiguitäten zwischen der semantischen Rolle des Agens als dem Handlungsurheber und des Patiens als Handlungsbetroffenem sind dennoch nicht ganz ausgeschlossen. Solche Fälle treten auf, wenn sowohl die Subjekt- als auch die direkte Objekt-Position eines Satzes, die in unmarkierten Fällen durch den Nominativ bzw. Akkusativ gekennzeichnet sind und die Agens- bzw. Patiensrolle beschreiben, mit einer belebten femininen oder neutrischen NP besetzt sind ${ }^{19}$ :

(13a) Die Tochter sieht die Mutter.

(13b) Das Pferd sieht das Schwein.

Wenn hier nicht der Kontext zusätzliche Informationen bereithält und somit die Rollenverteilung bekannt ist, muss von der unmarkierten Stellung der Satzkonstituenten ausgegangen werden, welche im Deutschen eine Subjekt-Verb-Objekt-Struktur (SVO), bzw. SOV im Nebensatz, ist.

Der oben (S. 97) genannte Zusammenhang zwischen dem femininen Genus und dem Plural, in dem das Femininum als Schnittstelle zwischen der Genuskategorie und dem Plural beschrieben wurde, schlägt sich sichtbar in den Formen des bestimmten Artikels nieder. Die Einträge dieser beiden Kategorien unterscheiden sich lediglich im Dativ (der vs. den). Um Verwechslungen bei endlungslosen (bzw. nullmarkierten) Pluralformen des Nomens ${ }^{20}$ auszuschließen, ist jedoch die Genusinformation relevant; lediglich der Dativ ist im Plural meist aufgrund einer Markierung am Nomen durch $-n$ eindeutig gekennzeichnet. Bei einer pluralen Nominativ- oder Akkusativ-NP wie z.B. die Lehrer stellt das Genus des Nomens die Pluralität sicher, denn Feminina erhalten im Plural keine endungslosen Formen. Bei der Form der Lehrer muss entweder Kasus (Nominativ oder Genitiv) oder Numerus (Singular oder Plural) bekannt sein, um diese NP zuordnen zu können.

19 Theoretisch sind solche ambigen Konstituentenstellungen auch mit unbelebten Nomina denkbar, m.E. wird in diesen Fällen jedoch eine Betonung seltener durch eine Topikalisierung realisiert. Hierzu würde vielmehr eine Struktur gewählt, die die hervorzuhebende Phrase in eine Subjekt-Position stellt, z.B. durch eine Passivkonstruktion (Die Flut bedroht die Insel vs. Die Insel wird von der/durch die Flut bedroht).

20 Im Gegensatz zum Kasus ist der Plural eine am Nomen offen markierte Kategorie (Haus - Häuser, Auto Autos). Endlungslosigkeit bzw. die Nullendung ist dabei lediglich eine von mehreren Markierungsarten. 


\subsubsection{Der unbestimmte Artikel}

Der Zusammenfall der Formen des unbestimmten Artikels entspricht nicht nur dem Verteilungsmuster des bestimmten Artikels, er geht sogar noch darüber hinaus, da Maskulinum und Neutrum selbst im Nominativ nicht unterschieden werden (ein Stuhl/Buch). Eine eindeutige Markierung des Genus erfolgt erst durch ein Adjektiv (ein grüner Stuhl vs. ein grünes Buch). Da die Akkusativ-Form der Maskulina einen häufig eine phonetische Reduzierung zu ein'n erfährt, die bei schnellem und informellem Sprechen zu einem totalen Wegfall der letzten Silbe führt, sind die Artikelformen des Maskulinum und Neutrum quasi komplett identisch. ${ }^{21}$

Die Possessiv- und Negationsartikel (mein, dein, etc. und kein) unterscheiden sich morphologisch vom unbestimmten Artikel lediglich durch die „Vorschaltung“ eines Konsonanten ( $m$ ein, d-ein; k-ein, etc.), das Paradigmensystem der Flexive entspricht jedoch dem des unbestimmten Artikels. Da diese Artikelformen ein Pluralparadigma aufweisen, finden wir hier wiederum dieselben Überschneidungen in der Kategorienanzeige wie beim bestimmten Artikel: Außer im Dativ, der wiederum mit der maskulinen Akkusativ-Form zusammenfällt, ist der Plural formengleich mit dem femininen Paradigma.

Während die Nominativ-Formen des bestimmten Artikels sich sowohl durch die Qualität des Vokals, welcher zudem wegen der einsilbigen Wortstruktur den Wortakzent trägt, als auch durch den Auslautkonsonanten phonetisch deutlich voneinander abheben, sind sich die Formen des unbestimmten Artikels mit den Schwa-haltigen lautlich wesentlich ähnlicher. Hinzu kommt, dass bei informellem, schnellem Sprechen der anlautende Diphthong ei- ausfällt und nur die zweite, unbetonte Silbe mit dem Flexiv übrig bleibt; lediglich der Genitiv ist hiervon nicht betroffen: 'n(en), 'ne, 'nem, 'ner, aber: *'nes.

\subsubsection{Zusammenfassung}

Die Zuweisung der Kategorien erfolgt nicht nur durch die Wahl der jeweiligen Form aus dem Paradigma, sie allein zeigt die entsprechenden Informationen nicht eindeutig an. Erst eine Betrachtung der gesamten Nominalphrase und der syntagmatischen Umgebung kann Aufschluss über die jeweilige syntaktische Funktion geben, wobei jedoch nicht immer eine eindeutige Differenzierung in der Genusanzeige erfolgt. So lässt sich das Genus einer SingularNP im Genitiv oder Dativ anhand der Flexionsformen lediglich als feminin oder nicht-feminin bestimmen, Maskulina und Neutra unterscheiden sich in diesen Kasus morphologisch nicht (des kleinen Mannes/Kindes, dem kleinen Mann/Kind). Die Markierung der semantischen Rollen durch die jeweiligen syntaktischen Relationen ergibt sich also erst aus dem Zusammenspiel der internen und der offenen Markierungen der Konstituenten einer NP. Die Wortarten allein enthalten dagegen immer nur bedingt Hinweise auf die Kategorien.

\subsection{Synkretismus der Formen}

Eine Frage, die bisher noch unerwähnt geblieben ist, ist die, ob es sich bei dem Mehrfachvorkommen der Formen in verschiedenen Kategorien um eine zufällige oder motivierte Gleichlautung (Homonymie vs. Synkretismus) handelt. Durrell beispielsweise nimmt ,ausnahmslos eine homonyme Realisierung verschiedener Morpheme“ (Durrell 1977:46) an. D.h., dass von

21 Aber auch im schriftlichen Sprachgebrauch ist der Trend zu beobachten, dass der phonetische Zusammenfall der Formen des Nominativ und Akkusativ im Maskulinum die graphische Wiedergabe beeinflusst. Dies beschränkt sich nicht mehr nur auf informelle Kontexte. Die zu beobachtende Zunahme auch in öffentlichen Bereichen wie Werbung, Hinweisschilder oder Informationstexte reflektiert die abnehmende Relevanz der Formendifferenzierung in diesem Bereich. 
der Identität in der Form zweier Artikel nicht auf Gemeinsamkeiten in ihren Funktionen verwiesen wird.

In Abschnitt 2.3 wurde der semantische Zusammenhang der Kategorien Femininum und Plural bereits erläutert. Darüber hinaus gilt generell, dass in verschiedensten Sprachen meist die gleichen Kategorien formal zusammenfallen (Leiss 1994:286). Es liegt somit nahe, dass bei identischen Formen ,auch in inhaltlicher Hinsicht ein gemeinsamer Nenner vorliegen könnte." (Ebd.:287) An dieser Stelle sei wiederholt, dass den Genera eine ursprüngliche Perspektivierung des Referenten zugeschrieben wird (Maskulina=Individuativa, Neutra=Kontinuativa, Feminina=Kollektiva), wobei die Kategorie Femininum eine Position zwischen dem Singular und dem Plural einnimmt. Mit dem Merkmal [-partikularisierend] stellt dieses Genus die markierte Kategorie gegenüber dem Maskulinum dar.

Für das Paradigmensystem des Gegenwartsdeutschen hat Bittner (2002b) die einzelnen Formen des bestimmten Artikels anhand von distinktiven semantischen Eigenschaften beschrieben, wobei sich jede Form durch spezifische Merkmale von den anderen unterscheidet. Die Autorin nimmt für die Kategorien Kasus und Genus/Plural parallele distinktive Merkmale an, auf die sich die kasus- und genusübergreifende Formengleichheit einer Artikelform zurückführen lässt. Dabei gilt, wieder dem Prinzip der hierarchischen Merkmalsstruktur aus der Natürlichen Grammatik folgend, dass die Formen durch jeweils ein weiteres positiv markiertes Merkmal aufeinander aufbauen. Neben dem Femininum und dem Plural sind auch Nominativ und Akkusativ unmarkierte Kategorien. Diese beiden Kasus werden - anders als Genitiv und Dativ - durch keine Artikelform exklusiv gekennzeichnet. Die Form die, die ausschließlich an den Überschneidungen dieser unmarkierten Kategorien im Paradigma erscheint, zeigt für eine NP also nur das Merkmal des bestimmten Artikels [+bekannt] an (vgl. Abschn. 3.1.2). Maskulina und Neutra - als typische Individuativa bzw. Kontinuativa - weisen das zusätzlich Merkmal [+begrenzt] auf (bei Kontinuativa ergibt sich diese Eigenschaft erst durch die Setzung eines Artikels). Diese Merkmale beziehen sich dabei nicht nur die Perspektivierung des nominalen Aspektes durch die Genera sondern auch auf das „Betroffensein von der Verbhandlung“" (Bittner 2002b:224) durch die Kasus. Neutra bzw. Kontinuativa grenzen sich wiederum von den Maskulina durch das weitere Merkmal der Teilbarkeit [+partitiv] ab, welches ebenso für den Genitiv gegenüber dem Dativ gilt (vgl. ebd.:213, 219f.). Die Kreuzklassifikation der Genus/Plural- und Kasusparadigmen bewirkt eine Überlagerung und Potenzierung der jeweiligen kategorialen Merkmalsdifferenzierungen an den einzelnen Positionen. Jede der sechs Form des bestimmten Artikels enthält somit ein spezifisches Merkmalsbündel aus bedeutungsunterscheidenden Eigenschaften. Zur vollständigen Disambiguierung der Referenzeigenschaften der NP dienen weitere Markierungen an anderen Wortarten oder der Kontext, denn

Sprache muss bekanntlich nur in einem ökonomischen Maße explizit sein. Was implikativ erschließbar ist, muss nicht explizit symobilisiert werden. (Ebd.:230)

\subsection{Fazit}

Für den Erwerb des Formenparadigmas und speziell der darin enthaltenen Genusdifferenzierung stellt sich die Frage, ob eine der Kategorien den Ausgangspunkt für den Aufbau des Formensystems bildet und welche das sein könnte. Es ist unklar, woran ein Kind erkennen könnte, dass es sich bei Formen wie der Teller und (in) der Flasche nicht um die gleichen Kategorien handelt (vgl. Wegener 1995:94ff.). Es ist unklar, an welcher Stelle in diesem eher minimal differenzierten Artikelsystem der Lerner den ersten Anknüpfungspunkt für den Aufund Ausbau des Paradigmas findet: Um eine Form aus dem Input „entziffern“ zu können, müssen die anderen Formen der jeweiligen Kategorie bereits bekannt sein, um diese zu wissen, müssen sie aber wiederum selbst zuvor kategorisiert worden sein (Mills 1986: 13f., We- 
gener 1995:96f.). Der Erwerb der Formen, die sich einerseits nach drei Kategorien richten, diese aber andererseits nicht eindeutig anzeigen, erscheint - zumindest für den Erstspracherwerb - theoretisch wesentlich komplizierter, als er sich in der Praxis erweist. ${ }^{22}$ Ein Schwerpunkt der Untersuchung wird also die Frage sein, welche Merkmale im Spracherwerb mit den einzelnen Formen verbunden werden.

\section{Die Lernprozesse im Spracherwerb}

Was bedeutet nun die Aufgabe, das Genussystem der Nomina zu erwerben und es (zusammen mit den jeweiligen Kasusforderungen) sprachlich, z.B. am bestimmten Artikel, zu realisieren? Im Ergebnis ist jeder kompetente Sprecher des Deutschen in der Lage, jedem Nomen das entsprechende Genus mit der Wahl der jeweils korrekten Flexionsendung der es begleitenden Wortarten zuzuordnen sowie Annahmen bezüglich des Genus eines unbekannten Nomens zu machen, die in der Regel mit dem bestehenden formal oder semantisch basierten Verteilungsmuster übereinstimmen.

Eine traditionelle Ansicht - sie wird in der heutigen Spracherwerbsforschung jedoch nicht mehr vertreten - beruhte auf der Vorstellung von einer arbiträren Verteilung der Genera und schlug eine Speicherung des Genusmerkmals als eine Art Genusmorphem oder „QuasiPhonem“ (Werner 1975:39) durch Auswendiglernen vor. Diese Art des Genuserwerbs stellt allerdings sehr hohe Anforderungen an die Speicherkapazitäten des menschlichen Gehirns. Im L1-Erwerb würde sich ein Erwerbsablauf durch Auswendiglernen in einer anfangs willkürlichen Auswahl der Artikelformen mit abnehmender Fehlertendenz widerspiegeln. Dies wird jedoch von keiner Erwerbsstudie bestätigt (vgl. Karmiloff-Smith 1979, Mills 1986, Müller 1990, 1999). Im natürlichen DaZ-Erwerb wurde dagegen tatsächlich ein anfänglicher Gebrauch der drei Genusformen des bestimmten Artikels als „freie Varianten“ beobachtet (Wegener 1999). Auch konnte Braine (1987) experimentell zeigen, dass vollkommen arbiträre Zuordnungssysteme signifikant schwerer zu erlernen sind als solche, die zumindest teilweise (im Experiment semantisch) motiviert sind.

\subsection{Lautliche Segmentierung}

Die Sprache, die ein Kind zu Beginn seines Spracherwerbs, also ab seiner Geburt hört, stellt für den Lerner zunächst eine kontinuierliche, unsegmentierte Lautkette dar. Der erste Lernschritt besteht darin, dass erste Sequenzen dieses Phonemstrangs wiedererkannt werden:

The sentence strings input to the learner must surely be perceived - at least initially - as strings of incomprehensible noise punctuated by islands of familiarity. (Bates/ MacWhinney 1987:188).

Die Aufmerksamkeit wird dabei zunächst auf betonte Einheiten sowie Elemente (Wörter, Silben) am Endrand einer Sequenz (Phrase, Wort) gerichtet, was sich in imitativen Äußerungen des Kindes niederschlägt (Kaltenbacher 1990:27f.). Slobin hat diese „self-instruction“ (Slobin 1973:191) zur Ausrichtung der Aufmerksamkeit als universelles Operating Principle A formuliert: "Pay attention to the ends of words." (ebd.) Dieses Prinzip ergibt sich einerseits aus der Beobachtung von Imitationen, andererseits daraus, dass z.B. Flexionen, die als Suffixe oder Post-Positionen eines Nomens realisiert werden, i.A. eher erworben werden, als solche, die durch ein Präfix oder eine Prä-Position, wie es der Artikel im Deutschen ist, angezeigt werden (ebd. 191f.). Aufgrund der sprachlichen und situativen Umgebungen, in denen eine

Für DaZ- und DaF-Lerner dürfte dieses System anfangs tatsächlich einen „Teufelskreis“ (Wegener 1995:97) darstellen. 
lautliche Sequenz sich wiederholt, wird ihr eine erste Funktion oder Bedeutung zugewiesen. Dabei kann es sich anfangs entweder um längere Phrasen handeln, die zunächst als unanalysierte, lexikalische Einheit gespeichert werden (z.B. isdas?; gehtnich!=expressiver/pronominaler Lerntyp), oder es werden bevorzugt Objektbezeichnungen in Form von Nomina aus dem Input aufgenommen (=referenzieller/nominaler Lerntyp) (Kaltenbacher 1990:14ff.). ${ }^{23}$ Dabei gilt, dass die einzelnen Formen nicht „rein zufällig“, in willkürlichen Ausschnitten aufgenommen werden. Je nach kognitivem Entwicklungsstadium hat das Kind spezifische Schwerpunkte, die sein Interesse für die sprachliche Umgebung lenken:

Die allgemeine kognitive Entwicklung liefert nicht nur den konzeptionellen Rahmen, in dem das Kind seine Welt begreift, sondern determiniert damit auch, welchen Umgebungszuständen es sich vorrangig zuwendet und somit auch für seine kommunikativen Zwecke selektiert. (Tracy 1984:280)

Artikel, wie auch Pronomen, erhalten wie die meisten Funktionswörter im Deutschen - wenn sie nicht deiktisch gebraucht werden - i.A. keine Betonung. Zudem erfahren sie beim schnellen, umgangssprachlichen Sprechen eine lautliche Reduzierung mit rhythmischem Anschluss an ein vorausgehendes oder nachfolgendes Wort (Klitisierung: biste, de-Papa). Ihre phonetische Auffälligkeit (Salienz) ist somit relativ gering innerhalb des sprachlichen Inputs und folglich werden sie erst später im lautlichen Input segmentiert als Inhaltswörter wie Nomina, Adjektive und Verben. Der Erwerb der Funktoren wird also nicht nur durch ihre semantischfunktionale Komplexität, sondern zusätzlich durch ihre wenig prägnanten phonotaktischen Eigenschaften erschwert (Kaltenbacher 1990:39ff.).

\subsection{Funktionszuweisung}

Lautliche Formen, die aus dem Inputstrang aufgenommen werden, werden, wie gesagt, gleich mit einer Bedeutung oder kommunikativen Funktion verknüpft. Der funktionalistische Ansatz geht davon aus, dass in der Regel die kognitive Weiterentwicklung des Kindes neue kommunikative Bedürfnisse mit sich bringt, die den Erwerb der jeweiligen Formen initiieren:

The forms of natural languages are created, governed, constrained, acquired and used in the service of communicative functions. (MacWhinney/Bates/Kliegl 1984:128; zit. in Bates/MacWhinney 1987:160; Hervorhebung von mir.)

Mit anderen Worten, das Kind entwickelt bestimmte Vorstellungen (wie Wünsche oder Eindrücke), die es seinen Bezugspersonen (in der Regel sind dies anfangs die Eltern) mitteilen möchte, es verfügt zunächst jedoch nicht über die notwendigen sprachlichen Möglichkeiten. Die jeweils adäquaten, formalen Mittel werden im Laufe des Spracherwerbs aus dem Inputangebot aufgenommen und gegeneinander differenziert (vgl. u.a. Slobin 1973, Bates/MacWhinney 1987, MacWhinney 1987b, Elsen 1999). Auch außersprachliche Einflüsse, wie der situative Gesprächskontext und die Sprecherintention, spielen bei der distributionellen Analyse, dem Vergleich der sprachlichen Formen und ihrer Vorkommensmuster, eine Rolle (z.B. Elsen 1999:32).

In Bezug auf die Artikelwörter bedeutet dies, auf der einen Seite zu erkennen, dass bestimmte Wortarten (wie bestimmter, unbestimmter oder Possessivartikel) häufig vor einem „Objektnamen" (also Nomen) und evtl. der Beschreibung seiner Eigenschaften (Adjektiv) vorkommen und mit ihnen auf unterschiedliche Weise auf diese Objekte verwiesen werden kann. Andererseits nimmt im Deutschen jeder Artikel je nach Bezugsnomen, seiner Ein- oder Mehrzahligkeit sowie der Position im Satz eine bestimmte Form an (je nach Genus, Numerus

23 Die unterschiedlichen Lernstrategien haben zwar Auswirkungen auf das Erwerbstempo, jedoch nicht auf den Erwerbserfolg (Klann-Delius 1999:47f.). 
und Kasus). D.h. die Lernaufgabe besteht darin, die verschiedenen Formen als Elemente derselben Wortart zu erkennen und das Verteilungsmuster dieser Formen im Zusammenhang mit dem zugehörigen Nomen zu entschlüsseln. Das Genussystem des Deutschen ist jedoch „quite subtle“ (MacWhinney 1987b:256): Die Zuweisung ist nur begrenzt regelmäßig und seine Funktion äußerst unklar (vgl. Kap. 2). Hinzu kommt, dass seine Markierung aufgrund der formalen Fusionierung mit der Kasus- und Numerusanzeige selten eindeutig ist (vgl. Abschn. 3.2). Diese Eigenschaften der Genusmarkierung laufen jedoch Slobins Operating Principle $G$ „The use of grammatical markers should make semantic sense“" (Slobin 1973:206) zuwider, denn der „semantische Sinn“ dieser Formendifferenzierung ist nur schwer fassbar - im Gegensatz zu den Kasus, die die syntaktischen Relationen innerhalb eines Syntagmas anzeigen und zum Plural, der die Vielzahl der Entitäten markiert.

Die genusbasierte Flexionsmorphologie widerspricht somit der Annahme von funktionsmotiviertem Formenerwerb. Daher stellt sich die Frage - will man die potenzielle Möglichkeit des Erwerbs von funktionslosen Kategorien ausschließen -, auf welcher Grundlage sich dieser Teil des Spracherwerbs vollzieht. Bates/MacWhinney (1987:177) nehmen an, dass beim Erwerb von Formen, deren Funktion für den Sprachlerner nicht offensichtlich zu erkennen ist, wie es beim deutschen Genussystem der Fall ist, dennoch die Formen aus dem Input aufgenommen werden, da sie mit anderen lexikalischen Einheiten verbunden sind, die das Kind beim Sprechen verwenden möchte, z.B. zur Anzeige der Referenzeigenschaft des Nomens durch die Artikel. Es ist der Zusammenhang zweier Formen (Nomen und Artikel), der in diesem Fall zunächst auswendig, lexikalisch, gelernt wird und die motivierende Basis für den Erwerb des Formensystems bildet. Die Zuordnung einer Funktion muss demnach nachträglich oder parallel geschehen, sie geht dem Erwerb der Formen in diesem Fall jedoch nicht voraus.

\subsection{Differenzierung der Formen}

Der Sprachproduktion und -verarbeitung wird in funktionalistischen Theorien häufig als permanente Informationsverarbeitung durch ein assoziatives neuronales Netzwerk interpretiert. ${ }^{24}$ Spracherwerb bedeutet demnach den Aufbau dieses Netzes aus den Informationen des sprachlichen und situativen Kontextes. Dabei entstehen während der distributionellen Analyse ,assoziative Muster“ (Elsen 1999:19) aufgrund von immer wiederkehrenden Wort- und/oder Merkmalskombinationen. D.h. durch die unterschiedlichen „Signale“ aus dem Input bilden sich formale Repräsentationen sowie Funktions- bzw. Bedeutungs-,,knoten“" mit netzwerkartigen Verbindungen. Je nach Vorkommens- und Gebrauchsfrequenz sprachlicher Einheiten werden diese Verbindungen aktiviert und verstärkt (vgl. z.B. Elsen 1999). Durch den permanenten Vergleich einer erworbenen Form mit ihrer jeweiligen Funktion im Input werden sowohl regelmäßige - mit funktionalistischem Terminus: prototypische - als auch abweichende, weniger prototypische Übereinstimmungen der Funktionen mit den jeweiligen Formen erkannt. Auf diese Weise können anfängliche Fehler in den Form-Funktion-Verbindungen korrigiert werden. Dies sind sowohl Übergeneralisierungen auf weniger prototypische Zuordnungen als auch falsche Annahmen über Zuweisungsmuster. Auf lexikalisch-semantischer Ebene zieht dies die Differenzierung von semantisch ähnlichen Bedeutungen nach sich (Dackel vs. Hund vs. Tier; Tasse vs. Becher), auf grammatischer Ebene bedeutet dies, die ,regelmäßigen“, aber falschen Zuordnungen durch die unregelmäßig gebildeten „Ausnahmen“ zu ersetzen und direkt mit ihrer Funktion zu verknüpfen (Nominalendung $-e>$ Fem., aber: Käse $=$ Mask.) (vgl. MacWhinney 1987b).

24 Die Annahme von assoziativen neuronalen Netzwerken orientiert sich an den biologischen neuronalen Netzen (vgl. Elsen 1999:21ff.). Speziell zu Genusverarbeitungsprozessen vgl. die Übersicht in Marx (2000). 
In den Informationen des sprachlichen Inputs kann das Kind unter den wiederkehrenden Merkmalsmustern z.B. erkennen, dass Nomina mit Schwa-Auslaut (wie Ente, Tasse) von Adjektiven und Artikeln begleitet werden, deren Flexionsendung - je nach Wortart - eine ganz spezifische Form aufweisen, nämlich meist die der femininen Flexionsparadigmen. ${ }^{25}$ Im Abstraktionsprozess (vgl. Tomasello 2000) können diese Nomina dann einer (im linguistischen Sinne) Kategorie Femininum zugeordnet und eine entsprechende Zuweisungsregel oder ein „Schema“ ${ }^{\text {"26 }}$ gebildet werden. Die Genuszuordnungen für Abweichungen wie Junge und Affe werden durch eigene distributionelle Muster erworben. Aufgrund ihrer höheren Aktivierungsfrequenz im assoziativen Netz können die Form-Funktion-Assoziationen der prototypischen Zuordnungen jedoch schneller ein stabiles Assoziationsmuster ausbilden als die weniger prototypischen. Daher sind Übergeneralisierungen auf letztere während der Erwerbsphase zu erwarten; sie zeigen an, dass ein typisches Muster bereits erworben ist. ${ }^{27}$ Elsen bestätigt anhand ihrer Spracherwerbsdaten die „critical mass hypothesis“ von Plunkett und Marchman (Elsen 1999:56ff.). Diese nimmt aufgrund von Computersimulationen einen prozentualen Schwellenwert in der Lexikonstruktur an, der zur Herausbildung der formalen Prototypen, die die Ursache für Übergeneralisierungen sind, erreicht werden muss. Elsen erkennt einen direkten Zusammenhang zwischen der Entwicklung der Flexionsmorphologie im Spracherwerb und der qualitativen und quantitativen Veränderung des Lexikons in den von ihr untersuchten Erwerbsdaten.

\subsection{Fazit}

Die Aufgabe, die Genuskategorisierung mit ihren Auswirkungen auf die Flexionsmorphologie der Artikel, Adjektive und Pronomen zu erwerben, stellt einen äußerst komplexen Prozess dar. Die Schwierigkeit besteht zunächst darin, seine Formen mit ihrer schwachen phonetischen Salienz überhaupt im Input zu selektieren. Darüber hinaus erfüllt es keine eindeutige, leicht erkennbare Funktion für den Sprachlerner, die den Erwerb veranlassen und vorantreiben würde. Es stellt sich die Frage, ob das im Abschnitt 2.2 beschriebene Bündel aus Einzelfunktionen die ausschlaggebende Eindeutigkeit der Funktion oder nur eine der Funktionen die notwendige Relevanz für den Erwerb der Formen aufweist. Es ist unklar, welches die konkrete Funktion sein sollte, die den zunächst lexikalisch, oder ,imitativ“ (Tomasello 2000) gelernten und anschließend schematisierten Formen zugewiesen wird. Die Kategorisierung der Nomina an sich kann nicht die funktionale Motivation für den weiteren Erwerbsprozess darstellen, denn die nominalen Kategorien haben keine jeweils spezifische semantische oder grammatische Funktion. Hinzu kommt, dass die Zuweisungsprinzipien für das Genus anhand von semantischen und/oder phonologischen Merkmalen keine 1:1-Korrelation bilden und daher u.U. nicht leicht zu erkennen sein dürften. Die Abstraktion von Zuweisungsschemata könnte sich somit als teilweise sehr kompliziert erweisen. Wenn aber eine spezifische Funktion als Auslöser und Motor des Formenerwerbs ausscheidet, müssen andere Strategien und Faktoren bei der Bildung dieser assoziativen Muster oder Schemata wirken.

In der folgenden Datenauswertung ist also nach Anhaltspunkten in den Formenzuweisungen, speziell den nicht-zielsprachlichen, zu suchen, die Aufschluss darüber geben könnten, auf

25 Bei Adjektiven kommt außerdem die Unterscheidung zwischen starker, gemischter und schwacher Flexion hinzu, je nach dem, ob ihm ein bestimmter, unbestimmter oder kein Artikel vorausgeht.

26 Bybee folgend schlägt Elsen die Bezeichnung „Schema“ als Alternative zum Terminus „Regel“ vor, um zu verdeutlichen, dass die Anwendung einer Regel nicht „,verpflichtend“ (Elsen 1999:34) sein kann, sondern lediglich eine starke Generalisierung bedeutet und probabilistisch zu interpretieren ist, es also durchaus Abweichungen geben darf (ebd.:33f.).

27 Oberflächlich, d.h. in den sprachlichen Äußerungen des Kindes, unterscheiden sich die Annahme von funktionalistisch verstandenem Spracherwerb und die vom regelgeleiteten Spracherwerb nicht. (Elsen 1999:56). 
welcher Grundlage die Formenzuweisungen vom Kind analysiert und schematisiert werden. Mögliche Zuordnungshinweise für die Genera liegen auf der formalen, hauptsächlich phonologischen, sowie der semantischen Ebene. Es gilt also zu untersuchen, wie, wann, bzw. ob das Kind solche Hinweis erkennt und produktiv für die Zuweisung der Formen nutzt.

\section{Datenanalyse}

\subsection{Das Datenkorpus}

Für meine Analyse habe ich ein Auswahlkorpus der Aufnahmen zusammengestellt, die von dem monolingual deutschen Mädchen Simone über einen Zeitraum von zwei Jahren und drei Monaten aufgezeichnet wurden. Simone stammt aus einer Mittelschicht-Familie aus dem Raum Frankfurt am Main, ist geistig gesund und hat einen um ein Jahr und zehn Monate jüngeren Bruder (Miller 1976:33f.). Die Daten sind in der CHILDES-Datenbank im Internet zugänglich und wurden im für diese Datenbank entwickelten CHAT-Format (MacWhinney 1995) verschriftet. Simones Alter zum Zeitpunkt der ersten Aufnahme beträgt $1 ; 9.11^{28}$, das der letzten 4;0.6. Insgesamt enthält dieses Korpus 74 Aufzeichnungen von sehr unterschiedlicher Länge (6-1494 Äußerungen von Simone). Für die Analyse im Rahmen dieser Arbeit habe ich mich auf eine Auswahl von 38 Aufnahmen beschränkt. Um bei der Auswahl eine gewisse Repräsentativität zu erreichen, sollten die ausgewählten Aufnahmezeitpunkte möglichst im Abstand von zwei, maximal drei Wochen liegen, was aufgrund des Datenangebotes jedoch nicht immer einzuhalten war. Vor allem in den letzten Monaten des Beobachtungszeitraums nehmen die Abstände zwischen den einzelnen Aufnahmezeitpunkten deutlich zu. Um eine möglichst breite Datengrundlage nutzen zu können, habe ich jeweils die gesamten Aufzeichnungen in meine Auswertung einbezogen, statt jeweils nur einen ,repräsentativen“ Ausschnitt von beispielsweise 100 Äußerungen auszuwählen. ${ }^{29}$

Von der Analyse habe ich solche Elemente ausgeschlossen, die keine selbstproduzierte, semantisch interpretierbare Lautkette enthalten. Dazu gehören neben den Imitationen unmittelbar vorangegangener eigener und fremder Äußerungen auch alle reinen ,ja“/ „nein“Äußerungen sowie Lied- und Reimtexte. Tabelle 2 zeigt die ausgewählten Aufnahmezeitpunkte mit der jeweiligen Anzahl der analysierbaren Äußerungen:

\begin{tabular}{|c|c|}
\hline Alter & $\begin{array}{c}\text { Anz. ana- } \\
\text { lys. Äuß. }\end{array}$ \\
\hline $1 ; 09.11$ & 286 \\
\hline $1 ; 10.20$ & 692 \\
\hline $1 ; 10.28$ & 137 \\
\hline $1 ; 11.14$ & 161 \\
\hline $2 ; 00.01$ & 617 \\
\hline $2 ; 00.05$ & 219 \\
\hline $2 ; 00.23$ & 277 \\
\hline $2 ; 00.26$ & 627 \\
\hline $2 ; 01.12$ & 447 \\
\hline $2 ; 01.21$ & 383 \\
\hline $2 ; 02.03$ & 453 \\
\hline $2 ; 02.07$ & 225 \\
\hline $2 ; 02.18$ & 108 \\
\hline
\end{tabular}

\begin{tabular}{|c|c|}
\hline Alter & $\begin{array}{c}\text { Anz. ana- } \\
\text { lys. Äuß. }\end{array}$ \\
\hline $2 ; 02.21$ & 440 \\
\hline $2 ; 04.17$ & 466 \\
\hline $2 ; 04.21$ & 369 \\
\hline $2 ; 05.13$ & 453 \\
\hline $2 ; 05.19$ & 252 \\
\hline $2 ; 06.16$ & 201 \\
\hline $2 ; 06.23$ & 541 \\
\hline $2 ; 07.19$ & 320 \\
\hline $2 ; 07.23$ & 286 \\
\hline $2 ; 08.08$ & 132 \\
\hline $2 ; 08.15$ & 357 \\
\hline $2 ; 09.26$ & 658 \\
\hline $2 ; 10.11$ & 689 \\
\hline
\end{tabular}

\begin{tabular}{|c|c|}
\hline Alter & $\begin{array}{c}\text { Anz. analys. } \\
\text { Äuß. }\end{array}$ \\
\hline $2 ; 11.18$ & 230 \\
\hline $3 ; 00.24$ & 154 \\
\hline $3 ; 00.28$ & 125 \\
\hline $3 ; 01.00$ & 390 \\
\hline $3 ; 01.11$ & 767 \\
\hline $3 ; 02.15$ & 192 \\
\hline $3 ; 03.25$ & 216 \\
\hline $3 ; 04.05$ & 241 \\
\hline $3 ; 05.15$ & 351 \\
\hline $3 ; 07.11$ & 394 \\
\hline $3 ; 09.18$ & 462 \\
\hline $4 ; 00.06$ & 603 \\
\hline
\end{tabular}

Tabelle 2: Das Simone-Auswahlkorpus mit der jeweiligen Anzahl der analysierbaren Äußerungen.

28 Das Alter ist jeweils in der Form Jahr;Monat.Tag angegeben.

29 So z.B. in Clahsen 1984. 
Es ist zu beachten, dass mir für den Zeitraum zwischen 2;2.21 und 2;4.17 keine Aufnahmen in dem Gesamtkorpus zur Verfügung standen. Die Auswertungen, die diesen knapp zweimonatigen Entwicklungsabschnitt umfassen, müssen daher unter einem gewissen Vorbehalt geschehen.

\subsubsection{Methode der Auswertung}

Die Analyse ist empirisch-funktional ausgerichtet, es gilt also Zuweisungsmuster und Funktionsannahmen zu ermitteln, die Simone im Laufe des Spracherwerbs möglicherweise macht und welche die Falschzuweisungen motivieren könnten. Die nicht-zielsprachlichen Artikelzuweisungen bilden daher den Schwerpunkt der Analyse.

Für die Auswertung von Simones Artikelgebrauch und dessen Entwicklungsverlauf habe ich aus den Transkripten der Aufnahmen alle Singular-NPs und -PPs, in denen zielsprachlich ein Artikel gefordert wird, nach den Kategorien „bestimmter Artikel“, „unbestimmter Artikel“ und „ausgelassener Artikel“ kategorisiert. Artikelwörter in deiktischer und pronominaler Funktion bilden dabei eine separate Spalte. Diese Formen sind nur dann in die folgende Analyse eingegangen, wenn der Bezug zum entsprechenden Nomen eindeutig ist, z.B. durch vorangegangene Äußerungen. Dabei mussten jedoch alle das-Formen in deiktischer Funktion ignoriert werden, denn in dieser Funktion können sie teilweise auch genusunabhängig gebraucht werden. Im Folgenden werde ich alle Formen des Artikels, die ohne ein zugehöriges Nomen auftreten, als pronominal bezeichnen - im Gegensatz zu den adnominalen, nomenbegleitenden -, unabhängig davon, ob es sich dabei tatsächlich um ein (deiktisches, demonstrativisches oder phorisches) Pronomen oder eine abgebrochene Äußerung handelt, bei der das intendierte Nomen lediglich nicht mehr realisiert wurde. Abweichungen von zielsprachlichen Pluralformen habe ich zwar in diesen ersten Auswertungsschritt einbezogen, sie sind jedoch nicht in die weitergehende Analyse eingegangen. Die Kategorie Plural ist in ihren Formen unabhängig vom Genus der Nomina und unterscheidet sich aufgrund ihres eindeutigen Konzepts der Mehrzahligkeit (welches i.A. früh im Spracherwerb erworben wird, vgl. Mills 1986, Müller 1990) sowie seiner (meist) eindeutigen morphologischen Kennzeichnung am Nomen m.E. eindeutig genug von der Singular-Kategorie Genus, um für die Untersuchung in der vorliegenden Arbeit verzichtbar zu sein.

Für den Rahmen dieser Arbeit habe ich mich entschlossen, auf den Erwerbsprozess nur eines Artikelwortes, nämlich des bestimmten Artikels, genauer einzugehen um möglichst detaillierte Ergebnisse zu erhalten. Dieser Artikel zeichnet sich durch seine höhere phonetische Salienz gegenüber dem unbestimmten Artikel aus (s. Abschn. 3.2.2). Im Nominativ weist er drei phonologisch klar differenzierte Formen auf, so dass eine Bewertung der Grammatikalität hier am eindeutigsten möglich ist. Beobachtungen zum unbestimmten Artikel ziehe ich ggf. zu Vergleichszwecken heran. Hierzu habe ich die Formen von ein sowie die des Negationspronomens kein und der Possessivpronomina mein, dein und sein zusammengefasst. Wie in 3.2.2 dargestellt, stimmen diese Formen flexionsmorphologisch mit dem unbestimmten Artikel überein. Da hier nicht der Erwerb der spezifischen Referenzkonzepte der verschiedenen Artikelwörter im Mittelpunkt stehen wird, halte ich es für vertretbar, in dieser Arbeit terminologisch nur zwischen bestimmtem und unbestimmtem Artikel zu unterscheiden.

Um Häufigkeiten in Simones Entwicklungsverlauf vergleichen zu können, habe ich die jeweilige Anzahl an zielsprachlichen Artikelforderungen (AF) eines Aufnahmezeitpunktes ermittelt. Diese setzt sich zusammen aus der Zahl der tatsächlichen Artikelproduktionen in ad- und pronominaler Position, den ungrammatischen Auslassungen eines Artikels sowie NPs, deren Semantik zwar nicht eindeutig ist, jedoch syntaktisch zweifelsfrei als NP mit obligatorischem 
Artikel intendiert sind. Ich habe nicht die Äußerungsanzahlen der Aufnahmen als Grundlage genommen, da eine Äußerung mehrere strukturelle Kontexte für Artikel enthalten kann.

An dieser Stelle sei bereits bemerkt, dass, wie auch Mills und Müller festgestellt haben, der Genitiv im frühen Spracherwerb keine Rolle spielt. Es kommen keine syntaktischen Kontexte vor, in denen zielsprachlich der Genitiv gefordert würde. Der im Spracherwerb früh erworbene possessivische Genitiv der Eigennamen der Form Peters Haus fällt nicht unter der Problematik des Genuszuweisung. Auf diesen Kasus werde ich daher in der Besprechung der Ergebnisse nicht weiter eingehen.

\subsubsection{Die quantitative Entwicklung des Artikelgebrauchs}

Zum ersten Aufnahmezeitpunkt mit 1;9.11 erscheint bereits ein bestimmter Artikel. Hierbei handelt es sich um die einzige Form in dieser Aufnahme, an der ein Genus zu identifizieren ist. Es kann also davon ausgegangen werden, dass zu früheren Zeitpunkten, von denen mir keine Aufnahmen zur Verfügung standen, noch keine wesentlichen Artikelproduktionen vorgekommen sind. Unbestimmte Artikel werden dagegen - vermutlich in reduzierten Varianten - bereits aufgetreten sein. Die Entwicklung des prozentualen Anteils bestimmter und unbestimmter Artikel an den jeweils zielsprachlich geforderten Artikeln zeigt die folgenden Graphik:

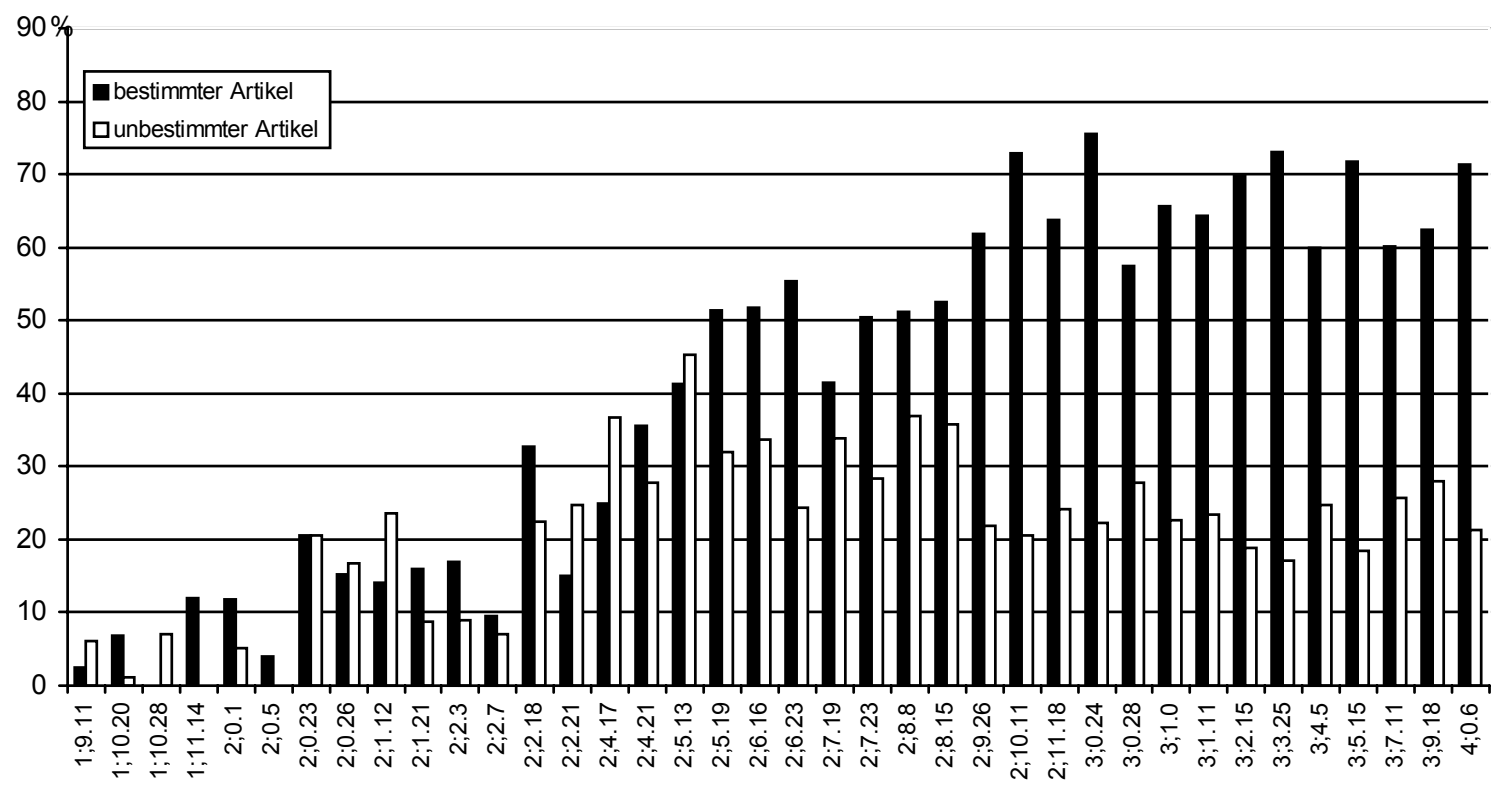

Abbildung 1: Gebrauch des bestimmten und des unbestimmten Artikels im Verhältnis zu allen zielsprachlich geforderten Artikeln (pro- und adnominal).

Bereits vor 2;0 produziert Simone bestimmte Artikel, hauptsächlich jedoch in der reduzierten Form de. Mit 2;0.23 ist ein plötzlicher Anstieg in der Produktion beider Artikel zu verzeichnen. Dies entspricht der allgemeinen Beobachtung zum Beginn des Artikelerwerbs mit ca. 2 Jahren. Spätestens ab 2;4.17 $7^{30}$ ist eine rapide Zunahme in der Artikelfrequenz zu verzeichnen, die bei 2;5.19 endet. Bis zu diesem Zeitpunkt schwankt die Priorität bezüglich der Verwendung der beiden Artikel, wobei der bestimmte Artikel insgesamt jedoch überwiegt. Anschließend nimmt die Differenz der Häufigkeiten der beiden Artikelwörter weiter zu Gunsten des definiten Artikels zu und hat sich gegen Ende des dritten Lebensjahres auf ein relativ konstantes Verhältnis eingepegelt. Ab 3;0.24 ist bis zum Ende der Aufzeichnungen kein wesentlicher

30 Es sei nochmals auf die knapp zweimonatige Unterbrechung der Beobachtung hingewiesen. 
Anstieg der Artikelfrequenz mehr zu verzeichnen. Der Anteil der realisierten Artikelforderungen beträgt ab hier konstant knapp $90 \%$.

Die reduzierte Form $d e$, phonologisch als $[\mathrm{d} \star]$ realisiert, erscheint bei Simone hauptsächlich in adnominaler Position. Ihr Anteil an allen zielsprachlich definiten NPs zeigt bis 2;4.17 starke Schwankungen und erreicht dabei bis zu über $80 \%$. Bis 2;5.13 fällt ihre Gebrauchsfrequenz zügig auf $6 \%$, diese Phase korreliert mit der starken Zunahme des definiten Artikels. Anschließend stagniert die Frequenz etwa auf diesem Niveau und fällt erst ab 2;10.11 langsam, mit einem Pegel um 2\%, weiter ab, bis die reduzierte Form ab 3;4.5 überhaupt nicht mehr in den Daten vorkommt.

Die reduzierte Form wird zwar für jedes Genus verwendet, eine Präferenz für den Einsatz bei maskulinen und femininen Nomen ist jedoch erkennbar. Mills (1985:174) hat dagegen ausschließlich die Reduzierung der maskulinen und femininen Artikelform beobachtet. Sie begründet dies mit der lautlich größeren Differenz zur das-Form. Da die neutrische Form das jedoch häufig zu des verkürzt wird, verkleinert sich m.E. der angebliche lautliche Abstand erheblich.

\subsection{Die Rolle der Genuszuweisungsregeln}

Bei der Auswertung der Genusfehler orientiere ich mich an den fünf von Wegener (1995) formulierten Zuweisungsregeln, die sie ausgehend von den Ergebnissen von Mills und Müller, eigenen Beobachtungen sowie experimentellen Datenerhebung formuliert hat. Die Ergebnisse meiner Analyse werde ich den Beobachtungen von Mills (1985, 1986) und Müller (1990, 1999) gegenüberstellen. Diese Arbeiten sind m.W. die einzigen, in denen Langzeitstudien unter dem Aspekt des erstsprachlichen Genuserwerbs untersucht wurden. Mills hat die Aufnahmen von drei monolingual deutschen Kindern (Gisela, Hanna und Georg) im Altersabschnitt 1;8-2;6 ausgewertet und mit Angaben aus den Tagebuchstudien von Preyer, Scupin/Scupin und Stern/Stern und Daten von Clahsen verglichen. Müller hat den Genuserwerb der bilingualen deutsch-französischen Kinder Caroline $(1 ; 6.3-5 ; 0.6)$ sowie Ivar $(1 ; 5-3 ; 0)$ und Pascal $(1 ; 5 .-2 ; 7)$ untersucht.

Den semantischen und formalen Zuweisungsregeln für das Genus (s. Abschn. 2.1) wird i.A. ein sehr großer Stellenwert im Spracherwerb zugeschrieben. Mills und Müller haben in den von ihnen ausgewerteten Daten Regelbildung beobachtet und sind zu dem Ergebnis gekommen, dass eine Genusregel um so eher erworben wird, je zuverlässiger und umfassender sie ein Genus vorhersagt:

The order of acquisition is related to the scope of the rule and the number of exceptions. (Mills 1986:85)

First gender rules are salient and clear. Rules which apply to a great number of nouns are acquired early. (Müller 1990:231)

Als „reine“ Genusfehler werte ich Falschzuweisungen im Nominativ und Akkusativ Singular. In diesen beiden Kasus muss jeder Artikelform eindeutig ein Genus zugeordnet werden: der/den=Maskulinum, $d i e=$ Femininum, $d a s=$ Neutrum. Die einzig mögliche Form, die in diesen Kontexten bezüglich des Genus doppeldeutig interpretiert werden könnte, ist der+Fem., die mit der Dativmarkierung der Feminina formengleich ist. Da aber die Form den nicht in Nominativ-Kontexten und die Form dem nicht im Nominativ- oder Akkusativ-Kontexten erscheint, ist auch bei den Vorkommen von der+Fem. eine Fehlermotivierung in der Kasusstatt der Genuswahl unwahrscheinlich. Die reduzierte Form de kann weder als eindeutig richtig noch als eindeutig falsch klassifiziert werden, da sie flexionslos ist. Sie wird daher nur in 
der Gesamtstatistik mit berechnet, jedoch nicht bei den Werten für richtigen oder falschen Genusgebrauch.

\subsubsection{Häufigkeiten der Falschzuweisungen}

Unter den insgesamt 117 festgestellten Falschzuweisungen von Formen des bestimmten Artikels sind 80 eindeutige Genusfehler, d.h. bei ihnen kann die Form des bestimmten Artikels als eindeutig falsch bzw. nicht-zielsprachlich bezüglich des Genus identifiziert werden. 14 von ihnen treten in pronominaler Position auf. Die folgende Tabelle zeigt die Verteilung der falschen Genusmarkierungen am bestimmten Artikel bei Simone $\mathrm{an}^{31}$ :

\begin{tabular}{|c|c|c|c|c|c|c|c|c|c|c|c|c|c|c|c|c|c|c|c|c|c|c|c|c|}
\hline 톤 & 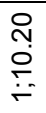 & 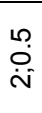 & $\begin{array}{l}\text { N̦} \\
\stackrel{+}{+} \\
\text { iv }\end{array}$ & $\begin{array}{l}\stackrel{\leftrightarrow}{N} \\
\stackrel{\leftrightarrow}{0} \\
\text { iv }\end{array}$ & ז̃ & $\begin{array}{l}\bar{N} \\
\stackrel{N}{N}\end{array}$ & 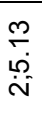 & 吕 & 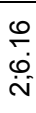 & $\begin{array}{l}\text { N̦} \\
\text { ஸे } \\
\text { ì }\end{array}$ & $\begin{array}{l}\stackrel{\sigma}{\pi} \\
\text { ì }\end{array}$ & $\begin{array}{l}\stackrel{\text { N̦}}{\text { ì }} \\
\text { in }\end{array}$ & $\begin{array}{l}\infty \\
\stackrel{\infty}{\circ} \\
\stackrel{\text { N }}{N}\end{array}$ & $\begin{array}{l}\stackrel{2}{0} \\
\stackrel{0}{0} \\
\dot{N}\end{array}$ & $\begin{array}{l}\stackrel{\leftrightarrow}{N} \\
\text { ọ } \\
\dot{N}\end{array}$ & זٓ & $\begin{array}{l}\stackrel{\sim}{N} \\
\stackrel{\circ}{ }\end{array}$ & $\underset{\dot{m}}{\stackrel{0}{\infty}}$ & $\frac{\check{\Gamma}}{\check{\check{m}}}$ & 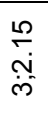 & 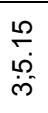 & $\begin{array}{l}\infty \\
\stackrel{\infty}{\sigma} \\
\dot{m}\end{array}$ & $\begin{array}{l}0 \\
\stackrel{\leftrightarrow}{+} \\
\dot{\forall}\end{array}$ & 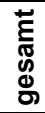 \\
\hline der & 1 & & & 4 & 1 & 2 & 1 & 1 & 1 & & & 2 & 2 & 1 & & 5 & 2 & & 3 & 1 & 3 & & & 30 \\
\hline die & & & & & & & & & & 1 & & & 4 & 1 & 3 & 6 & & 6 & 3 & & 1 & 6 & 2 & 32 \\
\hline das & & 1 & 2 & 2 & 1 & & & 1 & & & 1 & 2 & & & & 1 & & 1 & 1 & 1 & 3 & 1 & & 18 \\
\hline
\end{tabular}

Tabelle 3: Eindeutig falsche Genuszuweisungen bei Simone (ges. $=80$ )

Die 80 nicht-zielsprachlichen Genuszuweisungen bei definiten Artikeln verteilen sich auf den maskulinen, femininen und neutrischen Artikel mit 30:32:18. Nicht-zielsprachliche Verwendung der femininen Form die tritt erst auffallend spät im Erwerbsprozess auf, zuerst mit 2;6.23, häufiger ab 2;8.8. Ab diesem Zeitpunkt aber dominieren inkorrekte die-Zuweisungen zahlenmäßig. Es ist jedoch keine Zunahme des femininen Anteils im nominalen Gesamtlexikon zu verzeichnen, auch ist hier kein allgemein vermehrter Gebrauch des bestimmten Artikels bei Feminina zu verzeichnen.

Dieses späte Einsetzen des inkorrekten die-Gebrauchs ist im Vergleich mit den Ergebnissen von Mills bemerkenswert. Die Autorin hat in ihren Untersuchungen eine generelle Tendenz zur bevorzugten Übergeneralisierung des femininen bestimmten Artikels, besonders in den frühen Phasen des Spracherwerbs, beobachtet (Mills 1986:67). Müller konnte dagegen nur bei Caroline eine Bevorzugung von die für Neutra feststellen (Müller 1990:213). Die von Mills beobachteten Falschzuweisungen treten nicht später als mit 2;8 auf und liegen somit vor dem Zeitpunkt, in der die vermehrte Falschzuweisung dieser Form bei Simone eintritt. Aber auch bei den zielsprachlich korrekten Zuweisungen zeigen sich unterschiedliche Präferenzen: Während Mills auch bei diesen Formen bei den Kindern Hanna, Georg und Gisela ein deutliches Überwiegen der femininen Form beobachtet - Maskulina, Feminina und Neutra verteilen sich hier insgesamt auf 9:53:5 (ebd.:86) -, bilden bei Simone maskuline NPs die Mehrheit der korrekten Artikelverwendungen: Im entsprechenden Zeitraum (bis 2;6) liegt die Verteilung bei 172:140:76, aber auch über den gesamten Beobachtungszeitraum bleibt dieses Verhältnis bestehen: 1012:803:251.32 Als Ursache für die Bevorzugung der femininen Artikelform in ihren Daten vermutet Mills die höhere Frequenz der Form die im Input aufgrund ihrer zusätzlichen Funktion als Pluralmarkierer im Nominativ und Akkusativ. Unsicherheit könnte vor allem durch endungslose Pluralformen wie die Löffel entstehen, da solche Formen fälschlicherweise für Feminina gehalten werden könnten (Mills 1986:68f.). Müller hat bei allen drei von ihr untersuchten Kindern Probleme bei der Artikelzuordnung zu Neutra festgestellt. Beinahe alle übrigen (maskulinen und femininen) NP haben dagegen den zielsprachlichen Artikel erhalten (Müller 1999:378).

31 Aufnahmen, in denen keine eindeutig falsch zugewiesenen Genera auftraten, sind hier nicht aufgeführt.

32 Meine Angaben enthalten nur die Werte für Äußerungen im Nominativ und Akkusativ. Die Verhältnisse verändern sich aber auch unter Berücksichtigung der Dativ-Äußerungen nicht. 
Vertauschungen von unbestimmtem und bestimmtem Artikel treten in den von mir untersuchten Daten von Simone kaum auf, auch Fälle von Artikeln in zielsprachlich artikellosen NPs kommen nur äußerst vereinzelt vor. Der Erwerb der unterschiedlichen referenziellen Funktionen der Artikelwörter scheint daher wenig problematisch.

\subsubsection{Analyse der Genusfehler}

Die Genuszuweisungsregeln, wie sie Wegener formuliert hat, beschreiben insgesamt vier formale/phonologische und ein semantisches Prinzip für die Bestimmung des Genus eines Nomens. In Abschnitt 2.1 wurden solche Regularitäten der Genusverteilung genauer beschrieben. Wegener hat dabei weniger auf eine detaillierte Differenzierung der Ausgangsbedingungen einer Regel Wert gelegt (wie z.B. Köpcke 1982 und Köpcke/Zubin 1983) als vielmehr auf eine Formulierung, die mit wenigen Voraussetzungen einen möglichst großen Bereich des Wortschatzes umfasst. Um die Relevanz der einzelnen Genusregeln (GR) bzw. Prinzipien beurteilen zu können, hat die Autorin die jeweilige Validität (Zuverlässigkeit bei der Vorhersage eines Genus) sowie den zugehörigen Skopus (Anwendungsbereich im Wortschatz) ermittelt:

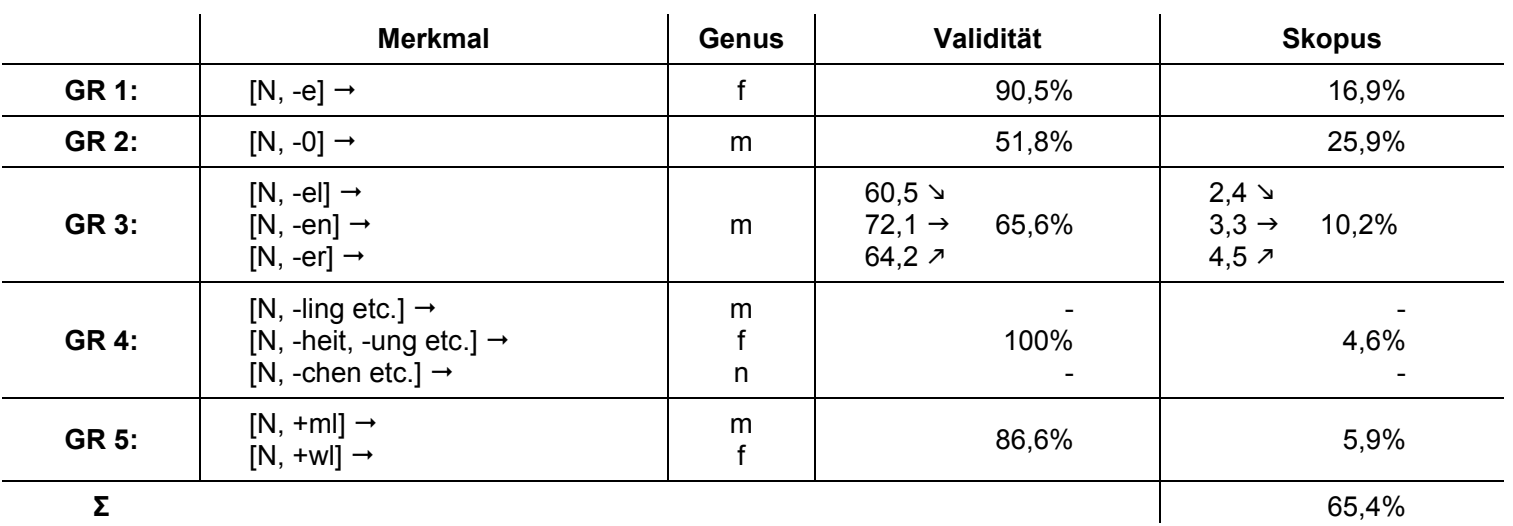

Tabelle 4: Genuszuweisungsregeln mit Validität und Skopus (Wegener 1995:93).

Diese Werte gelten für den von Oehler ermittelten Grundwortschatz der deutschen Sprache. In der Kindersprache verschieben sich die Verhältnisse ein wenig. In Simones gesamtem Nominallexikon gewinnt z.B. die GR 1 mit einer Validität von 92,1\% und einem Skopus von 21,1\% deutlich an Bedeutung, Gleiches gilt für die GR 3, die eine Gesamtvalidität von 69,4\% und einen Skopus von 14,0\% erreicht, und Ableitungen mit echten Suffixen (GR 4) stellen einen Anteil von 6,9\%.

Von den verschiedenen semantischen Wortfeldern (vgl. Abschn. 2.1.2) ist nach Wegener nur das Prinzip des natürlichen Geschlechts (GR 5) im Spracherwerb relevant. Andere Felder sind entweder nicht bzw. nicht ausreichend im Wortschatz des kindlichen Sprachlerners enthalten oder sie sind in ihrer Genusbestimmung nicht zuverlässig genug, so dass von ihnen kaum Zuordnungsprinzipien bezüglich des Genus abgeleitet werden können (Wegener 1995:70).

Diese semantische GR 5 steht wiederum mit den phonologischen in Konkurrenz (vgl. die Zuweisungshierarchie in Abschn. 2.1.3). Es wird häufig davon ausgegangen, dass eine Regel, die auf semantischer Grundlage wirkt, leichter und daher früher erworben wird als formale (vgl. Slobin 1973), nach dem sog. „semantic primacy“-Prinzip (vgl. u.a. van der Geest 1978 und Gleitmann 1981, zit. in Mills 1986:109). Sowohl Mills als auch Müller haben jedoch in ihren Untersuchungen keinen zeitliche Erwerbsvorsprung in den Genuszuweisungen aufgrund des natürlichen Geschlechts gegenüber phonologischen Nomeneigenschaften beobachten können. Sie stellten fest, dass semantische und formale Genusregeln parallel erworben werden (Mills 1986:111, Müller 1990:217, 1999:381). Ich werde daher die Analyse der Daten 
von Simone mit dieser semantischen Zuweisungsregel beginnen und anschließend auf die phonologischen eingehen.

Wenn der Prozess des Genuserwerbs bzw. des Formenerwerbs zur Genusmarkierung am bestimmten Artikel durch Regeln oder Prinzipien dieser Art geleitet wird, d.h. wenn das Kind Auffälligkeiten in Bezug auf die Form oder Bedeutung eines Nomens und die zugehörige Artikelform wahrnimmt und daraus Regularitäten bzw. Schemata für die Genuszuweisung ableitet, sollten sich während des Erwerbsprozesses Beispiele finden lassen, in denen eine erworbene Regel auf Abweichung angewendet, übergeneralisiert, wird, denn Ausnahmen würden erst später als solche erkannt und erworben (vgl. Abschn. 4.3).

\subsubsection{Natürliches Geschlecht}

Bezüglich des „Natürlichen Geschlechtsprinzips“ (NGP) (Wegener 1995:71), das das Genus bei belebten Wesen entsprechend dem Sexus zuweist, treten bei Simone in zwei Aufnahmen Übergeneralisierungen auf:

\begin{tabular}{ll} 
Übergeneralisierungen von GR 5: \\
\hline der Kind & $(2 ; 0.26)$ \\
die Aschenputtel (5x) & $(3 ; 9.18)$
\end{tabular}

Zu der Äußerung der Kind zeigt Simone auf einen abgebildeten Jungen (die gleiche Form tritt bei 2;6.16 erneut auf, der Transkriptionskommentar gibt hier jedoch keinen Aufschluss über das Geschlecht des bezeichneten Kindes). Dies könnte also als ein früher Hinweis darauf interpretiert werden, dass die Form des bestimmten Artikels mit der Wahrnehmung des natürlichen Geschlechts in Zusammenhang gebracht wird. Auch Mills beobachtet eine semantisch motivierte Falschzuweisung des femininen Artikels zu Kind (Mills 1986:99f.).

Mit der NP die Aschenputtel ordnet Simone noch gegen Ende des Beobachtungszeitraums diesem Namen insgesamt fünfmal das dem natürlichen Geschlecht entsprechende feminine Genus zu, jedoch nur zweimal das korrekte Neutrum ${ }^{33}$ (zum gleichen Aufnahmezeitpunkt). Die Wahrnehmung dieser Figur als weiblich wirkt sich hier bedeutend stärker aus als das „Wissen“ um das formal richtige Genus. Der Konflikt zwischen natürlichem und grammatischem Geschlecht dieses „hybriden“ (Corbett 1991:183) Nomens wird in einer Selbstkorrektur zum gleichen Aufnahmezeitpunkt deutlich: die des Aschenputtel.

Missachtungen dieser Genusregel treten dagegen wesentlich häufiger auf. Sie setzen relativ spät ein und erscheinen meist im Zusammenhang mit Eigennamen $(\mathrm{EN})^{34}$ :

\begin{tabular}{lll}
\multicolumn{2}{l}{ Verstöße gegen GR 5: } & \\
die Peter $(3 \mathrm{x})$ & $(2 ; 10.11)$ & der Weihnachtsgans \\
die (Peter) & $(2 ; 10.11)$ & der (Weihnachtsgans) \\
der (weibl. EN) & $(2 ; 10.11)$ & die Schneider \\
die Bernd & $(3 ; 1.0)$ & die Peter \\
die Tobias & $(3 ; 1.0)$ & die (Prinz) \\
die Martin & $(3 ; 1.0)$ &
\end{tabular}

\footnotetext{
33 Das Deminutivsuffix - el weist - im Unterschied zum in GR3 genannten homophonen Pseudosuffix - Neutrum zu.

34 Ich mache hier keine Unterschied zwischen Nomina und Eigennamen, da Simone im süddeutschen Raum aufgewachsen ist, wo Eigennamen sehr konsequent mit einem Artikel verwendet werden und sich daher syntaktisch nicht von anderen Nomina unterscheiden.
} 
Es fällt auf, dass hauptsächlich männlichen Eigennamen eine inkorrekte, und zwar ausschließlich die feminine Artikelform zugewiesen wird. In nur einem Fall wird die maskuline Artikelform in Zusammenhang mit einem weiblichen Eigennamen verwendet (mit 2;10.11, hier fällt Simone der Name eines Mädchens nicht ein). Noch im Alter von drei Jahren weist Simone sogar ihrem jüngeren Bruder Tobias den femininen Artikel zu. Den Eigennamen Peter gebraucht sie nicht nur mit 2;10.11 mit dem femininen Artikel, sondern weist ihm diesen drei Monate später (mit 3;1.11) erneut zu. ${ }^{35}$ Mills $(1986: 11,99)$ formuliert die Hypothese, dass die Formen für belebte Maskulina wegen ihres unmarkierten Status eher erworben werden müssten als die für belebte Feminina, wobei sie sich auf Greenbergs Markiertheitstheorie stützt, nach der in der Belebtheitskategorie Maskulina (nicht nur im Deutschen) gegenüber den Feminina unmarkiert sind (in Mills 1986:11). Mills konnte wegen nicht-produzierter entsprechender Fehler diese These jedoch weder bestätigen noch widerlegen. Die Daten von Simone widersprechen dagegen dieser Annahme: Gerade belebte Maskulina bilden den Schwerpunkt der Missachtungen des NGP.

Die beiden Fälle der Weihnachtsgans habe ich hier mit aufgenommen, da es sich jedes Mal um die Gans Auguste in der Bilderbuchgeschichte „Die Weihnachtsgans Auguste“ handelt. Die Personifizierung des Tieres durch einen weiblichen Eigennamen kann die feminine Genuszuweisung in diesen Fällen nicht unterstützen. Dass Simone die Bezeichnung „Weihnachtsgans Auguste" semantisch segmentiert hat, zeigt sich daran, dass sie die Elemente (Weihnachtsgans, Gans, Auguste) auch einzeln verwendet; der Eigenname Auguste erhält dabei immer zielsprachlich keinen oder den femininen bestimmten Artikel. Dennoch scheint sich bei Gans und Weihnachtsgans das maskuline Genus, das sich aus phonologischen Zuweisungsregeln für Gans erklären würde, durchzusetzen (vgl. unten, Abschn. 5.2.2.3).

Eine semantisch basierte Zuordnung des maskulinen und femininen Artikels zum jeweiligen natürlichen Geschlecht scheint Simone nennenswerte Schwierigkeiten zu bereiten, die Form das wird dagegen nie bei Personen oder personifizierten Figuren ${ }^{36}$ gesetzt. ${ }^{37}$ Während also die das-Form von Anfang an nicht mit Belebtheit assoziiert wird, scheint die Differenzierung der beiden anderen Formen auf der Grundlage des natürlichen Geschlechts Probleme zu bereiten. Die kognitive Verknüpfung von männlichen Personen und der stellt dabei das Hauptproblem dar. Das Erkennen des Zusammenhangs zwischen natürlichem Geschlecht und der Artikelform deutet sich zwar in der frühen Übergeneralisierung und der Dissoziation von das und belebten Wesen an, im weiteren Erwerbsprozess treten jedoch sehr zahlreiche Verstöße gegen dieses Zuweisungsprinzip auf. Bis zum Alter von 3;1.11 kann nicht davon ausgegangen werden, dass dieses Zuweisungsprinzip erworben ist. Erst gegen Ende des Untersuchungszeitraums tritt dieses „Wissen“ erneut in den Vordergrund; ihm steht jedoch seine zeitgleiche Missachtung in die für einen Prinzen gegenüber.

Diese Ergebnisse stehen im Gegensatz zu denen von Mills und Müller. Beide haben, wie oben erwähnt, beobachtet, dass dieses Prinzip früh und sicher beherrscht wird und am bestimmten Artikel zum Ausdruck kommt: Müller stellt den Erwerb des NGP bei Caroline bis 2;6 fest, wobei hier ebenfalls die das-Form nicht für belebte Wesen verwendet wird (Müller 1990:213f.). Mills (1986:99) konnte insgesamt nur einen Verstoß in ihren Daten feststellen. Vielmehr konstatiert sie fehlerfreien Artikelgebrauch bei Eigennamen sowie in pronominalen

35 Hierbei handelt es sich um die Hauptfigur aus dem Musikstück „Peter und der Wolf“ von P.I. Tschajkowskij.

36 Zur Beobachtung, dass personifiziertem Spielzeug teilweise das Merkmal [+human] im Spracherwerb zugeschrieben wird, vgl. Müller (1990:212).

37 Ähnliche Zuweisungsprobleme bei belebten Referenten hat Bittner (persönliche Kommunikation) auch bei anderen Kinder festgestellt. 
Konstruktionen. Auch in Experimenten mit 3- und 4-jährigen deutschen und englischen Kindern stellt sie bei ersteren im Gegensatz zu letzteren eine nahezu perfekte Zuweisungskompetenz in Bezug auf das NGP fest:

The performance level of German children is already so high in the 3-year-old group that no development over age is observed. (Ebd.:103)

Die Ergebnisse aus den Daten Simones können vielmehr eine Feststellung bestätigen, zu der Levy nach einem Vergleich von verschiedensprachlichen Erwerbsdaten kommt, nämlich dass

[...] children age 2-3 seem not to take advantage of whatever understanding they possess regarding cognitive gender distinctions in working out the intricacies of the linguistic system. (Levy 1983:91, zit. in Mills 1986:99)

Falls also der Unterschied im Sexus kognitiv zwar erkannt werden sollte, findet er bei Simone zuindest keine konsequente Anwendung bei der Zuweisung des bestimmten Artikels.

\subsubsection{Nomina mit Schwa-Auslaut}

Die GR 1, nach der Nomina mit Schwa-Auslaut zu gut 90\% Feminina sind, sollte im Spracherwerb kaum Probleme bereiten und eine der zuerst erworbenen Genusregeln im Erwerbsprozess sein. Mills bestätigt diese Vermutung anhand der Ergebnisse ihrer Untersuchungen sowie experimentell erhobener Daten (Mills 1986:72, 85). Müller (1990:214) beobachtet nicht nur den Erwerb dieser Regel bei dem Mädchen Caroline bis 2;6, sondern immerhin auch zweimal die Ausdehnung dieses Prinzips auf französische Nomina, deren gewöhnlich stumme Endung -e nun realisiert wird, wie z.B. die porte (Tür). Auch in Ivars Sprachproduktion findet sie entsprechende Übergeneralisierungen auf (deutsche) Nomina mit abweichendem Genus (Müller 1999:378).

Bei Simone kann dagegen nicht von einem frühen und problemlosen Erwerb dieses Zuweisungsprinzips gesprochen werden. Lediglich einmal, zudem relativ spät, übergeneralisiert sie den femininen bestimmten Artikel auf ein maskulines Nomen:

\section{Übergeneralisierung von GR 1: die (Hase) $\quad(3 ; 1.0)$}

Dagegen treten zahlreiche Fälle auf, in denen die Schwa-Regel nicht zur korrekten Genuszuweisung genutzt wird:

\begin{tabular}{llll}
\multicolumn{2}{c}{ Verstöße gegen GR 1: } & & \\
\hline das Fliege & $(2 ; 0.5)^{38}$ & der Ente & $(2 ; 10.11)$ \\
das Blume & $(2 ; 0.26)$ & des Schranke & $(2 ; 10.11)$ \\
das Mütze & $(2 ; 0.26)$ & das Geschichte & $(3 ; 1.11)$ \\
der Puppe & $(2 ; 1.12)$ & der Ente & $(3 ; 5.15)$ \\
der (Qu)itte & $(2 ; 7.23)$ & der (Ente) & $(3 ; 5.15)$
\end{tabular}

Während des gesamten Beobachtungszeitraums treten falsche Genuszuweisungen zu femininen Nomina mit Schwa-Auslaut auf, wobei jedoch keine der beiden Formenalternativen der und das bevorzugt wird. Auffällig ist besonders die wiederholte Falschzuweisung zu Ente mit 3;5.15, da dieses Substantiv bereits mit 2;0.1 in Simones aufgezeichneten Äußerungen erscheint, also schon lange bekannt und dennoch bis jetzt nicht vollständig mit seinem grammatischen Genus verknüpft ist. Auch bei der Puppe handelt es sich um ein Nomen, das ein sehr frühes Lexem in Simones Wortschatz ist; bereits zum ersten Aufnahmezeitpunkt $(1 ; 9.11)$ wird

38 In den genannten Fällen mit das als Falschzuweisung ist eine mögliche Interpretation der Äußerung als das ist $X$ ausgeschlossen. 
es von Simone geäußert. Dass im Fall von das Geschichte aufgrund der Affixkombination Ge-...-e neutrales Genus zugewiesen wird, kann kaum angenommen werden. Es ist nicht nur eine wesentlich komplexere Regel an sich, sie lässt sich auch nicht aus Simones bisher erworbenem Wortschatz abstrahieren.

Es zeigt sich also, dass die sehr valide Schwa-Regel selbst bei „altbekannten“ Nomina nicht immer korrekt eingesetzt wird. Ein einfacher, schneller Erwerb dieses sehr validen Genusprinzips kann anhand von Simones Spracherwerb daher nicht bestätigt werden. Statt der erwarteten Übergeneralisierungen auf nicht feminine Substantive, die auf einen Erwerb dieser Regel hinweisen würden, treten zahlreiche Verstöße gegen dieses Prinzip auf.

\subsubsection{Nicht-abgeleitete Nomina}

Die GR 2 bezeichnet Wegener zwar als „Einsilber-Regel“ (Wegener 1995:88), sie schließt aber auch mehrsilbige nicht-abgeleitete Nomina (wie Abend) ein. Diese machen zwar den geringeren Anteil dieser Wortgruppe aus (ebd.:89, Anm. 27), bewirken jedoch eine Verringerung der Zuweisungsvalidität von 64,1\% bei Köpcke (s. S. 90, Anm. 6) auf 51,8\% (s. Tabelle 4). Ich werde daher zunächst die tatsächlich einsilbigen Nomina in Simones Fehlerproduktionen besprechen.

Wegener formuliert eine pauschal Maskulinum zuweisende „Einsilber-Regel“ in Abgrenzung zu Köpckes (1982) äußerst differenzierten Einzelregeln. Es wird hier also nicht zwischen den verschiedenen phonologischen und strukturellen An-, Aus- und Inlautregeln unterschieden, da für den Spracherwerb eine solch detaillierte Aufstellung vermutlich irrelevant ist. Eine einzige Regel, die für monosyllabische Nomina maskulines Genus angibt, ist im Ergebnis ebenso valide wie eine Zuweisung aufgrund der wenigen wirklich eindeutigen Genusregeln (vgl. S. 90) nach Köpcke (Wegener 1995:78).

Bezüglich der monosyllabischen Nomina finden sich im Simone-Korpus folgende Falschzuweisungen des bestimmten Artikels:

\begin{tabular}{ll} 
Übergeneralisierungen von GR 2: \\
\hline der Kind & $(2 ; 0.26)$ \\
der (Schwein, 2x) & $(2 ; 2.21)$ \\
der Kind & $(2 ; 6.16)$ \\
der Gans (Akk) & $(2 ; 10.11)$ \\
der Gans (Akk) & $(3 ; 0.24)$ \\
der (Gans) & $(3 ; 1.11)$ \\
& \\
Verstöße gegen GR 2: & \\
\hline das Baum (Akk) & $(2 ; 7.23)$ \\
die Kopf & $(2 ; 9.26)$ \\
die Hund (2x, Akk) & $(3 ; 1.0)$ \\
das Klotz (Akk) & $(3 ; 1.0)$ \\
die (Topf) & $(3 ; 1.0)$ \\
die Bernd & $(3 ; 1.0)$
\end{tabular}

$\begin{array}{ll}\text { des Kern } & (3 ; 2.15) \\ \text { das klein Kuh } & (3 ; 9.18) \\ \text { die (Prinz) } & (3 ; 9.18) \\ \text { über die Müll (Akk?) } & (4 ; 0.6) \\ \text { die (Buch) } & (4 ; 0.6)\end{array}$

Die Übergeneralisierungen liegen zeitlich vor dem Schwerpunkt der Missachtungen dieses Zuweisungsprinzips, welche meist erst nach 3;0 und auftreten. Es fällt auf, dass diese Genusregel ausschließlich auf belebte Entitäten ausgeweitet wird, bei solchen jedoch auch ignoriert wird.

Die von der Regel abweichende Genusbestimmung bei Kind und Gans stellt sich offenbar als besonders problematisch dar. Das erste Auftreten von der Kind wurde oben bereits als Über- 
generalisierung des NGP beschrieben. Sechs Monate später tritt diese Form erneut auf. Diesem Nomen wird von Köpckes differenziertem Regelinventar nicht das richtige Genus Neutrum, sondern tatsächlich das Maskulinum zugewiesen. Solches „Scheitern“ dieser Regeln tritt bei nur etwa 10\% seines untersuchten Einsilber-Korpus ein. Diese Nomina werden vom Autor entweder aufgrund ihrer hohen kommunikativen Frequenz zum sogenannten „Kernwortschatz“ oder wegen ihrer Seltenheit zur „Peripherie“ des Wortschatzes gezählt. Diese Einträge könnten jedoch regelunabhängig auswendig gelernt und gespeichert werden (Köpcke 1982:43, 116-124). Die Singular-Form Kind erscheint allerdings nicht sehr häufig in Simones Input oder ihrer eigenen Produktion. Ihr Vater und Hauptkommunikationspartner in den Aufzeichnungen gebraucht es in den vorliegenden Daten zuerst bei 2;2.18 in an sie gerichteter Rede $^{39}$, regelmäßig tritt es in seinen Äußerungen erst ab 2;10.11 auf. Simone selbst verwendet dieses Wort zuerst in seiner Pluralform. Erst ab 2;11.18 sind in Simones Äußerungen ausschließlich zielsprachlich - sowohl im Genus als auch im Kasus - korrekte Singular-Formen von Kind belegt. Zuvor tritt es fünfmal in ihren Äußerungen auf: zweimal als artikellose EinWort-NP (2;7.19), zweimal mit o.g. der und nur einmal mit dem korrekten Artikel das - jedoch zu einem auffallend frühen Zeitpunkt: 2;2.18. Nach einer ersten lexikalischen Speicherung folgt offenbar eine lange Phase der Unsicherheit bezüglich der korrekten Genusmarkierung am bestimmten Artikel bei Kind. Dies ist insofern nachvollziehbar, als mit Kind ja mal ein weibliches, mal ein männliches Wesen bezeichnet wird. Es ist daher erstaunlich, dass diese semantische Grundlage für die Genusbestimmung insgesamt so häufig ignoriert wird (s.o., Abschn. 5.2.2.1).

Die wiederholten Zuweisungen der maskulinen Artikelform zu Gans überschneidet sich zeitlich bereits mit den ersten Fällen von Verstößen gegen die Einsilber-Regel. Die Wirkung dieser Regel als Ursache dieser Fehler scheint somit in Frage gestellt. Über den weiteren Zuweisungsverlauf zu diesem Nomen kann hier jedoch keine Aussage gemacht werden, da es nach 3;1.11 nicht mehr in den Aufzeichnungen verwendet wird. Es sei jedoch bemerkt, dass Köpckes phonologische Regel bei Gans aufgrund des Auslautmusters Nasal+Konsonant maskulines Genus zuweisen. Den Ausschlag für das zielsprachliche Femininum gibt jedoch die hierarchisch höhere, semantische Regel, die bei domestizierten Tieren eine Genusverteilung je nach dem natürlichen Geschlecht vorhersagt (Köpcke 1982:77f., 98f.).

Unter den Fällen, in denen das Einsilber-Prinzip nicht zur Zuordnung des korrekten Maskulinums angewendet wird (lediglich das Nomen Buch ist kein Maskulinum), finden sich zwar keine solch „hartnäckigen“ Wiederholungen, allerdings sind hier wesentlich mehr Lexeme (types) betroffen. Dabei ist eine Tendenz zur Bevorzugung der die-Form (7x) gegenüber der das-Form (3x) zu verzeichnen.

Die Zuweisung von das zu klein Kuh könnte theoretisch auf der geschlechtslosen Wahrnehmung von domestizierten Jungtieren beruhen, wie es Köpcke (1982) und Köpcke/Zubin (1984) als semantisches Genusprinzip formuliert haben. Da aber vor allem im frühen Spracherwerb semantisch-basierte Genusregeln neben dem NGP kaum eine Rolle spielen (s.o., S. 117), ist hierin auch nicht die Ursache dieser Falschzuweisung zu vermuten. Es spricht mehr dafür, hier Probleme beim Lexem-Abruf und Kälbchen als das intendierte Nomen anzunehmen, da Simone gleich im Anschluss diese Äußerung mit eben diesem Nomen wiederholt (das kleine Kälbchen).

Darüber hinaus lassen sich jedoch keine formalen oder semantischen Motivierungen für die Verstöße gegen das Einsilber-Prinzip finden. Es sind sowohl belebte als auch unbelebte Wesen, Eigennamen, Personenbezeichnungen sowie Tiere betroffen. Es gilt an dieser Stelle also

\footnotetext{
39 Zuvor ist es in einer Äußerung protokolliert, die an eine erwachsene Person gerichtet ist $(2 ; 0.5)$.
} 
festzuhalten, dass den wenigen, z.T. anderweitig ableitbaren Übergeneralisierungen zahlreiche, offenbar unmotivierte Missachtungen gegenüberstehen. Auch Mills und Müller stellen in ihren Arbeiten eine Reihe von phonologischen Zuweisungsregeln für Einsilber nach dem Muster von Köpcke vor. Nur bei Ivar wird jedoch eine deutliche Assoziation von Einsilbigkeit mit maskulinem Genus beschrieben (Müller 1999:379f.).

Im Unterschied zu den Einsilbern ist bei den mehrsilbigen Simplizia durchaus eine leichte Tendenz zur Übergeneralisierung der maskulinen Artikelform zu beobachten:

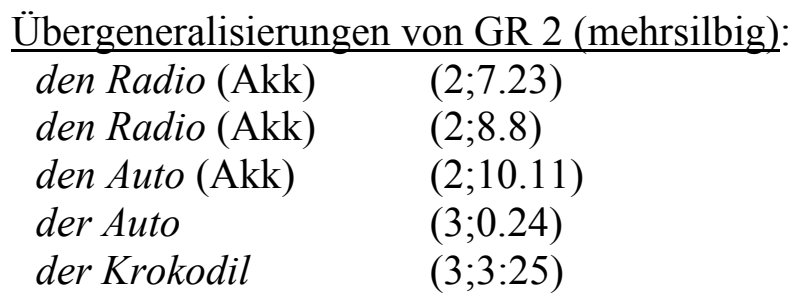

\begin{tabular}{lc} 
Verstöße gegen GR 2 (mehrsilbig) \\
\hline die Tobias & $(3 ; 1.0)$ \\
die Martin & $(3 ; 1.0)$ \\
die (Pony) & $(3 ; 1.11)$
\end{tabular}

Die Übergeneralisierung des maskulinen Genus auf mehrsilbige Simplizia setzt zeitgleich mit den Verstößen gegen die „echte“ Einsilber-Regel ein. Dabei sind hauptsächlich solche mit $o$ Auslaut betroffen (zwei types, vier tokens), obwohl es hierfür keine phonologische Grundlage im Lexikon gibt: Unter den insgesamt sieben Lexemen mit -o im Auslaut, die Simone während des gesamten Aufnahmezeitraumes verwendet, sind lediglich zwei Maskulina, wobei dieser Vokal in Kakao als zweites Diphthong-Element ungespannt und verkürzt realisiert wird. Nur das Nomen Popo, das in den Aufnahmen bei 2;0.26 zuerst in Simones Äußerungen erscheint und vermutlich bereits wesentlich länger bekannt ist, könnte somit die Grundlage für diese Assoziation des $o$-Auslautes mit dem maskulinen Genus bilden. Alle übrigen Lexeme dieser Art sind Neutra.

\subsubsection{Nomina auf -el, -en, -er}

Auch die GR 3, die Substantive auf -el, -en und -er mit gut 65\%iger Zuverlässigkeit dem maskulinen Genus zuordnet, wird häufiger missachtet als übergeneralisiert:

\begin{tabular}{ll} 
Übergeneralisierungen von GR 3: \\
\hline der Kugel & $(1 ; 10.20)$ \\
der Wasser & $(2 ; 0.26)$ \\
den (Angel) & $(2 ; 5.13)$ \\
den Kopfkissen & $(2 ; 5.19)$ \\
den Pflaster (Akk) & $(2 ; 8.8)$ \\
der Wasser & $(2 ; 8.15)$
\end{tabular}

Es fällt auf, das die Form der Wasser nach einer längeren Zeit erneut auftritt.

Bei den Verstößen gegen dieses Zuweisungsprinzip wird anscheinend die feminine Artikelform bevorzugt eingesetzt, wobei jedoch $\mathrm{zu}$ bedenken ist, dass gerade bei frühen $\mathrm{Zu}$ - 
weisungen von das häufig ein deiktischer Gebrauch nicht ausgeschlossen werden kann und uneindeutige Fälle hier jedoch nicht mit aufgeführt sind ${ }^{40}$ :

\begin{tabular}{llll} 
Verstöße gegen GR 3: & & & \\
\cline { 1 - 3 } das Wecker & $(2 ; 0.23)$ & in die Keller (Akk) & $(2 ; 10.11)$ \\
die Eimer & $(2: 6.23)$ & die Peter $(3 \mathrm{x})$ & $(2 ; 10.11)$ \\
das Teller (Akk) & $(2 ; 7.23)$ & die (Peter) & $(2 ; 10.11)$ \\
die Igel (3x) & $(2 ; 8.8)$ & die Schnuller & $(3 ; 1.11)$ \\
die Fernseh(er) (Akk) & $(2 ; 8.8)$ & die Schneider & $(3 ; 1.11)$ \\
die (Kinderwagen) (Akk) & $(2 ; 9.26)$ & die Peter & $(3 ; 1.11)$ \\
die (Deckel) (Akk) & $(2 ; 9.26)$ & des Tiger (Akk, 2x) & $(3 ; 7.11)$
\end{tabular}

Der Schwerpunkt der Regelmissachtungen liegt wiederum zeitlich nach den Übergeneralisierungen. Die bereits als Verstöße gegen das NGP besprochenen Fälle die Peter und die Schneider erscheinen in dieser Übersicht ein zweites Mal. Diese Auslautregel hat somit auch bei einer Überschneidung mit der semantischen Regel bezüglich des natürlichen Geschlechts keine wesentliche Auswirkung auf die Artikelzuordnung während des Erwerbsprozesses. Weder der semantische noch der phonologische Hinweis scheinen hier für die Artikelwahl genutzt zu werden.

Der Auslaut -er, für den in Experimenten am ehesten eine Assoziation mit dem maskulinen Genus nachgewiesen wurde (s.o., S. 90), scheint im Spracherwerb keine Unterstützung für die zielsprachliche Formenzuweisung zu sein. Bei nur zwei Lexemen mit diesem Auslaut wird die Genusregel übergeneralisiert, gegenüber neun, die zudem bei den Verstößen den Schwerpunkt bilden.

Aus anderen Untersuchungen liegen leider keine Angaben zu dieser Auslautregel im Spracherwerb vor.

\subsubsection{Suffigierung}

Nomina mit genusdeterminierendem Suffix machen $6,9 \%$ von Simones Gesamtwortschatz aus und damit einen größeren Anteil als der von Wegener für den Grundwortschatz des Deutschen ermittelten. Von den 45 Nomina (types) in den mir vorliegenden Daten sind mit 29 weit mehr als die Hälfte Ableitungen auf -chen. Daneben finden sich fünf weitere mit DiminutivSuffixen (Büdlein, Häselein, Männlein, Vögelein; Mädli), zwei Lexeme auf -ling (Däumling, Schmetterling), drei auf -in (Freundin, Königin, Prinzessin) sowie zwei auf die Endung -fon (Mikrofon, Telefon). Das Nomen Bücherei ist der einzige Vertreter des Ableitungssuffixes $-(e r) e i$.

Insgesamt treten hier keine Schwierigkeiten bei der Zuordnung einer Artikelform auf. Es wird nicht das Genus des Nomens, das einer (vor allem mit -chen oder -lein gebildeten) Ableitung zugrunde liegt, auf das Derivat übergeneralisiert. Auch bei seltenen Bezeichnungen wie $\mathrm{He}$ lenchen und Paulinchen wird weder der Artikel vermieden noch auf das NGP ausgewichen. Der Gebrauch des bestimmen Artikels in dieser Nomengruppe entspricht in etwa seiner generellen Frequenzentwicklung, er wird hier nicht seltener als bei anderen Nomina verwendet. Neben der offensichtlichen Problemlosigkeit bei der Artikelzuordnung zeigt sich ein Hinweis auf das Erkennen eines Zusammenhangs zwischen Suffix und Genus. Das Abstraktsuffix -ung erscheint an drei Lexemen (7 tokens), wobei zwei für Konkreta lexikalisiert sind (Heizung,

40 Es handelt sich hierbei um fünf solcher das-Fälle, die zwischen 2;0.26 und 2;7.23 zusammen mit einem Nomen auftreten und nicht in die Analyse eingegangen sind. 
Zeitung) ${ }^{41}$ Mit der Äußerung in die Füllung gehen (3;9.18) statt „,in Erfüllung gehen“ setzt Simone zwar inkorrekt den Artikel, jedoch in seiner für dieses Suffix genuskorrekten Form.

Möglicherweise haben die echten Ableitungssuffixe eine genügend hohe lautliche Salienz, um direkt mit ihrer jeweiligen Artikelform assoziiert zu werden. Sie bilden meist eine selbständige Silbe und zeichnen sich durch einem qualitativ salienten Vokal und konsonantischem Endrand aus. Der Stamm des Derivats hätte demnach nur eine Art „Präfix-Wirkung“, da er nicht für die Zuweisung der Artikelform in Betracht gezogen wird. Dies würde offensichtlich auch bei weniger frequenten Nomina gelten.

\subsubsection{Komposita}

Bei der Beschreibung der Genusfehler anhand der von Wegener formulierten Regeln sind bisher die Komposita unerwähnt geblieben. Bei ihnen richtet sich das Genus nach dem letzten Glied der Komposition, womit die Zuordnung von den beschriebenen Prinzipien erfasst wird. Da sie strukturell jedoch komplexer sind, stelle ich sie in einem separaten Abschnitt dar. Es treten folgende Falschzuweisungen auf:

$\begin{array}{llll}\text { der Fahrrad }(2 \mathrm{x}) & (2 ; 0.26) & \text { die (Kinderwagen) } & (2 ; 9.26) \\ \text { den Kopfkissen (Akk) } & (2 ; 5.19) & \text { der Weihnachtsgans } & (3 ; 1.11) \\ \text { des Teddybär (Akk.) } & (2 ; 7.19) & \text { der Motorrad } & (3 ; 1.11) \\ \text { die Bilderbuch (Akk) } & (2 ; 8.15) & & \end{array}$

Die vier Komposita Fahrrad, Kopfkissen, Teddybär und Motorrad gebraucht Simone zu den genannten Zeitpunkten zum ersten Mal in den Aufzeichnungen. Jedoch gilt nur für Fahrrad, dass das letzte Kompositaglied zuvor noch nicht als selbständiges Lexem in den untersuchten Daten aufgetreten ist. Bei den Genuszuweisungen von Fahrrad, Kopfkissen und Motorrad kann eine Übergeneralisierung der Regeln für das letzte Kompositaglied vorliegen. Da Falschzuweisungen bei Simone allerdings insgesamt weniger durch die Übergeneralisierung einer Zuweisungsregel zu Stande kommen, ist diese Annahme auch hier unwahrscheinlich. Eigene Kompositabildungen werden in den Aufzeichnungen leider nicht mit dem bestimmten Artikel versehen.

Das Ausbleiben von Genusfehlern bei komplexen Nomenstrukturen nach 3;1 ist insofern bemerkenswert, da Müller bei Caroline noch im Alter von 4;6 den Erwerb der Komposita-Regel beobachtet (Müller 1990:231). Mills vermutet dagegen, dass der Erwerb der DiminutivEndung sowie des Letzt-Glied-Prinzips bei Komposita mit ca. 3;0 abgeschlossen ist (Mills 1986:74).

Als letztes sind noch die Substantive das Ticktack (2;0.23) und das Wauwau (2;5.19) zu nennen. Sie erhalten als lautmalerische Bildungen ihr Genus nach der erwachsenensprachlichen Bezeichnungen ( $U h r, H u n d$ ). Eine Motivierung für den Gebrauch des Neutrums ist unklar, vor allem da die zielsprachlichen Zuweisungen mit keinem der genannten Genusprinzipien in Konflikt stehen.

\subsubsection{Zusammenfassung und Diskussion}

Die Falschzuweisungen der Formen des bestimmten Artikels liefern keine klaren Hinweise auf den Erwerb von phonologischen und semantischen Prinzipien für die Genusverteilung bei Simone. Insgesamt stehen wenigen Übergeneralisierungen, die als Zeichen für den Erwerb

41 Das Nomen Achtung bleibt hier unberücksichtigt, da es ausschließlich als Ausruf verwendet wird und vermutlich nicht als syntaktisches Nomen gespeichert ist. 
einer Genusregel interpretiert werden könnten, zahlreiche Regelverstöße gegenüber. Dabei sind drei Aspekte besonders bemerkenswert:

1. Die als besonders problemlos geltenden Regeln für Feminina mit Schwa-Auslaut und das NGP erweisen sich in den Daten von Simone nicht als leicht zu erwerbende Regeln im Erwerbsprozess. Unter den Regelverstößen setzen die gegen das NGP am spätesten (ab $2 ; 10.11)$ ein. Missachtungen der Schwa-Regel treten dagegen über den gesamten Beobachtungszeitraum auf, wohingegen es nur zu einer einzigen, zudem sehr späten, Übergeneralisierung kommt.

2. Im Zeitraum von 2;1.21 bis 2;4.21 treten keine Verstöße gegen eine Genusregel und nur eine Übergeneralisierung in den untersuchten Daten auf. ${ }^{42}$ Es scheint somit eine Phase der zwischenzeitlichen Beherrschung der Genuszuweisung vorzuliegen.

3. Nach 3;4.5 treten zwar keine Übergeneralisierungen (mit Ausnahme von die Aschenputtel) mehr auf, Verstöße gegen Genusregeln sind jedoch bis zum Ende des Beobachtungszeitraum $\mathrm{zu}$ verzeichnen.

Der Erwerbsprozess wird durch die Phase der Formenbeherrschung in drei Abschnitte gegliedert, die zusammen mit der Entwicklung der Gebrauchsfrequenz des bestimmten Artikels eine erste Interpretation erlauben: $\mathrm{Zu}$ Beginn des Artikelgebrauchs, der mit 2;0.23 mit einem ersten sprunghaften Anstieg einsetzt, treten einige Falschzuweisungen bei den Artikelformen auf. Die feminine Form die wird dabei jedoch nicht inkorrekt verwendet. Möglicherweise verhindert das häufige Auftreten dieser Form im Input ihren übermäßigen Gebrauch (statt ihn, wie in Mills Daten, zu forcieren). Da die die-Form auch als genusneutraler Pluralmarkierer im Nominativ und Akkusativ aller Nomina steht, wird seine Eigenschaft als Referenzanzeiger für eine spezifische Art von Nomina im Singular möglicherweise nicht so leicht erkannt, wie für die $d e r$ - und das-Form.

$\mathrm{Ab} 2 ; 1.21$ folgt die Phase, in der die Zuweisung zwischenzeitlich beherrscht wird. Sie fällt zusammen mit dem von 2;2.18 bis 2;5.13 verlaufenden steilen Anstieg der Artikelfrequenz (s. Abschn. 5.1.2). Eine gewisse Sicherheit in der Formenzuweisung scheint daher die Voraussetzung für die Ausweitung des Artikelgebrauchs zur Referenzbestimmung zu sein. Zeitgleich ist allerdings ein vermehrtes Ausweichen auf die genusunspezifizierte Form de zu beobachten. Es scheint entweder eine Art „Bewusstsein“ für die Notwendigkeit der Genuskongruenz vorzuliegen, so dass der Artikel lieber gar nicht als möglicherweise falsch in Bezug auf ein Genus spezifiziert wird. Oder die Bedeutung der Genusanzeige am Artikel tritt nun derart gegenüber dessen Referenzeigenschaft als irrelevant in den Hintergrund, dass, wann immer eine Form nicht ,zielsicher“ abgerufen werden kann, auf die Genusmarkierung verzichtet wird. Beides Mal ist aber die Vermeidungsstrategie als ein Indikator für die Unsicherheit in der Formenzuweisung zu interpretieren.

Das Wiedereinsetzen von Fehlern - Verstößen wie Übergeneralisierungen - korreliert mit einer relativ hohen Artikelfrequenz. Da ab diesem Zeitpunkt Genusfehler auch in AkkusativKontexten auftreten, darf vermutet werden, dass der Erwerb der Kasusparadigmen, der zu diesem Zeitpunkt zu einer stark ansteigenden Artikelfrequenz in den obliquen Kasus führt, der Auslöser für die erneute Unsicherheit in der Formenbestimmung ist. Das liegt nahe, da die Beherrschung des Genussystems an sich nicht für die Bestimmung der korrekten Artikelform ausreicht, denn jede Form ist gleichzeitig als Anzeiger der syntaktischen Relationen kasusabhängig.

\footnotetext{
${ }^{42}$ Es ist jedoch die Lücke in den veröffentlichten Daten zu beachten.
} 
Als Hinweise auf den reinen Genuserwerb können daher lediglich die Falschzuweisungen bis 2;4 betrachtet werden, da bis zu diesem Zeitpunkt die Kasusproblematik noch keine wesentliche Rolle in Simones Sprachgebrauch spielt. Auch in dieser Phase zeigen sich allerdings mehr Verstöße als Übergeneralisierungen, so dass die Ableitung der beschriebenen Genusregeln als Zuweisungsgrundlage weiterhin unwahrscheinlich ist. Da nach 2;1.12 bis 2;4.21 lediglich eine Falschzuweisung, genauer Übergeneralisierung auftritt, scheint der Erwerbprozess der Artikelformen in dieser Phase tatsächlich vorübergehend beendet zu sein. Die frühe Übergeneralisierung des NGP weist zwar auf das Erkennen des Sexus hin, wie weit der Erwerb des Konzepts des Genus als grammatische Kategorie an sich bis 2;4 bereits fortgeschritten ist, kann hieraus allerdings nicht ersehen werden. Die Flexion anderer Artikelwörter, Pronomen und Adjektive muss hierzu ebenfalls in ihrem Erwerbsprozess verfolgt werden. Es ist allerdings möglich, dass die (zunächst nur) genusabhängige Formenverteilung am bestimmten Artikel wegen ihren phonologisch kontrastierenden Eigenschaften im Spracherwerb am einfachsten gegenüber anderen genusabhängigen Wortarten im Input zu erkennen ist; aus diesen Gründen wurde sie auch für diese Arbeit als zu untersuchende Wortart ausgewählt.

Für den Altersabschnitt bis 2;4 kann bei Simone nur von einem vorläufigen Erwerb der genusanzeigenden Artikelformen gesprochen werden. Sobald es nämlich das gesamte, auch kasusabhängige Formeninventar $\mathrm{zu}$ beachten gilt, scheint das etablierte Zuweisungssystem regelrecht zusammenzubrechen.

Die später, nach 2;4 auftretenden Fehler können dann nicht mehr allein unter dem Aspekt der Genuszuweisung betrachtet werden und eine Unterscheidung in Übergeneralisierung von Genusregeln und Verstöße gegen diese ist hier nicht mehr möglich. Das bereits erworbene System der Formenzuweisung gerät wieder stark ins Wanken; unter den „Genusfehlern“ tritt die Mehrheit im syntaktisch unmarkierten Nominativ auf und besonders häufig wird das NGP missachtet - aber auch bezüglich der anderen Genusregeln sind bei Simone mehr Verstöße als Übergeneralisierungen zu beobachten. Der Aufbau des vollständigen Formenparadigmas wird offensichtlich nicht lediglich durch einen Anschluss der zusätzlichen Kasus mit ihrer Formenverteilung an die Nominativ-/Genus-Formen gemeistert. Dann wäre nämlich zu erwarten, dass die Zuweisung der Formen zumindest im Nominativ weiterhin keine Probleme bereitet, was jedoch nicht der Fall ist.

Es wird also keine generelle Verbindung von Merkmalen des Nomens zur Form des Artikels hergestellt und die Zuweisungsgrundlage ist nur so lange stabil ist, wie es nicht zwischen verschiedenen Kasus zu differenzieren gilt. Simone erwirbt die Zuweisung der Artikelformen anscheinend durch lexikalisches Lernen. Gerade die zahlreichen Verstöße gegen die besonders „einfache“ Schwa-Regel weisen darauf hin. Dass eine Regel durch den einsetzenden Kasusgebrauch wieder ,verlernt“ wird, ist kaum anzunehmen. Dies würde es aber bedeuten, wenn die erste Etappe im Formenerwerb bei Simone als regelgeleitet angenommen würde. Nur für echte Derivationssuffixe scheint eine direkte Assoziation zwischen der phonologischen Form des Morphems und der Artikelform zu bestehen, vermutlich aufgrund ihrer salienten phonologischen Struktur.

Das zuvor eindimensionale Genussystem muss vielmehr in ein zweidimensionales Paradigmensystem umgewandelt werden, was sich anhand der "Genusfehler“" wie eine komplette Neugestaltung der Zuweisungsgrundlagen ausnimmt.

\subsection{Der Zusammenhang von Genus und Kasus}

Die Aufgabe, die Formenverteilung des Artikels im Singular zu erwerben, bedeutet, ein Paradigmensystem aufzubauen, in dem sich die Formen nach beiden Kategorien, Genus und Kasus, richten. Spätestens ab dem Auftreten von Artikelformen in den obliquen Kasus Akkusativ 
und Dativ muss daher das gesamte Kasusparadigma bei der Interpretation der Fehler Berücksichtigung finden. Die syntaktischen Aufgaben des bestimmten Artikels dürften dabei im Erwerbsprozess leichter für das Kind zu erkennen sein als die Genusmarkierung (Wegener 1995:95), so dass letztere bei der Formenwahl des bestimmten Artikels zumindest phasenweise vermutlich weniger relevant sein oder mit der Markierung der Kasus in Konkurrenz stehen können. Im Gegensatz zu den Genera erfüllen die Kasus eine eindeutige grammatische Funktion. Durch die Anzeige von Nominativ, Akkusativ und Dativ werden die syntaktischen Relationen Subjekt, direktes Objekt und indirektes Objekt markiert, welche auf semantischer Ebene prototypischerweise die Rollen Agens, Patiens und Benefaktiv repräsentieren.

Der Auf- und Ausbau der Formenparadigmen für die Kategorien Genus und Kasus besteht darin, dass einerseits neue, kasusspezifische Formen (den und dem) zu den bereits verwendeten des Nominativs hinzutreten und andererseits die „bekannten“" Formen (der, die und das) funktional erweitert werden müssen.

Für den Erwerb der Artikelformen beobachtet Bittner bei dem Mädchen Anna, dass mit dem Beginn der Verbflexion im Spracherwerb die Belegung der Argumentpositionen durch bestimmte Artikel einhergeht, wobei den ersten Artikelformen (der, die, das) unterschiedliche funktionale Aufgaben zugeschrieben werden. Die Formen der und die werden dabei nur in Kontexten von finiten Verben verwendet, wobei der gleichzeitig auf Subjekt-Positionen eingeschränkt bleibt (Bittner 2002a:46). D.h. Übergeneralisierungen werden hier weniger von Genusregeln als von funktionalen Zuweisungen ausgelöst.

Die nicht-zielsprachlichen Formenzuweisungen müssen also unter beiden Aspekten - Genus und Kasus - betrachtet werden.

\subsubsection{Verteilung der Falschzuweisungen}

Die Entwicklung im Erwerbsprozesses von Simone gliedert sich in drei Phasen. Die erste Erwerbsphase dauert bis zu einem Alter von 2;4 und ist gekennzeichnet durch das erste Vorkommen von definiten Artikeln im Nominativ und einem Anstieg seines Gebrauches, auch Formen im Akkusativ treten hier bereits sporadisch auf. Den Beginn der Erwerbsphase II ab 2;5 markiert der Anstieg der Artikelzuordnungen im Akkusativ sowie das plötzliche Einsetzen von Dativmarkierungen, was mit dem beschriebenen, erneuten Einsetzen von Falschzuweisungen der Artikelformen einhergeht. Auch Pluralmarkierungen durch den bestimmten Artikel nehmen ab diesem Zeitpunkt deutlich zu. Ab 3;0 ist im Verlauf der korrekten Artikelproduktionen über die drei im Spracherwerb relevanten Kasus keine quantitative Steigerung mehr zu verzeichnen, so dass hier der Beginn der dritten Erwerbsphase anzusetzen ist. Ab diesem Alter gilt nach allgemeiner Einschätzung der Artikelerwerb im Großen und Ganzen als abgeschlossen.

Die folgende Tabelle zeigt die Verteilung der Falschzuweisungen während der einzelnen Erwerbsphasen nach Genus und Kasus (die Form dem wird in den mir vorliegenden Daten zu keinem Zeitpunkt übergeneralisiert und erscheint daher nicht in dieser Tabelle, die grauen Felder „belegen“ die von den jeweiligen Formen zielsprachlich markierten Kategorien, die Angaben in Klammern sind der prozentuale Anteil der Falschzuweisungen einer Form an allen ihren Vorkommen, die letzte Spalte gibt das Verhältnis der falschen gegenüber den korrekten Zuweisungen nach dem jeweiligen Genus des Nomens an): 


\begin{tabular}{|c|c|c|c|c|c|c|c|c|c|c|c|c|c|c|c|}
\hline \multirow{2}{*}{$\begin{array}{c}\text { Phase I } \\
-2 ; 4 \\
\end{array}$} & \multicolumn{3}{|c|}{$\operatorname{der}(12 \%)$} & \multicolumn{3}{|c|}{ die $(2 \%)$} & \multicolumn{3}{|c|}{ das $(12 \%)$} & \multicolumn{3}{|c|}{ den $(0 \%)$} & \multicolumn{3}{|c|}{ \% nach Genus } \\
\hline & $\mathrm{m}$ & $\mathrm{n}$ & $f$ & $\mathrm{~m}$ & $\mathrm{n}$ & $f$ & $\mathrm{~m}$ & $\mathrm{n}$ & $f$ & $\mathrm{~m}$ & $\mathrm{n}$ & $f$ & $\mathrm{~m}$ & $\mathrm{n}$ & $f$ \\
\hline NOM & & 6 & 2 & & & & 1 & & 5 & & & & 1 & 19 & 13 \\
\hline AKK & 1 & & & & & & & & & & & & 13 & & \\
\hline DAT & & & & & & 1 & & & & & & & -43 & - & - \\
\hline
\end{tabular}

\begin{tabular}{|c|c|c|c|c|c|c|c|c|c|c|c|c|c|c|c|}
\hline \multirow{2}{*}{$\begin{array}{l}\text { Phase II } \\
2 ; 5-2 ; 11\end{array}$} & \multicolumn{3}{|c|}{ der $(3 \%)$} & \multicolumn{3}{|c|}{ die $(7 \%)$} & \multicolumn{3}{|c|}{ das $(8 \%)$} & \multicolumn{3}{|c|}{ den $(13 \%)$} & \multicolumn{3}{|c|}{$\%$ nach Genus } \\
\hline & $\mathrm{m}$ & $n$ & $f$ & $\mathrm{~m}$ & $\mathrm{n}$ & $f$ & $\mathrm{~m}$ & $\mathrm{n}$ & $f$ & $\mathrm{~m}$ & $\mathrm{n}$ & $f$ & $\mathrm{~m}$ & $\mathrm{n}$ & $f$ \\
\hline NOM & & 3 & 2 & 8 & & & 1 & & 1 & & & & 3 & 8 & 1 \\
\hline AKK & 2 & & 1 & 5 & 1 & & 3 & & & & 5 & 1 & 17 & 21 & 2 \\
\hline DAT & & & & 1 & 1 & 7 & & & & 1 & & & 5 & 4 & 19 \\
\hline
\end{tabular}

\begin{tabular}{|c|c|c|c|c|c|c|c|c|c|c|c|c|c|c|c|}
\hline \multirow{2}{*}{$\begin{array}{c}\text { Phase III } \\
3 ; 0+\end{array}$} & \multicolumn{3}{|c|}{ der $(4 \%)$} & \multicolumn{3}{|c|}{ die $(5 \%)$} & \multicolumn{3}{|c|}{ das $(6 \%)$} & \multicolumn{3}{|c|}{ den $(4 \%)$} & \multicolumn{3}{|c|}{$\%$ nach Genus } \\
\hline & $\mathrm{m}$ & $\mathrm{n}$ & $f$ & $\mathrm{~m}$ & $\mathrm{n}$ & $f$ & $\mathrm{~m}$ & $\mathrm{n}$ & $f$ & $\mathrm{~m}$ & $\mathrm{n}$ & $f$ & $\mathrm{~m}$ & $\mathrm{n}$ & $f$ \\
\hline NOM & & 3 & 5 & 9 & 6 & & & & 1 & & & & 2 & 17 & 2 \\
\hline AKK & 4 & & 2 & 3 & 1 & & 5 & & 1 & & & & 9 & 1 & 2 \\
\hline DAT & 5 & 2 & & 1 & 1 & 1 & & 2 & & 4 & 1 & & 11 & 15 & 2 \\
\hline
\end{tabular}

Tabelle 5: Übergeneralisierung der pro- und adnominalen Artikelformen nach Kasus und Genus.

Phase I: Die Form die wird zu Beginn der Erwerbsphase im Nominativ und Akkusativ nicht übergeneralisiert, was bereits in der Analyse der ,echten“ Genusfehler festgestellt wurde. Nur der und das werden im Nominativ über ihre zielsprachliche Genuskategorie hinweg verwendet.

$\mathrm{Zu}$ diesem Zeitpunkt, am Anfang des Erwerbsprozesses, kann noch nicht von abstrakten Genuskategorien in der kindlichen Grammatik ausgegangen werden, auf der die Zuordnung der Artikelformen beruhen würden. Die Zuweisung erfolg aufgrund einer für jede Einzelform auswendig gelernten Form-Form-Assoziation, indem ein Nomen im Lexikon direkt mit der jeweiligen Artikelform verknüpft ist (vgl. u.a. Pinker 1984, Tomasello 2000). Es ist diese Artikelform selbst, die die Nomina „kategorisiert“. D.h. im nominalen Lexikon sind Maskulina als Wörter gespeichert, die zusammen mit der auftreten können, sie sind also als „der-Wörter“ klassifiziert. Entsprechend sind Feminina als „die-Wörter“" und Neutra als „das-Wörter“ gespeichert.

Die Übergeneralisierungen in den Nominativ-Formen betreffen die Belegung der Subjektposition. Bittner (2002a, 2002c) nimmt an, dass der der-Form zunächst die Aufgabe der Subjekt/Agens-Markierung zugewiesen wird. Gleiches kann in der hier durchgeführten Analyse auch für die Form das angenommen werden. ${ }^{44}$ Die die-Form bleibt demgegenüber in diesem Erwerbsabschnitt unspezifiziert. und wird somit nicht übergeneralisiert. Sie übernimmt lediglich die generelle Aufgabe des bestimmten Artikels, Bekanntheit des Verbarguments anzuzeigen. Müller hat bei Caroline und Pascal ebenfalls beobachtet, dass die z.T. unspezifisch verwendet wird, nämlich in Kontexten, in denen die NP syntaktisch einen nichtnominativischen Artikel verlangt. In solche Fällen, z.B. in Abhängigkeit von einer Präposition, wird die für alle Genera übergeneralisiert (Müller 1999:395, Anm. 26)

Phase II: Die Annahme einer funktionalen Assoziation von der und das als Agensmarkierer bestätigt sich im zweiten Erwerbsabschnitt (ab 2;5). Es sind deutliche Schwierigkeiten zu erkennen, Maskulina, den „der-Wörtern“, und mehr noch Neutra, „das-Wörtern“, die korrekte Akkusativ-Form zuzuweisen: Bei 17\% der Maskulina und 21\% der mit einem bestimmten

43 Der Dativ-Gebrauch ist in diesem Erwerbsabschnitt zu gering, um relative, wenn auch nur tendenzielle Werte angeben zu können.

44 Hierbei ist zu beachten, dass ich rein deiktischen Gebrauch von das aus der Analyse ausgeschlossen habe. Diese Interpretation von das gilt daher nur für Verwendungen, in denen die Übereinstimmung im Genus mit dem jeweiligen Referenten zwingend ist. 
Artikel verbundenen Neutra wird hier eine falsche Artikelform verwendet. Für beide gilt, dass die Nominativ-Form als Subjektmarkierer fungiert und deshalb nicht in einer Objekt-Position erscheinen sollte. Beide Formen werden daher kaum im Akkusativ, bzw. im Dativ überhaupt nicht, verwendet. Auch bei Maskulina wird nur selten im Akkusativ auf der zurückgegriffen; als „Ausweichmöglichkeit“, wenn die zielsprachliche Form den nicht gleich abrufbar ist, kann also nur die verwendet werden, denn es ist für keine semantische Rolle spezifiziert. Für Neutra wird dagegen hauptsächlich die Form den gebraucht, da die rollenmarkierte, wenn auch zielsprachliche das-Form im Akkusativ nicht eingesetzt werden kann. Wegen der zugrunde gelegten Funktion für der wird diese Form auch im Dativ der Feminina nur zögernd verwendet (19\% Falschzuweisungen im Dativ der Feminina). Stattdessen wird ausschließlich die die-Form, und niemals dem, eingesetzt. ${ }^{45}$ Die Form die wird also in allen Kontexten verwendet, was darauf hinweist, dass sie auch in der zweiten Erwerbsphase noch keine spezifische Funktion zugeschrieben bekommen hat. Diese Annahme wird zusätzlich durch die geringe Fehlerquote bei Feminina im Akkusativ (2\%) gestützt.

Eine weitere Beobachtung ist, dass die Formen den und dem nicht oder kaum für Feminina (,die-Wörter") im Akkusativ und Dativ übergeneralisiert werden. In den Objekt-Kasus deutet sich somit eine erste Opposition zwischen Feminina und Nicht-Feminina an: Die Formen den und dem werden (fast) ausschließlich für Maskulina und Neutra verwendet, nicht jedoch für Feminina. Während diese Artikelformen als spezielle Akkusativ- bzw. Dativ-Markierer für „der-“ und „das-Wörter" assoziiert werden, bleibt die auch weiterhin unmarkiert bezüglich einer rollenanzeigenden Funktion (so auch in Bittner 2002c).

Phase III: Ab 3;0 existiert die Agensspezifizierung für der und das offenbar nicht mehr, denn beide Formen erscheinen nun auch im Akkusativ und Dativ, und zwar hauptsächlich für Maskulina und Neutra. Besonders die problemlose Zuweisung von der im Dativ der Feminina fällt auf (2\% Falschzuweisungen bei Feminina im Dativ). Auch werden den und dem weiterhin nicht mit Feminina verbunden. Diese Formen bleiben auf ihre Verwendung in ObjektPositionen für Nicht-Feminina begrenzt, wobei für dem gilt, dass es gleich für seine zielsprachlichen Kategorien erworben wird. Es ist allerdings zu beobachten, dass die Zuweisungen im Dativ der Maskulina und Neutra nicht unproblematisch ist, da hier die Fehlerquote unter den zugewiesenen Formen immerhin 11\% bei Maskulina und 15\% bei Neutra beträgt. Dabei fällt auf, dass Falschzuweisungen zu Maskulina hier hauptsächlich mit anderen Artikel des maskulinen Paradigmas gebildet werden (der, den), wohingegen für Neutra in diesem Kasus alle Formen verwendet werden.

Anhand der nach Kasus und Genus differenzierten Falschzuweisungen ist jedoch für die Erwerbsphase nach 3;0 nicht zu erkennen, welche Strategie bei der Formenzuweisung nun verfolgt wird. Die Formen der, die und das erscheinen jetzt in fast allen Kontexten. Lediglich für Feminina ist die jeweils zuzuweisende Artikelform in allen drei Kasus fast vollständig erworben. Die Artikelform die wird allerdings relativ häufig - darunter besonders im Nominativ für die beiden nicht-femininen Genera verwendet. Es kann daher nur eine Nicht-Assoziation von der, das, den und dem für Feminina festgestellt werden. Umgekehrt gilt jedoch nicht, dass die mit dem femininen Genus assoziiert wird.

Die nach der Analyse der Genusfehler geäußerte Vermutung, dass mit dem Einsetzen der frequenten Kasusmarkierung am Artikel eine Umgestaltung des anfänglichen Zuweisungssystems notwendig wird, bestätigt sich unter Berücksichtigung beider Kategorien, Genus und

45 Für den DaZ-Erwerb berichtet Wegener, dass im Dativ der Feminina hauptsächlich auf den validesten Kasusanzeiger dem ausgewichen wird. Hierbei zeige sich, dass sich der Lerner gerade dessen bewusst ist, dass es sich hierbei um ein Femininum handelt und ihm daher die Kombination mit dem typisch maskulinen Artikel widerstrebt (Wegener 1995:101, Anm. 41). 
Kasus, bei der Fehlerauswertung. Zum Ende der ersten Erwerbsphase (bis 2;4) werden die Nomina mit ihren jeweiligen Artikeln assoziiert. Dass es sich dabei aber um vorläufige FormForm-Assoziationen handelt und keine zugrunde liegenden Kategorien oder Zuweisungsprinzipien erworben sind, zeigt die weitere Entwicklung der Formenverteilung. Im anfänglichen Gebrauch der Artikel wird zwischen den Artikelformen derart differenziert, dass der und das eine funktionale Eigenschaft zugeschrieben wird: Nur sie sind offensichtlich für die Agensrolle spezifiziert. Die Form die erhält dagegen kein Merkmal, das sie gegenüber den anderen Formen auszeichnet. Dies entspricht der Komplexitätshierarchie der semantisch distinktiven Merkmale der einzelnen Artikelformen (vgl. Abschn. 3.3). Diese Funktionsannahme für der und das kann allerdings nicht mehr aufrechterhalten werden, sobald zusätzliche semantische Rollen mit dem bestimmten Artikel ausgedrückt werden müssen.

Mit Beginn der zweiten Erwerbsphase (ab 2;5) muss diese Funktionszuordnung aufgegeben werden, denn der und das müssen nun auch in anderen syntaktischen Positionen eingesetzt werden. Die Falschzuweisungen lassen allerdings erkennen, dass dies nicht besonders leicht bewerkstelligt wird. Die Agensmarkierung für der und das bleibt offensichtlich während des gesamten zweiten Erwerbsabschnitts bestehen. Ein erster Kategorisierungsschritt zur Trennung von Feminina gegenüber Nicht-Feminina tritt zuerst im Akkusativ und Dativ deutlich hervor, denn die Formen den und dem werden nicht mit Feminina sondern ausschließlich mit Maskulina und Neutra in Verbindung gebracht.

$\mathrm{Ab} 3 ; 0$ ist zu erkennen, dass die Funktionszuweisung für der und das aufgehoben ist. In der Analyse der Genusfehler war allerdings deutlich geworden, dass auch jetzt die phonologischen und semantischen Genuszuweisungsregeln nicht wirken, denn auch im Nominativ treten noch immer zahlreiche Verstöße gegen die Zuweisungsprinzipien auf. Anhand des Verteilungsmusters der Falschzuweisungen ist lediglich zu erkennen, dass bisher nur eine Kategorie für Feminina gebildet wurde. Darüber hinaus ist nur für Maskulina im Dativ eine gewisse „Genustreue“ zu beobachten, da hier bevorzugt Formen desselben Genusparadigmas (der und den) übergeneralisiert werden. Hier liegt also die Unsicherheit hauptsächlich in der Kasusbestimmung. Bei Neutra werden im Dativ wiederum alle Formen verwendet - es liegt offenbar eine eindeutigere Assoziation von dem zu Maskulina vor. Dies ist zum einen mit dem Verlangen nach eindeutiger Kategorienmarkierung (Slobin 1973) begründbar, zum anderen könnte diese Assoziation lautlich motiviert sein, da sich diese Form nur in seinem Auslautkonsonanten von den übrigen maskulinen Artikeln der und den unterscheidet. Hier zeichnet sich somit ansatzweise die Bildung des maskulinen Paradigmas ab, indem die einzelnen Formen als zusammengehörige Vertreter einer Artikelkategorie erkannt werden. Dass dagegen die unterschiedliche Kategorienzuweisungen von der für Nominativ Maskulinum und Dativ Femininum offensichtlich weniger problematisch ist (nachdem die Agensmarkierung einmal aufgehoben wurde), rührt m.E. daher, dass die jeweilige Genuskategorie bei der-Zuweisungen syntaktisch klar unterschieden ist, während Vorkommen von dem mit Maskulina und Neutra sich positionell nicht gegenseitig ausschließen. In diesem Fall ist das Genus tatsächlich nicht erschließbar.

\subsubsection{Kategorisierung der Nomina}

Kurz vor Beginn der dritten Erwerbsphase muss sich bei Simone eine erneute Funktionsannahme einstellen, die die bisherige Agensmarkierung der Formen der und das abzulösen scheint. Im Abschnitt 5.1.2 wurde beschrieben, dass ab 2;10.11 der Gebrauch der reduzierten Artikelform de, die für Genus und Kasus unspezifiziert ist und hauptsächlich im Nominativ auftritt, ein sehr niedriges Niveau (etwa 2\%) erreicht hat und ab 3;4 nicht mehr verwendet wird. Das bedeutet, dass die Notwendigkeit der Formendifferenzierung auch im Nominativ mehr und mehr erkannt wird. Die Genusregeln werden aber, wie gesagt, auch jetzt nicht an- 
gewendet. Da die Gebrauchshäufigkeit der reduzierten Form als Indikator für die Zuweisungssicherheit angenommen wurde, scheint Simone offenbar eine alternative Annahme über Kriterien für die Formenzuweisung zu machen, so dass ein Ausweichen auf die genusneutrale Form zwar nicht mehr notwendig ist, aber zu nicht-zielsprachlicher Verwendung der Artikelformen führt.

Ab 2;10.11, also parallel zum niedrigen Pegel des de-Gebrauchs, setzen im Nominativ die massiven Verstöße gegen das NGP ein (s. Abschn. 5.2.2.1). Vor allem fiel hier die nichtzielsprachliche Verwendung von die bei Eigennamen auf. Falschzuweisungen von die treten an sieben Personenbezeichnungen (types) (Peter (5x), Tobias, Bernd, Martin, Schneider, Aschenputtel (5x), Prinz), drei Tierbezeichnungen (je 1x Hase, Pony, Wolf), jedoch bei nur einer Bezeichnung für einen nicht-belebten Referenten (Topf) auf. Mit der der-Form wird ab diesem Zeitpunkt ebenfalls hauptsächlich auf belebte, aber kaum auf menschliche Referenten verwiesen (Ente (4x), (Weihnachts)gans (2x), Krokodil sowie einmal auf einen weiblichen Eigennamen). Diesen stehen nur zwei Verknüpfungen mit Gegenständen gegenüber (je 1x Auto, Motorrad). Falschzuweisungen von das erscheinen nur zwei: eine bereits mit 2;10.11 (Schranke) sowie das späte klein Kuh (3;9.18), welches bereits als missglückter Abruf von Kälbchen erklärt wurde.

Für den maskulinen und femininen Artikel zeichnet sich in den Falschzuweisungen somit eine deutliche Assoziation mit der Belebtheit der Referenten ab, bei der femininen die-Form ist eine zusätzliche Verbindung mit dem Merkmal [+human] zu erkennen. Das Neutrum wird dagegen nicht mit einer bestimmten Kategorie assoziiert. Es kann auch keine Verbindung mit dem Merkmal [-belebt] angenommen werden, denn entsprechend häufige Übergeneralisierungen treten nicht auf. Die Zuweisung von das zu Neutra wird offenbar rein lexikalisch erworben, denn es wird kein spezifisches Merkmal mehr mit diesem Artikel (nach Aufgabe der Agensmarkierung) als Zuweisungsgrundlage angenommen, das Übergeneralisierungen auslösen würde. Auch Mills hat eine Assoziation für die und der mit Belebtheit beobachtet, sowie den damit einhergehenden, impliziten Rückschluss auf das für Unbelebtheit. Sie vermutet, dass dies mit dem anfänglichen frequenten Gebrauch des demonstrativischen das (in meiner Auswertung nicht enthalten) zusammenhängt, das auch im sehr frühen Spracherwerb kaum für belebte Referenten verwendet wird. Das Merkmal der Belebtheit wird demnach bereits in der frühen kognitiven Entwicklung wahrgenommen (Mills 1986:87ff.).

Im Akkusativ und Dativ findet sich die Kategorisierung in [+/-human] bei Belebtheit in den Falschzuweisungen weniger stark bzw. überhaupt nicht wieder. Nur die zweimalige Zuweisung von der zu Gans im Akkusativ in der ersten Hälfte dieser Periode $(2 ; 10.11$ und 3;0.1) lassen sich auf diese semantische Unterscheidung zurückführen. Darüber hinaus sind keine weiteren Anzeichen, die auf eine solche oder andersartige Einteilung der Nomina schließen lassen würden, erkennbar. Vor allem im Dativ, zum Teil aber auch im Akkusativ kommen die falsch zugewiesenen Artikelformen durch eine Missachtung des Kasus zu Stande, denn in den meisten Fällen wird eine Form des zielsprachlichen Genusparadigmas gesetzt. Die folgenden Transkriptionsausschnitte veranschaulichen eine korrekte Genuszuweisung bei gleichzeitigem Kasusfehler; sogar nach einem Hinweis durch ein kasusmarkiertes Fragepronomen vom Gesprächspartner: 
$3 ; 0.28$

Simone zeigt beim Betrachten eines Bilderbuches auf einen Mann

Sim: da ist der drunter, da.

Max: Und was macht - Warum ist der da drunten?

Max: Was macht der denn da?

Sim: der war da - der bricht der Kopf ab.

Max: Wem bricht der Kopf ab?

Sim: der Mann.

\section{$3 ; 3.25$}

Wieder wird eine Szene in einem Bilderbuch beschrieben

Sim: da rutschen se aus, von den Schlitten rutsche se aus

Ähnliche Beispiele lassen sich auch für Feminina und Neutra finden.

$\mathrm{Ab} 3 ; 2$ ist die Differenzierung von Maskulinum und Femininum durch das Merkmal [+/-human] nicht mehr zu beobachten. Lediglich die Belebtheitskategorie für beide Genera im Gegensatz zum Neutrum scheint sich weiterhin in einigen, jedoch wenigen Übergeneralisierungen zu halten.

Der Nominativ bezeichnet das syntaktische Subjekt eines Satzes, im unmarkierten Fall übernimmt es die Rolle des Agens einer Handlung. ${ }^{46}$ D.h. mit diesem Kasus werden i.A. die handelnden Aktanten bezeichnet, über die wir Sprecher reden. Deshalb ist dieser Kasus für die Bezeichnung von belebten Entitäten prädestiniert, mit ihm wird meist auf Personen und höhere Lebewesen referiert. Im Akkusativ sowie im Dativ als Objektkasus erscheinen dagegen Elemente, die auf die eine oder andere Art von der Handlung, die das Verb ausdrückt, betroffen sind oder durch eine Präposition in ein (oft temporales, lokales, modales oder kausales) Verhältnis zu anderen Elementen gesetzt werden. Referenten in diesen Kasus sind jedoch nicht selbständig an der Handlung beteiligt. Im Akkusativ treten daher meist unbelebte Referenten auf. Für den präpositionslosen Dativ sind dagegen zwar wiederum belebte Wesen typisch, diese Eigenschaft ist aber für die vom Verb beschriebene Handlung weniger von Bedeutung. In Zusammenhang mit einer Präposition wiederum gilt für beide Objektkasus, dass sie gleichermaßen mit belebten sowie unbelebten Entitäten belegt werden. Eine Differenzierung bei Belebtheit in den Objekt-Positionen ist also nicht erforderlich, denn sie ist für die Art der ausgedrückten Tätigkeit weniger relevant als in der Subjektposition. Darüber hinaus wird der enge Zusammenhang von Agens und Handlung syntaktisch durch die Kongruenz zwischen Subjekt-NP und VP markiert.

Für ein sprechen lernendes Kind liegt es somit nahe, für die notwendige Genuskategorisierung im Nominativ eine Motivierung in der Belebtheitskategorie anzunehmen, um die unterschiedlichen Merkmale des agentivischen Subjektes zu kennzeichnen. Die beiden nächstliegenden, für Nomina in Agensrollen sich anbietenden Differenzierungen sind die nach Mensch vs. Tier und männlich vs. weiblich. Sie stehen der unmarkierten Klasse der unbelebten Entitäten gegenüber. Die Sexusdifferenzierung gilt jedoch nur für einen Teil der belebten Nomengruppe, für Menschen, denn Tiere werden besonders in der Kindersprache nur sehr bedingt nach dem natürlichen Geschlecht wahrgenommen. Es ist also durchaus naheliegend, dass vom kindlichen Sprecher für eine begrenzte Periode eine Kategorisierung in die belebten Klassen Mensch und Tier angenommen wird, um den semantischen Unterschied zwischen diesen Kategorien in Bezug auf die Handlung anzuzeigen. In den Daten von Simone weisen

46 Für den Spracherwerb dürften die unmarkierten Rollenbelegungen der Kasus im Vordergrund stehen, da die kindgerichtete Rede (motherese) sich u.a. durch eine „einfache Syntax“ (Keller et al. 1982:292, zit. in Klann-Delius 1999:144) auszeichnet. 
die Übergeneralisierungen auf eben diese Kategorisierung hin, denn hier fallen die häufigen Zuweisungen von die zu männlichen Personenbezeichnungen und Eigennamen vor allem in der Phase von 2;10 bis 3;1 auf. Das natürliche Geschlecht als alternatives und zielsprachliches Gliederungskriterium wird in der Folgezeit als Zuweisungsgrundlage offensichtlich weitgehend erworben. Die Assoziation von Tieren mit vorwiegend maskulinem Genus dauert dagegen bis $3 ; 5$ an.

In den Objekt-Kasus wird demgegenüber keine derartige Kategorisierung der Nomina angenommen, da sie in den semantischen Rollen des Patiens und Benefaktiv kaum relevant sind.

Zusammenfassend kann festgehalten werden, dass mit der Aufhebung der anfänglichen Assoziation der Formen der und das als Agensmarkierer ab 2;10 eine semantische Kategorisierung der Nomina angenommen wird, die hauptsächlich für Entitäten in Subjekt- bzw. Agenspositionen relevant ist. Dabei werden die folgenden Merkmale angenommen:

$$
\begin{array}{ll}
\text { Maskulinum } & =[\text { +belebt }] \\
\text { Femininum } & =[+ \text { belebt }], \text { bis } 3 ; 2:[+ \text { human }] \\
\text { Neutrum } & =\text { unspezifiziert }
\end{array}
$$

In den Objektkasus gilt diese Einteilung weniger, da in diesen Positionen Belebtheit in Bezug auf die ausgedrückte Handlung oder Tätigkeit weniger relevant ist. Vor allem im Dativ liegen die Probleme hauptsächlich in der Zuweisung des von einer Präposition geforderten Kasus.

\subsection{Zusammenfassung}

Aus den hier untersuchten Daten von Simone ergibt sich ein enger Zusammenhang zwischen dem Erwerb der Genuszuweisungen zu den Nomina und der Kennzeichnung der semantischen Rollen durch die Kasus. Erst mit dem Beginn der differenzierten Kasusanzeige am bestimmten Artikel (ab 2;5), die durch Veränderungen der Verbstellung im Spracherwerbsprozess ausgelöst wird (vgl. Tracy 1984, Clahsen 1984), ergibt sich die Notwendigkeit, nicht in den (bis dahin nur nominativischen) Artikelformen selbst bestimmte Funktionen anzunehmen, sondern stattdessen Kategorien zu entwickeln, die für die nominalen Lexeme gelten und durch die spezifischen Artikelformen zum Ausdruck gebracht werden. Die Häufigkeit der genusneutralen, reduzierten Form de kann dabei als Indikator für die Sicherheit bei der Zuweisung betrachtet werden. Er zeigt an, inwieweit die Notwendigkeit der differenzierten Formenmarkierung am Artikel erkannt ist, je nachdem, wie häufig auf ihn ausgewichen wird.

In der ersten Erwerbsphase, in der hauptsächlich nominativische NPs verwendet und mit einem Artikel bezeichnet werden (bis 2;4.21), erwirbt Simone den bestimmten Artikel zur Markierung der definiten Referenz. Die Zuweisung der Artikelformen wird offenbar lexikalisch durch eine Form-Form-Assoziation erworben. Hinweise auf den Erwerb bzw. die Anwendung von Genusregeln, die auf semantischer oder phonologischer Basis den Nomina ein Genus zuweisen, sind in den untersuchten Daten aufgrund fehlender Übergeneralisierungen nicht zu erkennen. Vor allem die häufigen Verstöße gegen die Schwa-Regel, die aufgrund ihrer hohen Validität als besonders leicht und frühzeitig zu erwerben gilt, belegen, dass sich Simone bei der Formenwahl nicht an Merkmalen des Nomens orientiert. Aber auch für die anderen Prinzipien sind keine entsprechend häufigen Übergeneralisierungen zu beobachten. Für das Erkennen des Sexus gibt es in den Daten zwar ein frühes Anzeichen, anschließend zeigen sich jedoch keine weiteren, bestätigenden Hinweise darauf, dass es konsequent für die Artikelzuordnung genutzt würde. Die gespeicherten Formen werden also nicht für die Abstraktion des Zusammenhangs von phonologischen Merkmalen des Nomens und der jeweiligen Artikelform verglichen. Zur Motivierung der Formendifferenzierungen wird vielmehr eine funktionale Unterscheidung angenommen, indem die Formen der und das als Agensmarkierer einge- 
setzt werden. Die Form die bleibt bezüglich syntaktischer Merkmale dagegen unspezifiziert, wie sie auch für semantisch distinktive Merkmale die am wenigsten komplexe Form ist. Der stellenweise sehr hohe Anteil der reduzierten Artikelform de zeigt die Unsicherheit bezüglich der Artikelzuweisung und damit bezüglich der Frage nach dem eigentlichen Nutzen der Formen- bzw. Genusdifferenzierung an.

Nach kurzer Zeit (ab 2;1.21) zeigt sich in den Daten von Simone eine dreimonatige Phase der Zuweisungssicherheit, die mit einem starken Anstieg des Artikelgebrauchs und gleichzeitiger Abnahme in der Häufigkeit der reduzierten Form de abschließt (spätestens 2;4.17). Eine gewisse Sicherheit oder Vertrautheit in der Formenverteilung des bestimmten Artikels im Nominativ scheint daher die Voraussetzung für seinen vermehrten Einsatz zu sein.

Ab 2;5.13 wird der bestimmte Artikel auch im Akkusativ und Dativ frequent verwendet. Die zweite Erwerbsphase ist bezüglich der Formenverteilung des bestimmten Artikels inhaltlich durch den Erwerb der Kennzeichnung der semantischen Rollen durch die Kasusdifferenzierung geprägt. Durch die gleichzeitig auch im Nominativ wieder einsetzenden Falschzuweisungen wird deutlich, dass der vorangegangene Erwerb der Zuweisungen unabhängig von Merkmalen der Nomina und somit lexikalisch mit gleichzeitiger funktionaler Differenzierung geschehen sein muss. Denn sollten den Zuweisungen bereits Genusregeln zugrunde gelegen haben, bliebe die Frage offen, weshalb sie nun nicht mehr angewendet werden. Im Akkusativ und Dativ zeigt sich eine erste erkennbare Opposition innerhalb der Nomina, die mit der Beobachtungen korreliert, dass den Formen der und das eine Funktion zugeordnet wird, gleichzeitig die in der Form-Form-Verbindung gespeicherten Artikel als Klassifikationskriterien der Nomina fungieren: Aus den ,der-“ und „das-Wörtern“ bildet sich eine Kategorie der NichtFeminina, deren Objekt-Formen den und dem kaum bzw. gar nicht auf Feminina/,dieWörter" übergeneralisiert werden.

In dieser Phase muss die anfängliche Funktionsannahme für der und das aufgehoben werden und der notwendige Abstraktionsprozess stattfinden, in dem erkannt wird, dass die Bedingungen für eine Artikelform in den Merkmalen des Nomens liegen. Diesen Erkenntnisprozess scheint die beginnende Kasusmarkierung auszulösen, denn nun müssen einem Nomen je nach syntaktischer Position verschiedene Artikelformen zugewiesen werden. Die anfängliche Klassifizierung der Nomina durch die jeweiligen Artikelformen muss also durch eine alternative Kategorisierung ersetzt werden. Die Komplexität dieser Aufgabe schlägt sich bei Simone einerseits in den Falschzuweisungen nieder, die hauptsächlich mit der Agensmarkierung von der und das begründbar sind, andererseits in der benötigten Zeitspanne: Erst ab 2;10.11, fünf Monate nach Beginn der zweiten Erwerbsphase, zeigen die Falschzuweisungen eine Kategorisierung der Nomina an, die als Hauptursache für die Übergeneralisierungen gelten kann. Erst kurz vor Beginn der dritten Erwerbsphase wird der Spracherwerb durch die Bildung von - zunächst nicht-zielsprachlichen - Genuskategorien geleitet. Die Kategorisierung erfolg bei Simone durch die Orientierung an typischen Merkmalen des Nominativs als Agensmarkierer. Es wird innerhalb belebter Wesen, die hauptsächlich in dieser Position erscheinen, zwischen Personen und Tieren unterschieden. Dabei wird Entitäten mit den Merkmalen [+belebt] und [+human] die die-Form, solchen mit nur [+belebt] die der-Form zugewiesen. Die Kategorie Neutrum bleibt unspezifiziert, so dass die Zuweisung von das vermutlich lexikalisch erworben wird. Dieses Genus ist generell das am wenigsten markierte, außer durch einige Diminutiv-Suffixe wird es durch keine der Genusregeln einem Nomen zugewiesen.

In den Objekt-Kasus ist diese Unterscheidung nicht so eindeutig zu beobachten, da sie für die Patiens- und Benefaktiv-Positionen weniger relevant ist. Vor allem im Dativ beruhen die Falschzuweisungen auf inkorrekten Kasuszuweisungen nach Präpositionen und erfolgen innerhalb des zielsprachlichen Genusparadigmas. Bei Maskulina zeigt sich das Einhalten des 
Genus auch bei Falschzuweisungen in präpositionslosen Dativ-Positionen, was auf den Aufbau eines maskulinen Paradigmas hindeutet, denn die einzelnen Formen werden offenbar als zusammengehörig klassifiziert.

Bis etwa 3;3.25 wird die semantische Kategorisierung der Nomina aufrecht erhalten. Anschließend ist die Verknüpfung des Merkmals [+human] mit der femininen Artikelform aufgehoben, nur die übergeneralisierende Kennzeichnung von Belebtheit durch die Formen die und $d e r$ wird noch vereinzelt weitergeführt. Phonologische Zuweisungsprinzipien spielen somit auch im Kategorisierungsprozess der dritten Erwerbsphase keine wesentliche Rolle im Erwerbsverlauf von Simone.

In diesem, späten Prozess werden das Genussystem und die Formenparadigmen allmählich erworben und systematisiert. Die beobachteten Kategorisierungsprinzipien gelten nur für Nominativ-NPs, d.h. die gebildeten Paradigmen hängen nicht von den Zuweisungen im Nominativ bzw. in der Subjekt/Agens-Position ab. Das bedeutet, dass die Nominativ-Formen der Artikel nicht mehr als direkte, klassifizierende Form-Form-Verbindungen gespeichert sein können. Darüber hinaus scheinen nun die einzelnen Artikelformen eines Genus zunehmend miteinander - und somit als zu einer abstrakten Genuskategorie gehörig - assoziiert zu werden. Je nach semantischer Rolle werden sie als Vertreter eines Genus interpretiert und in den verschiedenen Kontexten unmittelbar abgerufen.

\section{Diskussion und Ausblick}

Beim Erwerb der Genusmarkierung am bestimmten Artikel ist in den hier untersuchten Daten von Simone keine vorrangige Orientierung an phonologischen Regularitäten der Nomina zu erkennen. Auch semantische Hinweise durch das NGP werden im ersten Erwerbsabschnitt nicht als produktives Zuweisungsprinzip erkannt. Im beschriebenen Abstraktionsprozess des Spracherwerbs (s. Abschnitt 4.3), in dem anhand der gespeicherten Formenzusammenhänge Zuweisungsregeln oder -schemata abgeleitet werden, scheint bei Simone die Suche nach zugrunde liegenden Funktionen im Vordergrund zu stehen - zunächst für die einzelnen Repräsentanten des bestimmten Artikels, anschließend für die Kategorisierung der Nomina. Erst spät wird in den Daten überhaupt ein genereller Zusammenhang zwischen dem Nomen selbst und der jeweiligen Artikelform erkannt.

Eine erste Kategorisierung deutet sich darin an, dass ab der zweiten Erwerbsphase in den Objektkasus die Nicht-Feminina als eine Klasse gegenüber den Feminina abgegrenzt werden, da die Artikelformen des maskulinen und neutrischen Paradigmas nicht auf Feminina übergeneralisiert werden. Dies korreliert mit der funktionalen Unterscheidung von der und das gegenüber die und unterstützt die Annahme einer Einteilung der Nomina aufgrund ihrer zugewiesenen Artikelform. Innerhalb der nicht-femininen Kategorie zeichnet sich somit ein erstes, semantisch-funktionales Paradigma ab: Die Formen der und das kennzeichnen die typischerweise nominativische Agensrolle, den wird innerhalb dieser Kategorie pauschal für Patiensund dem für Benefaktiv-Positionen eingesetzt. Diese erste Kategorisierung muss jedoch allein auf lexikalisch erworbenen Zuweisungen basieren, denn sie wird nicht außerhalb dieser gespeicherten Formen auf feminine Lexeme angewendet, die entsprechende, typische phonologische Merkmale wie z.B. Einsilbigkeit aufweisen. Dagegen schlägt sich die Annahme einer Funktion für die Formen der und das wesentlich prägnanter in den Falschzuweisungen nieder. Im Gegensatz zu die bereitet es erhebliche Schwierigkeiten, die Nominativ-Form das zielsprachlich auf den Akkusativ der Neutra zu erweitern, obwohl die Verteilung beider Formen hier identisch ist (jeweils im Nominativ und Akkusativ eines Genusparadigmas). Hinzu kommt, dass entgegen Mills Beobachtung von übergeneralisierten Nominativ-Formen im Ak- 
kusativ (Mills 1985:178), was sich nur bei Maskulina als eine Falschzuweisung auswirken würde, die Form der von Simone äußerst selten auf den Akkusativ der Maskulina übergeneralisiert wird.

Auch beim zweiten Ansatz zu einer Schematisierung der Formenzuweisung (ab 2;10), die notwendig wird, da das anfängliche System mit Beginn der Kasusmarkierung nicht mehr aufrecht erhalten werden kann, bleiben die phonologischen Merkmale der Nomina weiter unbeachtet. Es ist jedoch bereits erkannt worden, dass die Formendifferenzierung der Artikel vom jeweiligen Nomen abhängt und nicht in funktionalen Eigenschaften der Artikel selbst liegen kann. Für die Motivierung der Formenzuweisung wird nun - statt des natürlichen Geschlechts - ein semantisches Merkmal angenommen, dass mit den semantisch-funktionalen Eigenschaften der Kasus bzw. der durch sie typischerweise angezeigten semantischen Rollen korreliert. Die Überlegung, dass gerade der feminine Artikel mit dem Merkmal [+human] assoziiert wird, gegenüber dem maskulinen, der nur für [+belebt] spezifiziert ist, mit dem eigenen Geschlecht von Simone zusammenhängt, ist zwar spekulativ, jedoch nicht ausgeschlossen. ${ }^{47}$ Offensichtlich steht das Bedürfnis nach einer semantischen Differenzierung im Vordergrund, denn die zielsprachliche Verteilung der Genera aufgrund von phonologischen Merkmalen des Nomens wird von Simone offenbar nicht genutzt.

Die phonologischen Regelmäßigkeiten werden von Simone vermutlich regressiv aus dem bereits etablierten Zuweisungen erworben, also erst nachdem die semantisch basierte Zuweisung wieder aufgegeben worden ist. Dies ist zwar nicht anhand von Übergeneralisierungen in den Daten direkt erkennbar, liegt aber insofern nahe, als der Erwerb der Artikelzuweisung und damit auch die Genusunterscheidung schließlich insgesamt gemeistert wird. Auch eine rein oberflächliche Betrachtung der Falschzuweisungen bei anderen Wortarten, wie unbestimmtem Artikel oder Adjektiv, lassen keinen Grund zur Annahme zu, Simone würde grundsätzliche, schwer wiegende Probleme im Abschluss des Genuserwerbs haben.

Vor dem Hintergrund, dass die phonologischen Hinweise zur Etablierung der Genuskategorie im Spracherwerb nicht genutzt, sondern semantische Merkmale zugrunde gelegt werden, wird das semantic primacy-Prinzip durch die hier untersuchten Daten bestätigt. Es zeichnet sich allerdings erst spät im Erwerbsprozess ab, nachdem die Formen zuerst syntaktisch interpretiert wurden, und erst anschließend in den Annahmen über kategorisierende Prinzipien von einer semantischen Motivierung ausgegangen wird.

Der Vergleich mit den Daten anderer Studien zum Genuserwerb hat gezeigt, dass offenbar unterschiedliche Strategien zur Absolvierung dieser Lernaufgabe angewendet werden. Dem Genuserwerb, der hauptsächlich durch den Formenvergleich der Nomina geleitet wird - und anscheinend zum direkten Erfolg führt -, steht der alternative Verlauf gegenüber, in dem sich der Erwerb durch die Suche nach zugrunde liegenden Funktionen auszeichnet. Während von anderen Kindern berichtet wird, dass phonologische Merkmale des Nomens sowie das Prinzip des natürlichen Geschlechts z.T. früh im Spracherwerb mit den einzelnen Artikelformen assoziiert werden, sucht Simone dagegen vorwiegend nach syntaktisch und semantisch funktionalen Eigenschaften, um zunächst die Formen des bestimmten Artikels selbst und anschließend die Nomina zu kategorisieren und für die Zuweisung einer Artikelform zu nutzen. Diese Strategie, eine funktional motivierte Verteilung der Artikelformen anzunehmen, wird bisher hauptsächlich von Kinder berichtet, die Deutsch als natürliche Zweitsprache erwerben. Sie sind bereits mehr oder weniger mit dem Phänomen der Genusklassifikation aus ihrer ersten Muttersprache vertraut, gehen aber lange Zeit im Erwerbsverlauf von einer funktionalen Motivierung der Formenunterschiede aus, die sich in den einzelnen Stadien des Spracherwerbs in

47 Vgl. Mills (1986:103f.) zu entsprechenden Beobachtungen im englischen Spracherwerb. 
unterschiedlichen Zuweisungsstrategien mit jeweils typischen Übergeneralisierungen niederschlägt (vgl. Wegener 1999).

Die hier vorgestellten Ergebnisse können nicht verallgemeinert werden, sondern müssen vielmehr mit Erwerbsdaten zur Entwicklung der Genuszuweisung von weiteren Kindern verglichen werden. Vor allem der Beginn der Kasusmarkierungen an den genusabhängigen Wortarten spielt dabei, wie sich hier gezeigt hat, eine wesentliche Rolle im weiteren Erwerbsprozess. Der Aspekt der Genuszuweisung allein kann für das Erkennen der Erwerbsstrategie nicht immer ausreichen. Ab diesem Zeitpunkt zeigt sich, ob die bisher angenommene Zuweisungsbasis (formal vs. funktional) beibehalten werden kann, oder ob sie wieder aufgegeben und nach neuen Kriterien für die Formenverteilung gesucht werden muss.

In Longitudinalstudien zum Genuserwerb wurde der reduzierten Form de bisher wenig Aufmerksamkeit geschenkt. Ihr Auftreten wird zwar meist vermerkt, in der weiteren Analyse aber nicht auf ihren Entwicklungsverlauf eingegangen. Es konnte hier jedoch gezeigt werden, dass die Entwicklung ihrer Gebrauchsfrequenz Aufschluss über die Unsicherheit bezüglich des zugrunde liegenden Verteilungssystems gibt und Änderungen in der Zuweisungsstrategie anzeigen kann.

Es ist zu beachten, dass die hier ermittelten Ergebnisse nur auf einem Ausschnitt des Gesamtdatenkorpus sowie der Analyse nur einer genusabhängigen Wortart beruhen. Es sind daher weitere Arbeitsschritte notwendig, um meine hier vorgestellten Beobachtungen zu bestätigen oder zu relativieren. Vor allem die Auswertung der Entwicklung anderer Artikelwörter und Adjektive im Spracherwerb werden hierbei von großem Nutzen sein. Wie weit die gebildeten Genuskategorien in den einzelnen Erwerbsstadien abstrahiert werden, dürfte sich an ihrer Markierung in den jeweiligen Flexionsformen niederschlagen. Eine Auswertung der jeweiligen Kontexte, in denen ein Artikel nur reduziert verwendet oder ausgelassen wurde, kann Aufschluss darüber geben, wann eine genusanzeigende Form vermieden wird und Selbstkorrekturen des Kindes zeigen an, zwischen welchen Artikelformen und somit Zuweisungsprinzipien es in der Formenwahl schwankt. Auch Imitationen von Äußerungen seiner erwachsenen Kommunikationspartner können durch eine genaue Analyse möglicherweise Hinweise darauf geben, worauf das Kind im Spracherwerb seine Aufmerksamkeit richtet. Auf diese Aspekte konnte jedoch im Rahmen der vorliegenden Arbeit leider nicht weiter eingegangen werden.

\section{Referenzen}

Bates, Elizabeth/Brian MacWhinney (1987): Competition, Variation, and Language Learning. In: MacWhinney (Hg.), 157-193.

van Berkum, Jos J.A. (1996): The psycholinguistics of grammatical gender. Studies in language comprehension and production. Nijmegen: University Press.

Bisle-Müller, Hansjörg (1991): Artikelwörter im Deutschen. Semantische und pragmatische Aspekte ihrer Verwendung. Tübingen: Niemeyer.

Bittner, Dagmar (1998): Entfaltung grammatischer Relationen im NP-Erwerb: Referenz. In: Folia Linguistika XXXI/3-4. Berlin, 255-283.

Bittner, Dagmar (1999): Gender classification and the inflectional system of German nouns. In: Unterbeck et al., $1-23$.

Bittner, Dagmar (2002a): Emergence of Grammatical Complexity and Markedness in the Acquisition of Verb and Noun Phrases in German. In: Dzuibalska-Kolaczyk, Katarzyna/Jaroslaw Weckwerth (Hgg.): Future Challenges for Natural Linguistics. München: Lincom, 25-55.

Bittner, Dagmar (2002b): Semantisches in der pronominalen Flexion des Deutschen. In: Zeitschrift für Sprachwissenschaft, 21/2, 196-233. 
Bittner, Dagmar (2002c): Markiertheit und Komplexität im Erwerb der deutschen Nominalflexion. Ms zur 30. Österreichische Linguistentagung, 6.-8.12.2002, Innsbruck.

Braine, Martin D. S. (1987): What is Learned in Acquiring Word Classes - A Step Toward an Acquisition Theory. In: MacWhinney (Hg.): Mechanism of Language Acquisition, 65-87.

Bußmann, Hadumod (1990): Lexikon der Sprachwissenschaft. Stuttgart: Kröner.

Clahsen, Harald (1984): Der Erwerb von Kasusmarkierungen in der deutschen Kindersprache. In: Linguistische Berichte 89, 1-31.

Claudi, Ulrike (1985): Zur Entstehung von Genussystemen. Überlegungen zu einigen theoretischen Aspekten, verbunden mit einer Fallstudie des Zande. Hamburg: Buske.

Corbett, Greville (1991): Gender. Cambridge: University Press.

Der Duden, in 12 Bänden. Mannheim; Leipzig; Wien; Zürich.

Bd. 1: Die deutsche Rechtschreibung; 21., völlig neu bearb. und erw. Auflage, 1996.

Bd. 4: Grammatik der deutschen Gegenwartssprache; 5. völlig neu bearb. u. erw. Auflage, 1995.

Bd. 5: Fremdwörterbuch; 5., neu bearb. u. erw. Auflage, 1990

Durrell, Martin (1977): Zur morphologischen Struktur der deutschen Nominalgruppe. In: Deutsch als Fremdsprache 14/1, 44-52.

Elsen, Hilke (1999): Ansätze zu einer funktional-kognitiven Grammatik. Konsequenzen aus Regularitäten des Erstspracherwerbs. Tübingen: Niemeyer

Kaltenbacher, Erika (1990): Strategien beim frühkindlichen Syntaxerwerb. Eine Entwicklungsstudie. Tübingen: Gunter Narr.

Karmiloff-Smith, Annette (1979): A functional approach to child language. A study of determiners and reference. Cambridge University Press

Klann-Delius, Gisela (1999): Spracherwerb. Stuttgart: Metzler.

Köpcke, Klaus-Michael (1982): Untersuchungen zum Genussystem der deutschen Gegenwartssprache. Tübingen: Niemeyer.

Köpcke, Klaus-Michael/David Zubin (1983): Die kognitive Organisation der Genuszuweisung zu den einsilbigen Nomen der deutschen Gegenwartssprache. In: ZGL 11.2/1983, 166-182.

Köpcke, Klaus-Michael/David Zubin (1984): Sechs Prinzipien für die Genuszuweisung im Deutschen: Ein Beitrag zur natürlichen Klassifikation. In: Linguistische Berichte 93/1984, 26-50.

Köpcke, Klaus-Michael/David Zubin (1996): Prinzipien für die Genuszuweisung im Deutschen. In: Lang, Ewald/Gisela Zifonun: Deutsch - typologisch. Berlin: de Gruyter 473-491.

Leiss, Elisabeth (1994): Genus und Sexus. Kritische Anmerkungen zur Sexualisierung von Grammatik. In: Linguistische Berichte 152, 281-300.

Leiss, Elisabeth (1997): Genus im Althochdeutschen. In: Glaser, Elvira/Michael Schlaefer (Hgg.): Grammatica ianua artium. Festschrift für Rolf Bergmann zum 60. Geburtstag. Heidelberg: Winter, 33-48.

MacWhinney, Brian (Hg.) (1987a): Mechanisms of Language Acquisition. Hillsdale/NJ: Erlbaum.

MacWhinney, Brian (1987b): The Competition Model. In: Ders. (Hg.), 249-308.

MacWhinney, Brian (1995): The CHILDES Project: Tools for Analyzing Talk. Second Edition, Hillsdale/NJ; Hove: Erlbaum.

Marx, Edeltrud (2000): Versprecher und Genusverarbeitung. Analysen spontaner und experimentell erzeugter Sprechfehler. Wiesbaden: DUV.

Meyers Taschenlexikon: in 12 Bänden. Bd. 1 (=A-Behö, 1996). Mannheim; Leipzig; Wien; Zürich.

Miller, Max (1976): Zur Logik der frühkindlichen Sprachentwicklung. Empirische Untersuchungen und Theoriediskussion. Stuttgart: Klett.

Mills, Anne E. (1985): The Acquisition of German. In: Slobin, Dan Isaac: The Crosslinguistic Study of Language Acquisition. Vol. 1: The Data. Hillsdale/NJ: Erlbaum, 141-254.

Mills, Anne E. (1986): The Acquisition of Gender. A Study of English an German. Berlin, Heidelberg: Springer.

Müller, Natascha (1990): Developing two Gender Assignment Systems Simultaneously. In: Meisel, Jürgen (Hg.): Two first languages. Dordrecht: Foris, 193-294.

Müller, Natascha (1999): Gender and number in acquisition. In: Unterbeck et al. (Hg.), 351-399.

Pinker, Steven (1984): Language Learnability and Language Development. Cambridge/ MA: Harvard University Press. 
Pons-Globalwörterbuch, Deutsch-Englisch. Teil 2 [Nachdruck von 1983]. Stuttgart: Klett 1988.

Ruoff, Arno (1981): Häufigkeitswörterbuch gesprochener Sprache. Tübingen: Niemeyer.

Slobin, Dan I. (1973): Cognitive Prerequisites for the Development of Grammar. In: Ferguson, Charles A./Dan Isaac Slobin (Hg.): Studies of Child Language Development. New York, 175-208.

Tomasello, Michael (2000): Acquiring syntax is not what you think. In: Bishop, Dorothy V.M./L.B. Leonard (Eds.): Speech and language impairments in children: Causes, characteristics, intervention and outcome. Hove: Psychology Press, 1-15.

Tracy, Rosemarie (1984): Fallstudien: Überlegungen zum Erwerb von Kasuskategorie und Kasusmarkierung. In: Czepluch, H./ H. Janßen (Hgg.): Syntaktische Struktur und Kasusrelation. Tübingen: Narr, 271-313.

Unterbeck, Barbara/Matti Rissanen/Terttu Nevaleinen/Mirja Saari (Hgg.) (2000): Gender in Grammar and Cognition. Berlin; New York: Mouton de Gruyter.

Vater, Heinz (1979 [1963]): Das System der Artikelformen im gegenwärtigen Deutsch. 2., verb. Auflage. Tübingen: Niemeyer.

Vater, Heinz (Hg.) (1986): Zur Syntax der Determinantien. Studien zur deutschen Grammatik 31, Tübingen: Narr.

Weber, Doris (2001): Genus. Zur Funktion einer Nominalkategorie exemplarisch dargestellt am Deutschen. Frankfurt/Main; Berlin; Bern; Bruxelles; New York; Wien: Lang.

Wegener, Heide (1995): Die Nominalflexion des Deutschen - verstanden als Lerngegenstand. Tübingen: Niemeyer.

Wegener, Heide (1999): German gender in children's second language acquisition. In: Unterbeck et al. (Hgg.), 511-544.

Werner, Ottmar (1975): Zum Genus im Deutschen. In: Deutsche Sprache, 1/1975, 35-58.

Zubin, David A./Klaus-Michael Köpcke (1984): Affect Classification in the German Gender System. In: Lingua 63, 41-96.

Datenkorpus von Simone in der CHILDES-Datenbank:

Download-Datei: simone.zip (Stand: 24.5.2001) unter: http://childes.psy.cmu.edu/data/germanic/german (zuletzt eingesehen am: 2.4.2003) 